University of Louisville

ThinkIR: The University of Louisville's Institutional Repository

$4-2012$

\title{
Analysis of EEG rhythms using custom-made MatLab application for processing of data collected during neurofeedback training in ADHD subjects.
}

Brent Hillard

University of Louisville

Follow this and additional works at: https://ir.library.louisville.edu/etd

\section{Recommended Citation}

Hillard, Brent, "Analysis of EEG rhythms using custom-made MatLab application for processing of data collected during neurofeedback training in ADHD subjects." (2012). Electronic Theses and Dissertations. Paper 620.

https://doi.org/10.18297/etd/620

This Master's Thesis is brought to you for free and open access by ThinkIR: The University of Louisville's Institutional Repository. It has been accepted for inclusion in Electronic Theses and Dissertations by an authorized administrator of ThinkIR: The University of Louisville's Institutional Repository. This title appears here courtesy of the author, who has retained all other copyrights. For more information, please contact thinkir@louisville.edu. 


\title{
ANALYSIS OF EEG RHYTHMS USING CUSTOM-MADE MATLAB APPLICATION FOR PROCESSING OF DATA COLLECTED DURING NEUROFEEDBACK TRAINING IN ADHD SUBJECTS
}

\author{
By \\ Brent Hillard \\ B.S., University of Louisville, 2011 \\ A Thesis \\ Submitted to the Faculty of the \\ University of Louisville \\ J.B. Speed School of Engineering \\ as Partial Fulfillment of the Requirements \\ for the Professional Degree

\section{MASTER OF ENGINEERING}

Department of Bioengineering

April 2012 
ANALYSIS OF EEG RHYTHMS USING CUSTOM-MADE MATLAB APPLICATION FOR PROCESSING OF DATA COLLECTED DURING NEUROFEEDBACK TRAINING IN ADHD SUBJECTS

Submitted by:

Brent Allen Hillard

A Thesis Approved On

\section{Date}

by the Following Reading and Examination Committee:

Ayman El-Baz, Ph.D., Thesis Director

Estate Sokhadze, Ph.D.

Palaniappan Sethu, Ph.D.

Karla Welch, Ph.D. 


\section{ACKNOWLEDGEMENTS}

Without the help of numerous individuals, this thesis and research presented herein would not be possible. The first such individual that has made this possible is Dr. Estate Sokhadze. Dr. Sokhadze has given me nearly unlimited access to his lab to aid in the research experience. His guidance throughout this project has been instrumental in its completion. Additionally, Dr. Sokhadze has provided valuable education over this year to me concerning aspects of the research process such as scientific poster preparations and the writing of journal papers.

Dr. Ayman El-Baz has played a highly influential role in this thesis, as well as throughout my entire academic career. In addition to serving as my advisor for this thesis, Dr. El-Baz served as my academic advisor during my undergraduate years in bioengineering. Dr. El-Baz has freely given me advice, time in the lab, and the knowledge base necessary to complete this thesis. His classes in signal processing have paved the way for completion of this thesis.

Finally, this thesis would not have been possible without the support -financial, mental, and spiritual - given to me by my family these past five years. I owe more to them than I can express in words and am truly grateful for all they do and continue to do. They have been with me every step of the way in my life, and have helped me in any way they can. Their guidance has been immensely helpful in my completion of this chapter of my life and the pursuit of the next chapter. 


\begin{abstract}
INTRODUCTION: Attention Deficit/Hyperactivity Disorder (ADHD) is a disorder that is prevalent throughout the world. It is believed that $5 \%$ of school aged children suffer from ADHD, with some estimates indicating as high as $10 \%$ may suffer from the disorder. Primarily, three subtypes of ADHD have been associated with certain electroencephalographic (EEG) abnormalities. The most common treatment for ADHD is medication. However, neurofeedback is considered an efficacious treatment for ADHD. It is proposed that neurofeedback training aimed to mitigate inattention and low arousal in ADHD will be accompanied by changes in EEG bands' relative power.
\end{abstract}

DATA COLLECTION: Patients were 18 children with ADHD. The neurofeedback protocol used to train patients has focused attention training mode, which according to specifications, represents an EEG desynchronization measure. The neurofeedback protocol provides one numeric output for "Focus" and one numeric output for "Alertness". This does not allow for collecting information regarding changes of specific EEG bands' power within 2-45 Hz range. Therefore, data was collected for EEG bands through the use of BioExplorer and BioReview software. Each subject completed 12 sessions with a target length of 25 minutes per session. Additionally, IVA+Plus test and $\mathrm{ABC}$ behavioral survey measures were administered both pre- and post- neurofeedback.

DATA PROCESSING AND ANALYSIS: Analysis was completed on each of the 25 min long twelve sessions using a custom-made MatLab application to determine the relative power of each of the EEG bands throughout each session and from the first session to the 
last session. Additional statistical analysis was performed to determine significant changes in relative power within sessions (from minute 1 to minute 25), and between sessions (from session 1 to session12) for an individual patient using an ANOVA. Additionally, a correlation analysis was performed to determine possible correlations between the "Focus" measure and changes in relative power of Theta, Alpha, Low and High Beta, Theta/Alpha, Theta/Beta, and Theta/Low Beta and Theta/High Beta ratios. Additional measures of patients' post-neurofeedback outcomes were assessed using an audio-visual selective attention test and behavioral evaluation scores and analyzed through a paired t-test.

RESULTS: Through statistical analysis of the data computed in the MatLab application, we determined that, as expected, Theta/Low Beta and Theta/Alpha ratios decreased significantly from Session 1 to Session 12 and from minute 1 to minute 25 within sessions. "Focus" measure also demonstrated a significant gradual increase from session 1 to session 12 and from minute 1 to minute 25 within sessions. The "Focus" measure of the protocol showed high negative correlation with both Theta/Alpha and Theta/Beta ratios.

CONCLUSIONS: The findings will help in elucidation of neural mechanisms of neurofeedback aimed to improve focused attention in ADHD. Also, this analysis differs from those prior studies in the consideration of what is transpiring not only from session to session, but also within each session. Therefore, improvement can be indicated within a shorter number of sessions (i.e. 12) compared to previous protocols that required 30-40 
sessions per subject to indicate statistically significant improvement either in EEG or clinical behavioral measures. Probably more than 12 sessions might contribute to better consolidation of results of operant conditioning using neurofeedback and currently, we have a study in progress that will compare outcomes of 12 vs. 18 sessions of neurofeedback using the same protocol. 


\section{TABLE OF CONTENTS}

APPROVAL PAGE

ACKNOWLEDGMENTS.................................................................................... iv

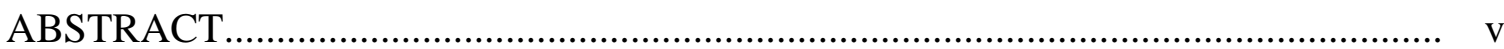

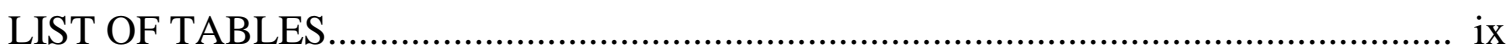

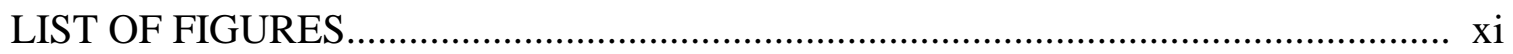

I. INTRODUCTION .................................................................................. 1

A. ADHD Prevalence and Clinical Significance ................................... 1

B. Causes of ADHD in Childhood Population......................................... 2

C. EEG Subtype Characteristics of ADHD and Comorbidities................ 3

D. ADHD Treatment Options................................................................ 6

E. Goals and Expectations of this Study................................................ 10

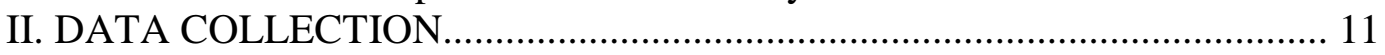

A Subject Demographics and Recruitment.............................................. 11

B. Neurofeedback Protocol and Data Recording..................................... 11

C. Clinical and Neuropsychological Measures of ADHD......................... 15

III. DATA PROCESSING AND ANALYSIS................................................. 16

A. EEG Signal Processing................................................................. 16

B. Statistical Analysis....................................................................... 21

IV. RESULTS.......................................................................................... 23

A. EEG Measures changes by Session.................................................... 23

B. EEG Measures changes by Minute.................................................... 27

C. Correlation between "Focus" Measure and EEG Band Relative

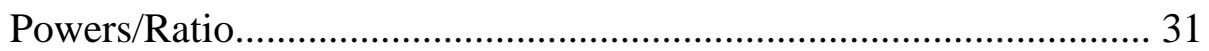

D. IVA+ and ABC Survey - Pre- and Post-Neurofeedback.................... 34

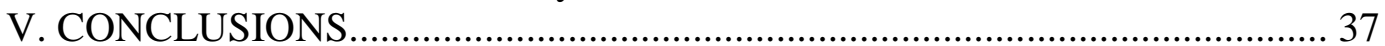

VI. FUTURE WORK AND RECOMMENDATIONS....................................... 44

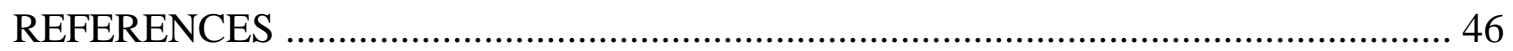

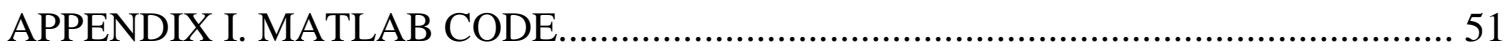

A. EEG Signal Processing Main Code............................................... 51

B. Input Signal Filtering Function.................................................... 54

C. 2-45 Hz Band-pass Filter Function......................................................

D. Harris Window Function

E. Impulse Response LPF Function.................................................... 58

F. Main Analysis Code....................................................................... 59

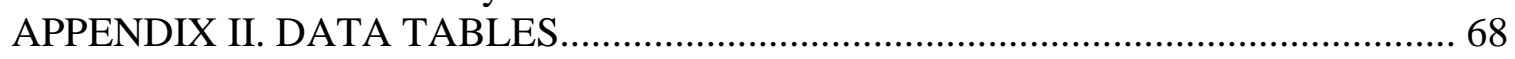

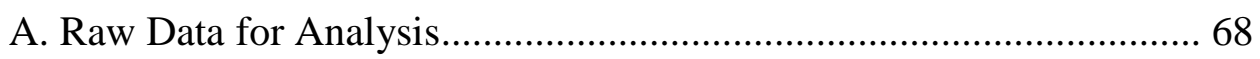

B. T-test Results for ABC and IVA+Plus Measures................................ 80

C. Minitab ANOVA Table Output and Pearson Correlation Test Output 82

VITA. 86 


\section{LIST OF TABLES}

Table 1: Summary of ANOVA results for each EEG measure and Investigated EEG band power ratio using Session as a Factor and the interested EEG measure as the response.

Table 2: Summary of ANOVA results for each EEG measure and investigated EEG band power ratio using Session as a Factor and the interested EEG measure as the response.

Table 3: Summary of results of Pearson correlation test using corresponding average values of EEG band relative powers and EEG band ratios with "Focus" measure. Table also includes linear relationship equations for significant correlations with $\mathrm{R}^{2}$ values. In the table, the y-variable represents "Focus" and the $\mathrm{x}$-variable represents either the EEG band relative power or the EEG band ratio.

Table 4: Summary of significant changes within the IVA+Plus using a two tailed t-test comparing data of Pre- and Post- Neurofeedback.

Table 5: Summary of significant changes in clinical measures as indicated by the Aberrant Behavior Checklist survey using a two tailed t-test comparing data of Pre- and Post- Neurofeedback. A p-value $<0.05$ was considered significant for the t-test.

Table 6: Raw data from MatLab analysis for Session 1. Data used for ANOVA calculations in MiniTab.

Table 7: Raw data from MatLab analysis for Session 2. Data used for ANOVA calculations in MiniTab.

Table 8: Raw data from MatLab analysis for Session 3. Data used for ANOVA calculations in MiniTab.

Table 9: Raw data from MatLab analysis for Session 4. Data used for ANOVA calculations in MiniTab.

Table 10: Raw data from MatLab analysis for Session 5. Data used for ANOVA calculations in MiniTab.

Table 11: Raw data from MatLab analysis for Session 6. Data used for ANOVA calculations in MiniTab.

Table 12: Raw data from MatLab analysis for Session 7. Data used for ANOVA calculations in MiniTab.

Table 13: Raw data from MatLab analysis for Session 8. Data used for ANOVA calculations in MiniTab. 
Table 14: Raw data from MatLab analysis for Session 9. Data used for ANOVA calculations in MiniTab.

Table 15: Raw data from MatLab analysis for Session 10. Data used for ANOVA calculations in MiniTab.

Table 16: Raw data from MatLab analysis for Session 11. Data used for ANOVA calculations in MiniTab.

Table 17: Raw data from MatLab analysis for Session 12. Data used for ANOVA calculations in MiniTab. 


\section{LIST OF FIGURES}

Figure 1: Sample Neurofeedback interface as seen by a patient during a neurofeedback session showing the EEG signal with DVD video embedded in screen.

Figure 2: The setup is shown for a subject undergoing neurofeedback. The image clearly illustrates the positioning of sensors, subject, and monitor.

Figure 3: BioReview report block diagram with filters for each EEG band collected [raw signal, Delta (2-4 Hz), Theta (4-8 Hz), Alpha (8-13 Hz), Low Beta (13-18 Hz), High Beta (18-30 Hz), Gamma (30-45 Hz)]

Figure 4: Block Diagram to demonstrate MatLab coding for cell array. Each subsequent row in the array represents the subsequent session. Each column represents an additional subject. The mean for each session is calculated by summing across each row of the cell array to determine the mean of the EEG measures for each minute within that session.

Figure 5: Plot of average Theta/Low Beta ratio value for each session (session number 112) indicating a decrease in the value of Theta/Low Beta ratio as session number increases. $\mathrm{R}^{2}$ value and equation for linear relationship included on the plot.

Figure 6: Plot of average Theta/Alpha ratio value for each session (session number 1-12) indicating a decrease in the value of Theta/Alpha ratio as session number increases. $\mathrm{R}^{2}$ value and equation for linear relationship included on the plot.

Figure 7: Plot of average "Focus" value for each session (session number 1-12) indicating an increase in the value of "Focus" as session number increases. $\mathrm{R}^{2}$ value and equation for linear relationship included on the plot.

Figure 8: Plot of average Theta/Low Beta ratios (averaged across all sessions) for each minute of Neurofeedback (1-25) indicating a decreasing Theta/Low Beta ratio as minute of NFB within a session increases. $\mathrm{R}^{2}$ value and equation for logarithmic relationship included on the plot.

Figure 9: Plot of average Theta/Alpha ratios (averaged across all sessions) for each minute of Neurofeedback (1-25) indicating a decreasing Theta/Alpha ratio as minute of NFB within a session increases. $\mathrm{R}^{2}$ value and equation for logarithmic relationship included on the plot.

Figure 10: Plot of average "Focus" values (averaged across all sessions) for each minute of Neurofeedback (1-25) indicating an increasing "Focus" measure as minute of NFB within a session increases. $\mathrm{R}^{2}$ value and equation for logarithmic relationship included on the plot.

Figure 11: Plot of correlation between corresponding average "Focus" values and Theta/Low Beta ratios for Sessions 1-12 and Minute 1-25 of NFB within a session. 
Figure 12: Plot of correlation between corresponding average "Focus" values and Theta/Alpha ratios for Sessions 1-12 and Minute 1-25 of NFB within a session.

Figure 13: The surface chart provides evidence supporting the decrease in the Theta/Low Beta ratio with regards to increasing session number and increasing minute of each session. As is consistent with the results of the ANOVA, Session trends, and Minute trend analysis, a general decrease is seen from (Session 1, Minute 1) through (Session 12, Minute 25) for the Theta/Low Beta ratio. The legend on the right side of the figure gives the color-coded ranges for the Theta/Low Beta ratio, as seen in the chart.

Figure 14: The surface chart provides evidence supporting the decrease in the Theta/Alpha ratio with regards to increasing session number and increasing minute of each session. As is consistent with the results of the ANOVA, Session trends, and Minute trend analysis, a general decrease is seen from (Session 1, Minute 1) through (Session 12, Minute 25) for the Theta/Alpha ratio. The legend on the right side of the figure gives the color-coded ranges for the Theta/Alpha ratio, as seen in the chart.

Figure 15: The surface chart provides anecdotal evidence supporting the increase in the "Focus" measure with regards to increasing session number and increasing minute of each session. As is consistent with the results of the ANOVA, Session trends, and Minute trend analysis, a general increase is seen from (Session 1, Minute 1) through (Session 12, Minute 25) for the "Focus" measure. The legend on the right side of the figure gives the color-coded ranges for the "Focus" measure, as seen in the chart. 


\section{INTRODUCTION}

\section{A. ADHD Prevalence and Clinical Significance}

Attention Deficit/Hyperactivity Disorder (ADHD) is a disorder that is prevalent throughout the world. It is believed that 5\% of school aged children suffer from ADHD, with some estimates indicating as high as $10 \%$ may suffer from the disorder (American Psychiatric Association, 2000; Faraone et al. 2003). Male children are 3 times as likely as female children to be diagnosed and treated for ADHD. The primary indications of ADHD are moderate to extreme inattention, evidenced by the inability to "focus" on specific tasks, and the hyperactivity component evidenced through fidgeting, agitation, and impulsivity (Biederman 2005; Gevensleben et al. 2009). Of the 5\% of children that exhibit ADHD symptoms in childhood, 30-50\% of those children exhibit symptoms in a chronic manner that continues to present into adulthood (Holtmann and Stadler 2006). Although, certain diagnostic differences exist between children who outgrow the disease compared to children who continue to present in adulthood (Clarke et al. 2010). The functional outcomes of ADHD can be detrimental to childhood development and prevent the necessary foundation for a successful life. Common problems associated and attributed to ADHD include poor academic performance, lower occupational success, increased risk-taking behavior, and diminished social relationships (Holtmann and Stadler 2006). The literature also cites that ADHD diagnoses increase the likelihood of other psychiatric diagnoses, which could lead to impaired functional adaptations later in 
life (Gillberg et al. 2004; Gevensleben et al. 2009). This distinction of an ADHD diagnosis accounts for the high prevalence of comorbidities associated with ADHD that are common in childhood cases. For instance, diagnoses of ADHD are commonly associated with psychiatric disorders including, but not limited to, conduct disorder, oppositional defiant disorder, and learning disorders (Pliszka 1998; Holtmann and Stadler 2006).

\section{B. Causes of ADHD in Childhood Population}

Despite similar diagnosis amongst a large patient demographic, the underlying causes of ADHD are varied, but well documented. Extensive research (Biederman 2005) demonstrates the strongest indicator of ADHD is a genetic/hereditary etiology with environmental factors believed to play a key role. Studies (Faraone et al. 2005) have shown that a familial connection with ADHD increases the chances of exhibiting the disorder by a factor of 2 to 8 . Since familial studies don't expressly separate genetic and environmental factors, twin and adoption studies have been utilized to determine the balance of effects believed to cause ADHD. Based on extensive twin studies (Faraone and Mick 2010), it was hypothesized that approximately $76 \%$ of the cause of ADHD could be attributed to familial factors and genetic. When correcting for bias due to interaction between twins, the estimate was reduced, although still the majority, with familial influence accounting for $60 \%$ of the diagnoses of ADHD (Cortese 2012; Wood et al. 2009). Additionally, adoption studies (Cortese 2012) have been clear in their implications regarding the hereditary nature of ADHD. In adoption studies, it has been 
shown that children with a biological connection to ADHD are more likely to exhibit hyperactivity than their adoptive counterparts with no biological link to ADHD.

\section{EEG Subtype Characteristics of ADHD and Comorbidities}

Attention Deficit/Hyperactivity Disorder has been known to associate with certain symptoms for many years. However, recently interest has been focused on studying the EEG patterns of children with ADHD to determine whether certain abnormalities existed in the EEG patterns of diagnosed children and how those abnormalities correlate to clinical manifestations of ADHD. As a result of initial studies (Barry, Clarke, and Johnstone 2003), it has been determined that compared to gender- and age-matched control, children with ADHD express three different manifestations of EEG signals. In general, EEG signals are separated into frequency ranges for characterization purposes. The range of frequencies for each group can vary, but from low to high frequencies the characterization is Delta, Theta, Alpha, Beta, and Gamma ranges. One group shows an increase in slow wave activity (e.g. Delta) and a decrease in the faster wave (e.g. Alpha and Beta) frequencies (Clarke et al. 2001, 2002). This group was initially labeled as "maturationally-lagged." A second group, labeled "hyperaroused", showed increased Theta amplitude, with decreased Beta activity (Clarke et al. 1998, 2001, 2002).

Intuitively, this manifests as an increase in the Theta/Beta ratio, which has been shown to be one of the most significant measures changing in ADHD treatment studies (Barry, Clarke, and Johnstone 2003). The third group, also identified tentatively as "hyperaroused", exhibited an increase in Beta activity (Clarke et al. 2001). However, as previously noted, ADHD diagnosis commonly presents with comorbidities. The studies 
isolating these groups screened exclusively for children only presenting an ADHD diagnosis. Therefore it was not representative of the clinical population. As a result, an additional study has been completed where children were not screened for comorbidities prior to inclusion.

In the most recent study into EEG subtypes relating to ADHD, Clarke et al. (2011b) separated the EEG manifestations into five clusters, with two being later combined due to similarities to yield a total of four central nervous system (CNS) abnormalities. In this study, the two combined clusters displayed an increase in total power and Theta signals with a decrease in Alpha and Beta activity. This combined cluster was designated in a previous study (Barry, Clarke, and Johnstone 2003) as "hyperarousal" and represented 35\% of patients in this study (Clarke et al. 2011b). Another cluster of patients presented with an increase in Delta and Theta activity and a decrease in Alpha activity coupled with a decrease in total power (Clarke et al. 2011b). This cluster is comparable to the previously labeled group defined as "maturationallylagged (Barry, Clarke, and Johnstone 2003)." The final cluster that was previously noted and tentatively labeled as "hyperarousal" (Barry, Clarke, and Johnstone 2003) represented 23\% of patients in this study (Clarke et al. 2011b). This group presented with increased total power and Beta activity. Additionally, this cluster displayed some decrease in Theta and Alpha activity. Finally, the last cluster determined in this group of patients, representing $17 \%$ of patients, did not present in the previous study which excluded all comorbidities (Clarke et al. 2011b). As a result of this newly identified group, which displayed increased Alpha activity with decreased Delta and Theta activity (Clarke et al. 2011b), no attempt was made to characterize this subtype. 
An extension of the linking of EEG characteristics to the ADHD diagnosis, concerns the connection between EEG patterns and clinically relevant subtypes of the ADHD diagnosis. The three DSM-IV subtypes of ADHD investigated by Clarke were Inattentive, Hyperactive-Impulsive, and Combined (2011b). Inattentive and Combined subscales showed a correlation with the Theta band, represented by two clusters in one EEG characteristic study (Clarke et al. 2011b). The other measure to display correlation specifically with a subtype was the Theta/Beta ratio, which showed a correlation with Hyperactive-Impulsive subtype, as well as the Combined subtype with two EEG clusters associating with these clinical subtypes (Clarke et al. 2011b).

As previously noted, a common clinical manifestation of ADHD involves many possible comorbid diagnoses. The increased Theta activity found in ADHD EEG characterizations has also been found in some of these diagnoses (e.g. learning disabilities, mental retardation, etc.). Whereas, increased Theta activity was originally theorized to be a result of brain dysfunction, the association of increased Theta activity with Inattentiveness shows that it is possible that Theta activity is actually an indicator of inattention (a symptom present in all these comorbid diagnoses) (Clarke et al. 2011a). A study (Clarke et al. 2011a) of ADHD patients presenting with a comorbid diagnosis of autism with a group presenting only with ADHD found several qualitative differences between the two groups. However, the primary diagnosis for each group was ADHD. This study found that a second comorbid group presented EEG abnormalities that could be considered independent of the ADHD diagnosis. Based on these findings by Clarke et al. (2011a), the inclusion of participants with comorbid disorders in ADHD studies seems logical. 


\section{ADHD Treatment Options}

\section{$\underline{\text { 1. Pharmacological }}$}

Due to the broad, highly present, and potentially severe impact of ADHD, it is of high importance to efficaciously and safely treat the symptoms of ADHD. The most prevalent method of treatment for ADHD is the use of medication, whether it be stimulant based (i.e. methylphenidate - the most prominent medication) or nonstimulant based (i.e. atomoxetine) (The MTA Cooperative Group 1999). Both varieties of medication have been shown to be efficacious for treatment of symptoms; however, 25 - 30\% of patients experience no response to medication or adverse effects (Greenhill et al. 1999, 2001). Additionally, withdrawal of medication results in patients reverting to previous levels of symptoms. Another important consideration regarding disadvantages of pharmacological treatment is that parents/guardians generally are hesitant to this approach due to side effects commonly associated with medicine (e.g. appetite loss) and the stigma associated with long-term medication in children (Taylor et al. 2004; Banaschewski et al.2006). Besides pharmacological treatments, several nonpharmacological treatments have been considered in the clinical setting, such as dietary elimination strategies, with results showing a non-significant impact for the majority of ADHD patients (Ferguson 2000). 


\section{Non-Pharmacological}

However, one non-pharmacological solution that has yielded positive results is neurofeedback (also called EEG biofeedback) training. The primary rationale for the utilization of neurofeedback in the treatment of ADHD stems from studies showing abnormal EEG findings in patients with ADHD (Barry, Clarke, and Johnstone 2003). In the majority of patients presenting with ADHD, studies have shown that there is a cortical slowing, or hypo-arousal, in some cases during EEG examinations (Monastra 2005; Holtmann and Stadler 2006). Therefore, neurofeedback treatments have been developed to target the two previously noted EEG abnormalities. It was theorized that through reinforcing a specific change in cortical activity through an auditory or visual display that the patient could normalize this reinforced activity and develop the ability to maintain and control targeted behavior (i.e. hyperactivity or inattention) (Monastra 2005).

Initially, proof of biofeedback producing significant changes in EEG signals was demonstrated in non-human models (Wyrwicka and Sterman 1968). Later, the first documented use of "Sensorimotor Rhythm" (SMR) training in the treatment of ADHD was accomplished in humans (Lubar and Shouse 1976). SMR training targets the brain waves in the $12-15 \mathrm{~Hz}$ range at the motor cortex, but this research was later expanded to include increasing EEG activity at higher frequencies (16-20 Hz or "Beta"), while suppressing activity at lower frequencies (4-8 Hz or "Theta"). As a result of these studies, clinical responses have been demonstrated in hyperactive children when treated with neurofeedback (Lubar and Shouse 1976). Most recently, several papers (Arns et al. 2009; Gevensleben et al. 2009; Sherlin et al. 2010a; Van den Bergh 2010) have reported 
neurofeedback as being an efficacious treatment in subjects with ADHD. These include meta-analysis, randomized clinical trials, and literature reviews supporting clinical efficacy associated with the utilization of neurofeedback. Therefore, neurofeedback as a treatment for ADHD is widely regarded as having Level 5 (efficacious and specific) efficacy as described by the American Psychological Association (Sherlin et al. 2010a). However, some clinicians in ADHD treatment area have certain concerns and argue that neurofeedback should be considered less efficacious clinically (Lofthouse, Arnold, and Hurt 2010). Nevertheless, the topic of clinical efficacy level of neurofeedback-based intervention in ADHD is still far from consensus and encourages more basic EEG research and clinical trials (Sherlin et al. 2010b).

Three general protocols are prevalent in the literature and have been investigated and shown efficacy in the treatment of ADHD. One such protocol is the SMR Enhancement/Theta Suppression. In this protocol, patients receive feedback based on the amount of time that the SMR signal is above pretreatment thresholds and the Theta signal is below pretreatment thresholds (Rossiter and La Vaque 1995). A secondary protocol utilizes SMR Enhancement combined with "Beta-2" (22-30 Hz) suppression (Fuchs et al. 2003). A third protocol, derived from the second protocol, involved the reinforcement of Theta suppression with "Beta-1" (13-22 Hz) enhancement (Linden, Habib, and Radojevic 1996). One more approach to neurofeedback application in ADHD treatment proposes a protocol (so called "Focus/Alertness" training) that uses wide band EEG spectrum suppression (Sokhadze 2012) rather that control of individual bands.

Due to the difficulty in interpretation of the meaning of the Theta-Beta ratios and other EEG terminology, terms such as "Focus" and "Alertness" that are defined in a clear 
way and can be understood through some simple introduction lessons have been developed. Sokhadze has described this protocol in detail (Sokhadze 2012). For instance, instead of telling a subject to suppress Theta or increase Beta, the subject is only instructed to increase "Focus". "Focus", in actuality, is a desynchronization measure of activation of the underlying cortex. This protocol has also been referenced as "InAll", "InhibitAll", or wide band suppression. Using "Focus" as a measure, the higher the quality of visualization of an activity, the larger the resulting "Focus" measure. This is extremely valuable for training via visualization. In contrast to "Focus", "Alertness" is primarily a numerical representation of the arousal of the central nervous system, responsible for creating the underlying pattern of psychophysiological changes associated with excitement and the "fight or flight" response. This measure of the underlying common pattern of emotional engagement can potentiate a variety of emotions: anxiety, anger, interest, and excited happiness. If these experiences are absent, then lower values of "Alertness" may reflect a calm or relaxed state. Alertness seems to be a good measure of the continuum underneath the inverted $U$ shaped curve relating the quality of performance to arousal. Finding the ideal level of "Alertness" for every point in the sequence of an activity by recording the EEG during visualization or video replay can be very valuable. It is far better training than just trying to adjust the level of Alertness at the beginning of the sequence. The "Focus" and "Alertness" measures were trained using the "Peak Achievement Trainer" that is commercially available (Cowan and Albers 2008). Prior studies have shown positive outcomes using this device (Sokhadze 2012). 


\section{E. Goals and Expectations of this Study}

The goal of this study was to conduct neurofeedback in ADHD subjects using the Peak Achievement Trainer (PAT) device with the "Focus/Alertness" protocol to investigate:

1) relative changes in EEG measures throughout the entire course of neurofeedback,

2) success of neurofeedback over 12 sessions could be shown through IVA+Plus (Braintrain Inc, VA) and Aberrant Behavior Checklist (ABC) (Aman and Singh 1994) measures,

3) and most importantly, how EEG power ratios are changing and how the changes correlated with measures of "Focus" and "Alertness."

A number of expectations were held prior to the study. It was expected that all participants would complete 12 sessions of "Focus/Alertness" training and learn to control "Focus" and "Alertness" parameters in biofeedback mode. Additionally, it was expected that there would be an improvement in the clinical (ABC) and neuropsychological (IVA+Plus) measures as previously reported in the treatment of ADHD in neurofeedback. It was expected that an improvement in "Focus" would manifest in the gradual decrease of the Theta/Beta EEG ratio. As more of an exploratory aim, it was planned to analyze correlations between the "Focus" measures with specific EEG relative powers and proportions. Finally, MatLab (Mathworks, Inc. MA) would be used to code an application that could effectively and efficiently analyze and compute all the desired measures. 


\section{DATA COLLECTION}

\section{A. Subject Demographics and Recruitment}

Eighteen children and adolescents with ADHD (mean age 13.6 years, SD=3.5, 6 female, 12 males) were enrolled in this study. Participating subjects and their parents were provided with all information about this study purposes and the consent/assent forms were signed. During the course of the study, only 4 subjects were not taking stimulant medication. Participants were not required to be off medication during the course of neurofeedback training; however, all participants were requested to not take medication before their neurofeedback session on a day of visit. Participants with ADHD were recruited through the University of Louisville Weisskopf Child Evaluation Center (WCEC). Diagnosis was made according to the DSM-IV-TR and was further ascertained by Dr. Sears through a clinical interview. In addition to diagnosis, Dr. Sears performed pre- and post-neurofeedback clinical evaluations. Neurofeedback sessions were conducted by Dr. Sokhadze. All required IRB-approved consent/assent forms were signed by the participants and parent/guardian of the participating subjects.

\section{B. Neurofeedback Protocol and Data Recording}

This study involved the use of existing neurofeedback protocols to train the measures of "Focus" and "Alertness". Subjects completed sessions using a "Focus/Alertness" 
protocol designed to train the "Focus" and "Alertness" measures. The goal of each subject was to enhance "Focus" throughout the session while maintaining an adequate measure of "Alertness" within a certain range. All sessions were completed using different fragments of documentary films depicting nature scenes from the BBC "Planet Earth" and "Life" series. Different scenes were utilized to maintain the engagement and motivation of participants. Based on the thresholds set, the subject would receive biofeedback both in the visual and auditory modalities. Visual feedback was arranged in a form of control of brightness, size, and continuation of the documentary by the "Focus" and "Alertness" measures. For instance, based on processing of "Focus" and "Alertness" measures in real time, the video feed will shrink or enlarge and fade or become brighter. Auditory feedback was used to inform subjects when these measures were under the threshold level, in the case of "Focus", or outside the acceptable range, in the case of "Alertness". Figure 1 illustrates a sample interface seen by a subject during a neurofeedback session. 


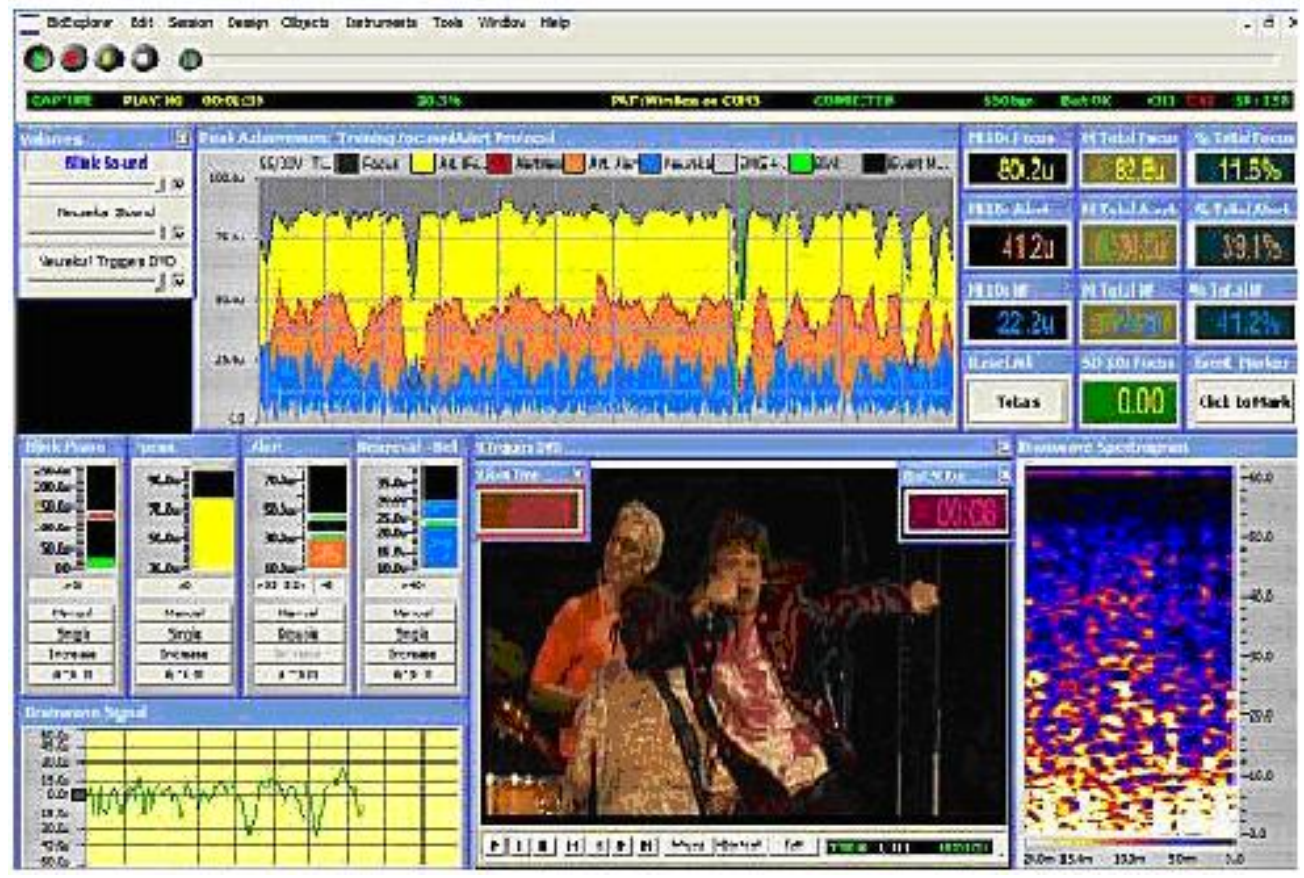

FIGURE 1: Sample Neurofeedback interface as seen by a patient during a neurofeedback session showing the EEG signal with DVD video embedded in screen.

All EEG signals and training parameters were measured from the same sensors, one active electrode at the prefrontal EEG $(\mathrm{FPz})$ site and the second a reference on the left ear with a third sensor serving as a ground at the right earlobe. The sensors were soaked in a potassium chloride solution, compatible to concentration of salt in medical saline solution. The setup (e.g. sensor placement, monitor placement, patient orientation, etc.) for each neurofeedback session is shown in Figure 2. 


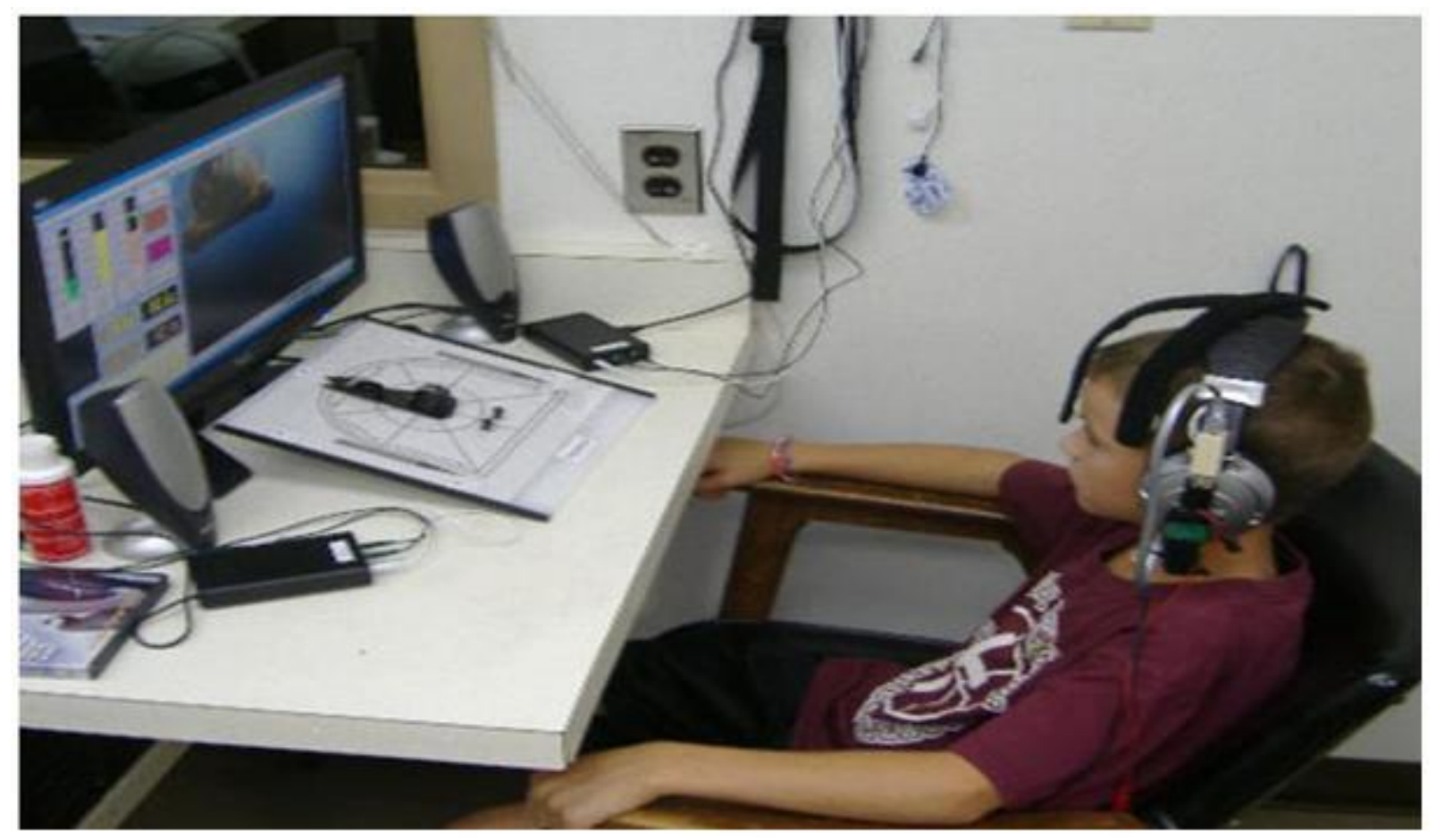

FIGURE 2: The setup is shown for a subject undergoing neurofeedback. The image clearly illustrates the positioning of sensors, subject, and monitor

Each subject completed a minimum of 12 weekly neurofeedback sessions. The goal, as explained to each subject, was the training of an increase in "Focus" using the "Focus/Alertness" protocol. The target length of each session recorded was $25 \mathrm{~min}$, with most sessions reaching 20-min minimum length goal ( $n=185$ sessions out of 216 total sessions), with the shortest session recorded containing only 15 minutes of data. Eye blink artifacts removal was implemented using a custom made BioExplorer (BioExplorer 1.5, CyberEvolution, WA) application. 


\section{Clinical and Neuropsychological Measures of ADHD}

\section{Clinical Measures and Evaluation}

In conjunction with neurofeedback, clinical measures along with pre- and postneurofeedback data were collected. A clinical behavioral outcome measures in ADHD patients included scores from the Aberrant Behavior Checklist (ABC). The $\mathrm{ABC}$ is a rating scale assessing five problem areas: Irritability, Lethargy/Social Withdrawal, Stereotypy, Hyperactivity, and Inappropriate Speech, and is based on caregiver reports (Aman and Singh 1994). Scoring of the ABC reports was completed by Dr. Sears.

2. Neuropsychological Measures and Evaluation

In addition to the collection of clinical measures, commonly accepted neuropsychological measures of selective attention were collected. The continuous performance IVA+Plus (BrainTrain Inc, VA) selective attention test was administered before and after the 12 session "Focus/Alertness" neurofeedback course. This 20-min long test provides accurate measures of sustained auditory and visual attention quotients and is widely accepted as an acceptable neurocognitive test of attention in children (Sandford 2009). 


\section{Data Processing and Analysis}

\section{A. EEG Signal Processing}

\section{$\underline{\text { 1. BioReview }}$}

As previously stated, the EEG signal was collected and recorded with BioExplorer-based software application. The first goal of signal processing was to separate the raw signal based on the desired frequency bands. The first step in the filtering process was completed in BioReview - an extension of BioExplorer that serves for analysis of recorded sessions. The frequency ranges for each selected band are similar to, yet a slight modification of those described by Miller (2007). The signal was separated into Delta (2-4 Hz), Theta (4-8 Hz), Alpha (8-13 Hz), Low Beta (13-18 Hz), High Beta $(18-30 \mathrm{~Hz})$, and Gamma $(30-45 \mathrm{~Hz})$ components using a band-pass filter with a Harris window configuration. Additionally, the raw signal was exported for later use if additional filtering would be needed. The report design in BioReview is based on a Visual Basic design. Each filter is added to the report block diagram and then the settings of the filter are customized and edited according to what is desired. Figure 3 shows the layout of the block diagram designed for this application. 


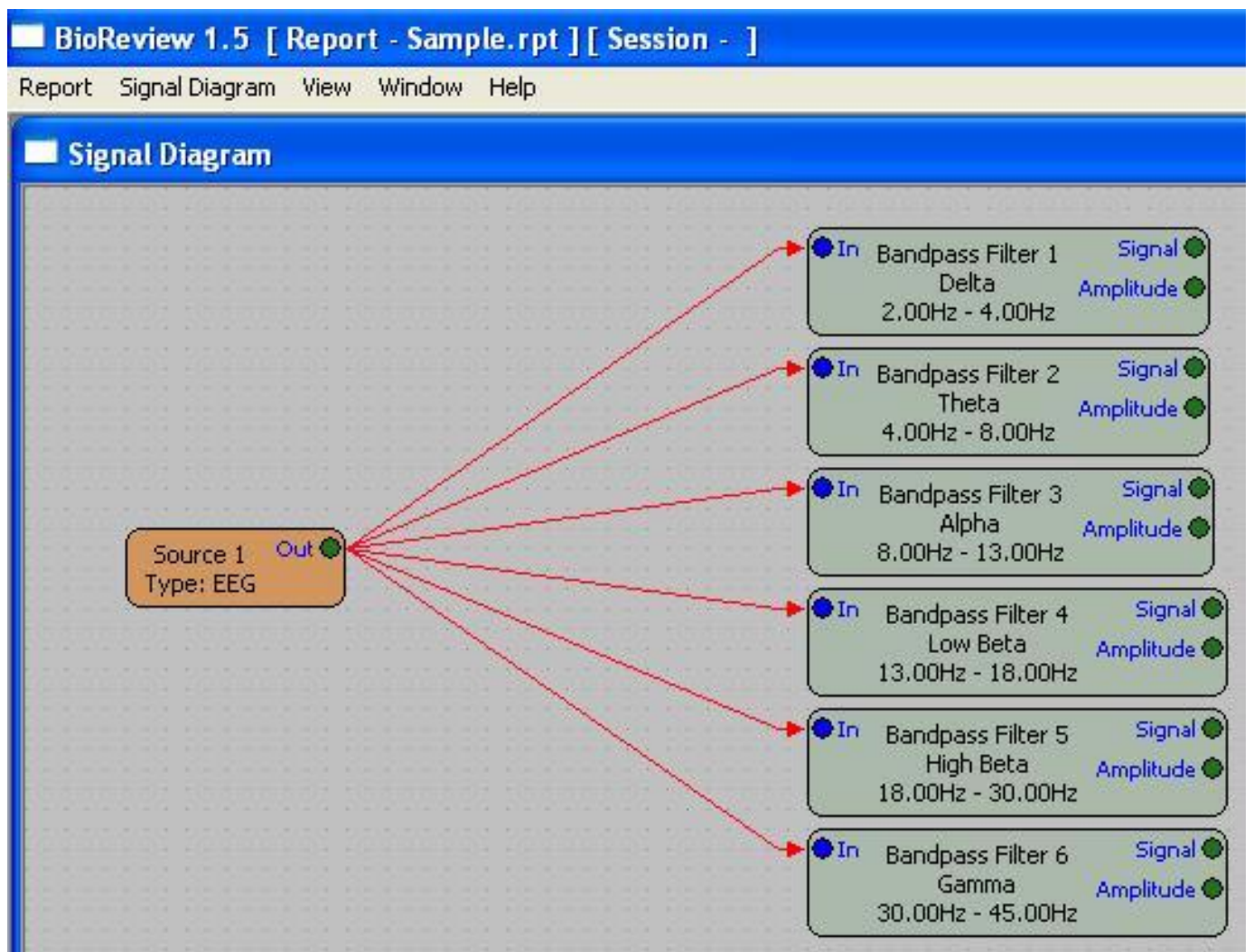

Figure 3: BioReview report block diagram with filters for each EEG band collected [, Delta (2-4 Hz), Theta (4-8 Hz), Alpha (8-13 Hz), Low Beta (13-18 Hz), High Beta (18-30 $\mathrm{Hz})$, Gamma (30-45 Hz)]. The raw signal is output once the report is run.

Each session was processed using this report. The sampling rate for all data was $256 \mathrm{~Hz}$. After processing through the BioReview report, each session was exported as raw data. In this configuration, every data point was exported to a text file where the different measures were organized into columns and each subsequent row represented the change in time between samples. 


\section{MatLab}

After exporting the text file from BioReview, the data was then to be analyzed and processed in MatLab. Based on the nature of the neurofeedback system, it was determined that relative power comparisons between bands would be appropriate for this analysis. For instance, the system used in neurofeedback did not have a calibration measure. As a result, of this lack of calibration it was decided power measures were more appropriate based on an assumption of constant resistance within the system instead of assuming the system measured voltage consistently across all subjects. Through this assumption of equivalent resistance based on constant wire length, wire gauge, thermostat controlled temperature (at room temperature) of lab where neurofeedback occurred, and uniformity in the EEG sensors used across all subjects the relative power equation could be simplified. As can be seen in equation 1 showing the traditional calculation of power in electrical signal, resistance is present.

$$
P=\frac{V^{2}}{R}
$$

However, resistance being constant across each session would allow for the removal of that term in any relative power calculation. This is pertinent since the exact resistance of the system is not known for each session.

Therefore, it was necessary to filter in MatLab from 2-45 Hz to gain the total power of the band of interest. To complete the filtering necessary for completion of the 
analysis, MatLab code was designed using a custom band-pass filter application created through the integration of wavelet transformation of the raw signal (effective for handling any noise in the signal) and a Harris window configuration that separates the $2-45 \mathrm{~Hz}$ portion of the raw signal into its own filtered signal. Therefore, band-pass filtering of the raw signal in MatLab provided a "total" signal $(2-45 \mathrm{~Hz})$ that could then be utilized in relative power calculations.

After filtering of the raw signal to the desired frequency, relative power calculations for each minute of every neurofeedback session were completed in MatLab using an iterative for loop function on each recorded session with the filtered total signal of interest replacing the raw signal. The formula used to calculate relative power in this analysis is given in Equation 2, where $b$ represents the band signal and $t$ represents the "total" signal from 2-45 Hz.

$$
R P=\frac{\sum_{i}^{n} b^{2}}{\sum_{i}^{n} t^{2}}
$$

The summation includes every data point for 1 minute of recorded data, 15360 data points per minute based on a $256 \mathrm{~Hz}$ sampling rate. Therefore, an average relative power for each band was calculated for each minute of each session. It is important to note that since relative power was investigated instead of relative amplitude, that the calculated measure is not a pure percentage and will not be labeled as such. In addition to the calculation of relative power for each band, the ratio of certain bands was calculated 
using the relative power values calculated for each band. The formula for calculating the ratios of certain bands is given in Equation 3.

$$
B R=\frac{R P_{1}}{R P_{2}}
$$

Therefore, the band ratio was calculated for each minute of each session. The ratios of interest for this study were the Theta/Low Beta, Theta/High Beta, Theta/Beta, and Theta/Alpha proportion. Theta/Beta ratio was calculated using the sum of the Low Beta and High Beta relative powers for each minute, but otherwise the formula in Equation 3 was followed.

Initially, each session for each subject was analyzed independently and output into an Excel summary file for that subjects' session. However, the goal of the research involved a deeper look into EEG changes according to minute and session of neurofeedback. Therefore, to differences between subjects were assumed to be normal during each minute of each session of neurofeedback. This facilitated the averaging of EEG measures across subjects which made possible a more intensive analysis of session number and minute number of neurofeedback possible. In order to gain single output files for each session of neurofeedback, a cell array configuration was utilized in MatLab where each session for each individual subject was placed in a row of the array corresponding to session number. Then session 1 averages for all measures were calculated across the row according to minute and number of sessions with data at that 
minute of neurofeedback. Figure 4 uses a block diagram setup to illustrate the concept utilized for this method of data processing.

\begin{tabular}{|c|l|l|}
\hline$\Sigma$ & Subject 1 Session 1 & \\
\hline$\Sigma$ & Subject 1 Session 2 & \\
\hline$\Sigma$ & Subject 1 Session 3 & \\
\hline$\Sigma$ & Subject 1 Session 4 & \\
\hline$\Sigma$ & Subject 1 Session 5 & \\
\hline$\Sigma$ & Subject 1 Session 6 & \\
\hline$\Sigma$ & Subjeet 1 Session 7 & \\
\hline$\Sigma$ & Subject 1 Session 8 & \\
\hline$\Sigma$ & Subject 1 Session 9 & \\
\hline$\Sigma$ & Subjeet 1 Session 10 & \\
\hline$\Sigma$ & Subject 1 Session 11 & \\
\hline$\Sigma$ & Subject 1 Session 12 & \\
\hline
\end{tabular}

\begin{tabular}{|l|l|l|}
\hline & Subjeet N Session 1 & Mean Session 1 \\
\hline & Subject N Session 2 & Mean Session 2 \\
\hline & Subject N Session 3 & Mean Session 3 \\
\hline & Subject N Session 4 $\rightarrow$ & Mean Session 4 \\
\hline \hline & Subject N Session 5 & Mean Session 5 \\
\hline & Subjeet N Session 6 & Mean Session 6 \\
\hline & Subject N Session 7 & Mean Session 7 \\
\hline & Subject N Session 8 & Mean Session 8 \\
\hline & Subjeet N Session 9 & Mean Session 9 \\
\hline & Subject N Session 10 & Mean Session 10 \\
\hline & Subjeet N Session 11 & Mean Session 11 \\
\hline Subjeet N Session 12 & Mean Session 12 \\
\hline
\end{tabular}

FIGURE 4: Block Diagram to demonstrate MatLab coding for cell array. Each subsequent row in the array represents the subsequent session. Each column represents an additional subject. The mean for each session is calculated by summing across each row of the cell array to determine the mean of the EEG measures for each minute of neurofeedback within that session.

The end result of the data processing was twelve Microsoft Excel files output according to session number with essentially the summary data for each measure (organized by columns) at each minute of neurofeedback.

\section{B. Statistical Analysis}

Statistical analysis techniques were utilized to determine the significance of session number (1-12) and minute (1-25) with regards to each EEG measure calculated. A General Linear Model ANOVA was utilized with $\alpha=0.05$ to determine significant changes in each EEG band, band ratio, and "Focus/Alertness" measures. Potential linear correlations between session and minute averages of "Focus" and other significant EEG 
measures were investigated using the Pearson Correlation statistic with $\alpha=0.05$ for significance. Additionally, student's two tailed t-test $(\alpha=0.05)$ was used to determine significant changes between pre- and post- data collected through the IVA+ tests and the ABC survey. Statistical analysis was conducted using MiniTab16.0 (State College, PA) and SPSS v.15 software (SPSS, Inc., IL). 


\section{$\underline{\text { IV. RESULTS }}$}

\section{A. EEG Measures changes by Session}

The ANOVA supported that there were main effects of session for all interested EEG measures. Specifically, the effect of session was determined to be significant for Theta relative power $[\mathrm{F}(11,264)=6.96$, $\mathrm{p}$-value $<0.001]$, Low Beta relative power $[\mathrm{F}(11,264)=6.85, \mathrm{p}$-value $<0.001]$, Theta/Low Beta ratio $[\mathrm{F}(11,264)=9.02, \mathrm{p}-$ value $<0.001]$, Theta/Alpha ratio $[\mathrm{F}(11,264)=19.74$, p-value $<0.001]$, and "Focus" $[F(11,264)=32.39, \mathrm{p}$-value $<0.001]$. The full summary of the ANOVA results for changes in EEG measures from session 1-12 are presented in Table 1.

TABLE I

SUMMARY OF ANOVA RESULTS FOR CHANGES IN EEG MEASURES FROM SESSION $1-12$ OF NFB $(\mathrm{P}<0.05$ SIGNIFICANT)

\begin{tabular}{|c|c|c|c|c|}
\hline EEG Measure & $\begin{array}{c}\text { Degrees of } \\
\text { Freedom }\end{array}$ & $\begin{array}{c}\text { F- } \\
\text { Statistic }\end{array}$ & $\begin{array}{c}\text { p- } \\
\text { value }\end{array}$ & $\begin{array}{c}\text { Direction of } \\
\text { Change }\end{array}$ \\
\hline Delta Relative Power & 11 & 8.03 & $<0.001$ & Decrease \\
Theta Relative Power & 11 & 6.96 & $<0.001$ & Decrease \\
Alpha Relative Power & 11 & 7.74 & $<0.001$ & Increase \\
Low Beta Relative Power & 11 & 6.85 & $<0.001$ & Increase \\
High Beta Relative Power & 11 & 5.67 & $<0.001$ & Decrease \\
Gamma Relative Power & 11 & 5.97 & $<0.001$ & Decrease \\
Theta/Low Beta Ratio & 11 & 9.02 & $<0.001$ & Decrease \\
Theta/High Beta Ratio & 11 & 7.64 & $<0.001$ & Decrease \\
Theta/Beta Ratio & 11 & 7.49 & $<0.001$ & Decrease \\
Theta/Alpha Ratio & 11 & 19.74 & $<0.001$ & Decrease \\
"Focus" Measure & 11 & 32.39 & $<0.001$ & Increase \\
"Alertness" Measure & 11 & 3.85 & $<0.001$ & Decrease \\
\hline
\end{tabular}


Changes were determined to be either increasing or decreasing based on the trend the data exhibited when charted. Therefore, from session 1-12 Theta relative power, Theta/Low Beta ratio, and Theta/Alpha ratio are shown to be significantly decreasing. An increase is seen from session 1-12 with Low Beta relative power and "Focus" measure. Changes in Theta/Low Beta ratio, Theta/Alpha ratio, and "Focus" measure were of particular interest. To gain an understanding of the relationship between changes in session number and these measures, the average value for each session of each EEG measure were plotted from session 1-12. Figures 5-7 display the change in average Theta/Low Beta ratio, Theta/Alpha ratio, and "Focus" measure, respectively, from session 1-12. A linear relationship is the most obvious fit for average changes from session 1-12. 


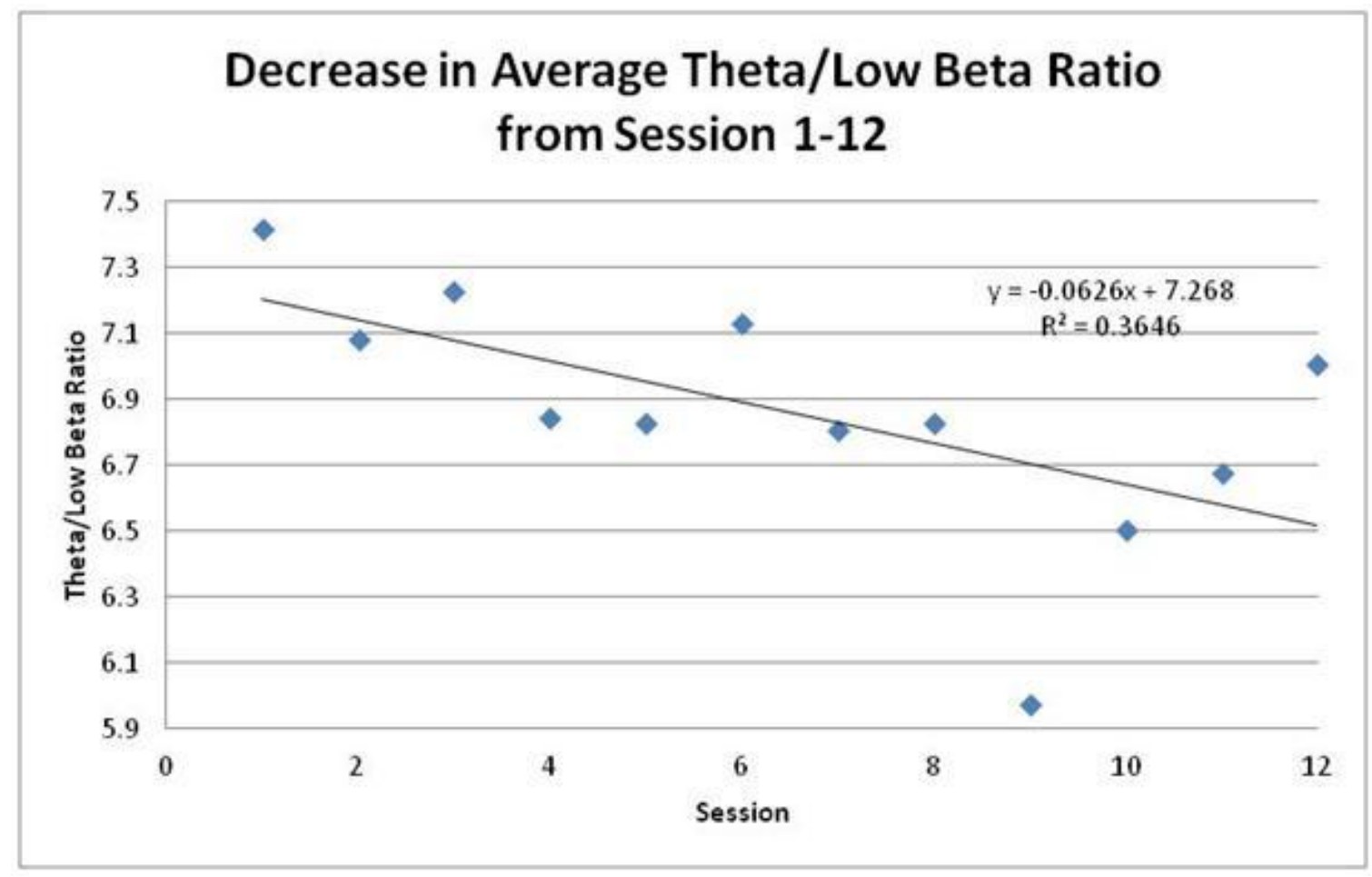

FIGURE 5: Plot of average Theta/Low Beta ratio value for each session (session number 1-12) indicating a decrease in the value of Theta/Low Beta ratio as session number increases. $\mathrm{R}^{2}$ value and equation for linear relationship included on the plot. 


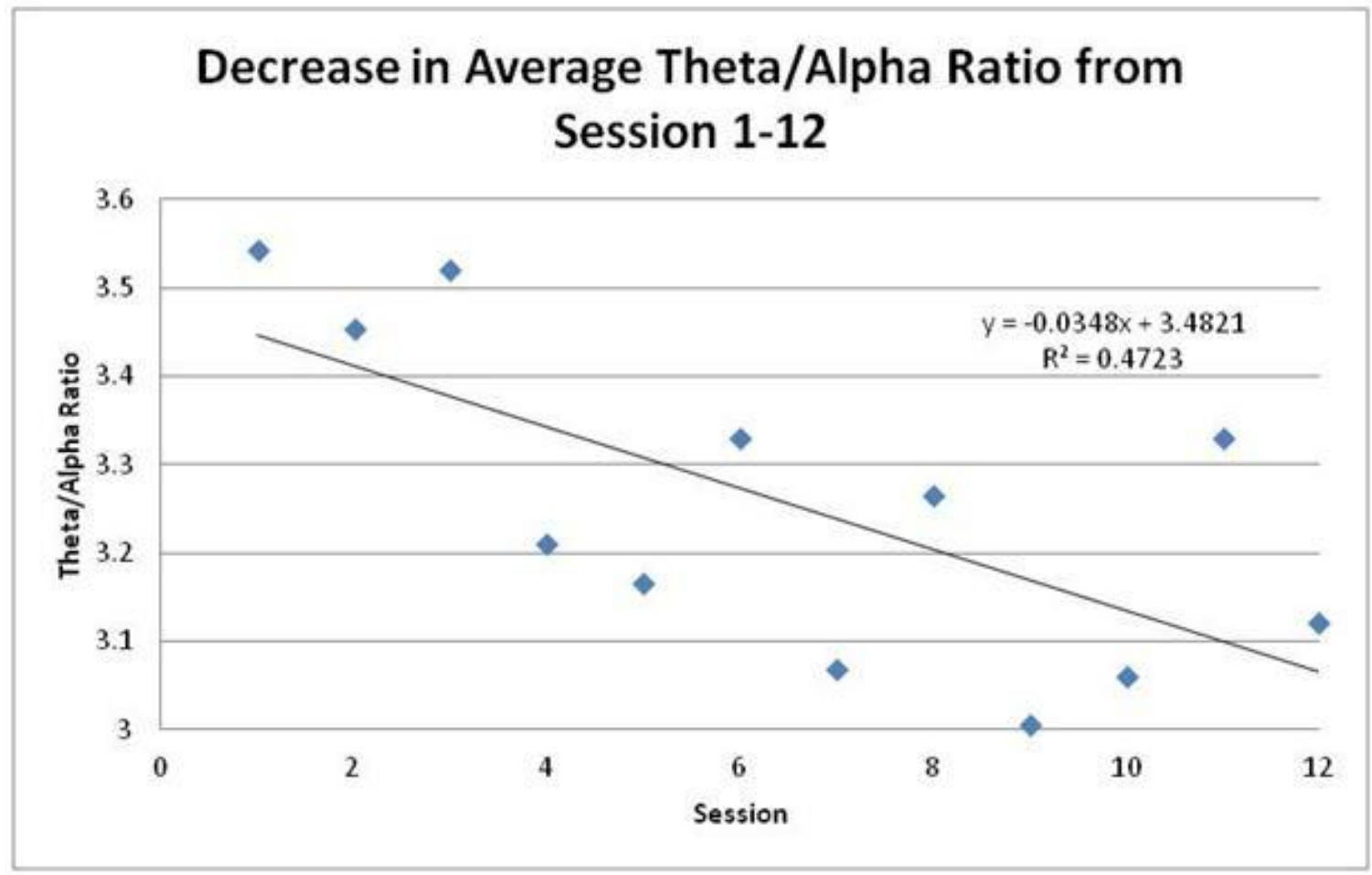

FIGURE 6: Plot of average Theta/Alpha ratio value for each session (session number 112) indicating a decrease in the value of Theta/Alpha ratio as session number increases. $\mathrm{R}^{2}$ value and equation for linear relationship included on the plot. 


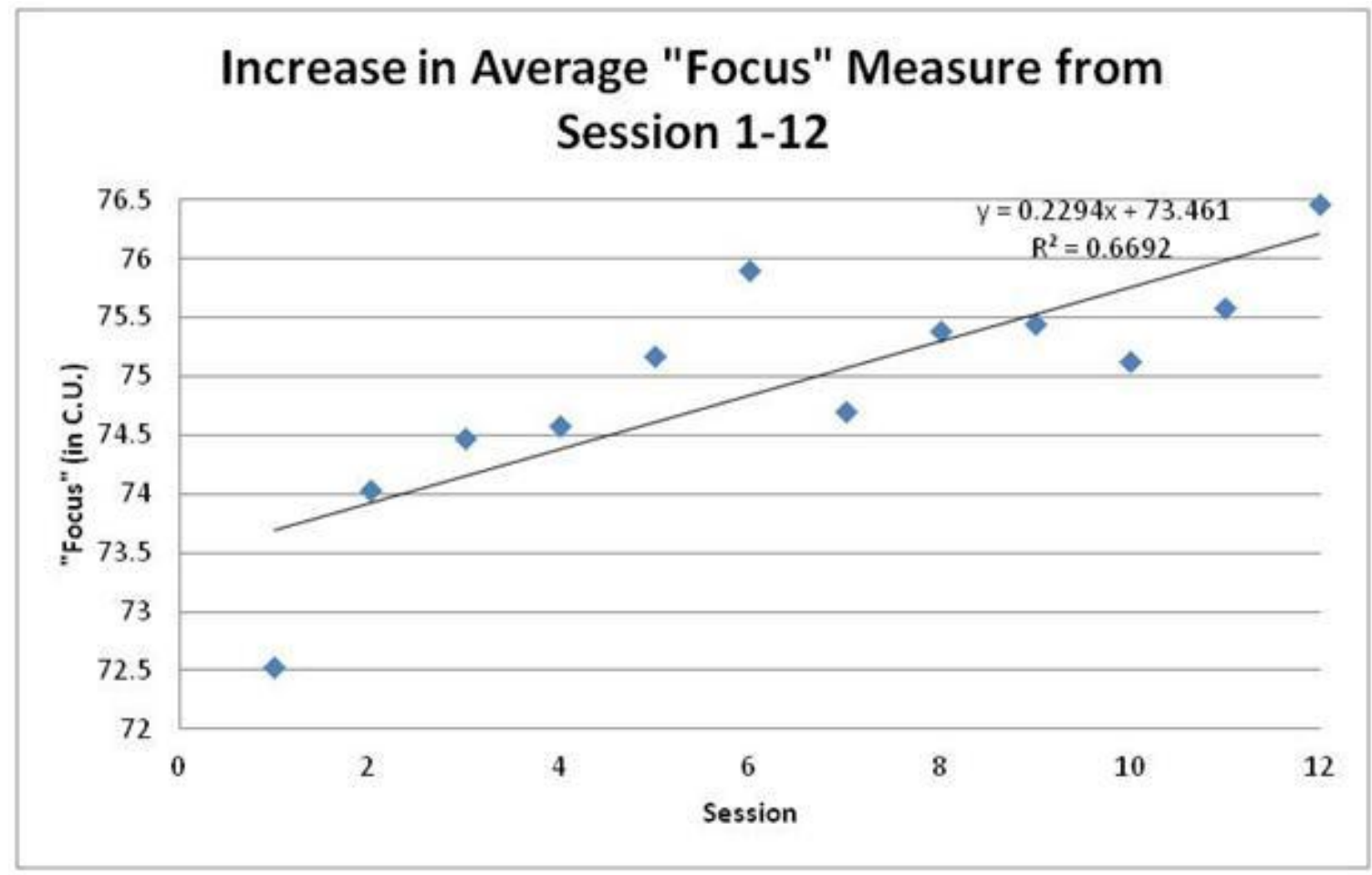

FIGURE 7: Plot of average "Focus" value for each session (session number 1-12) indicating an increase in the value of "Focus" as session number increases. $\mathrm{R}^{2}$ value and equation for linear relationship included on the plot.

\section{B. EEG Measures changes by Minute}

The ANOVA supported that there were main effects of minute for some interested EEG measures. Specifically, the effect of minute was determined to not be significant for Theta relative power $[\mathrm{F}(24,264)=0.98, \mathrm{p}=.493]$ or Low Beta relative power $[\mathrm{F}$ $(24,264)=0.88, \mathrm{p}=.633]$. However, the Theta/Low Beta ratio $[\mathrm{F}(24,264)=2.12, \mathrm{p}=$ 0.002], Theta/Alpha ratio $[\mathrm{F}(24,264)=2.05, \mathrm{p}=0.003]$, and "Focus" measure [F $(24,264)=4.35, \mathrm{p}<0.001]$ were shown to change significantly according to minute. The full summary of the ANOVA results for changes in EEG measures from minute 1-25 are presented in Table 2 . 
TABLE II

SUMMARY OF ANOVA RESULTS FOR CHANGES IN EEG MEASURES FROM MINUTE 1-25 OF NFB WITHIN A SESSION (P<0.05 SIGNIFICANT)

\begin{tabular}{|c|c|c|c|c|}
\hline EEG Measure & $\begin{array}{c}\text { Degrees of } \\
\text { Freedom }\end{array}$ & F Statistic & $\begin{array}{c}\text { p- } \\
\text { value }\end{array}$ & $\begin{array}{c}\text { Direction of } \\
\text { Change }\end{array}$ \\
\hline Delta Relative Power & 24 & 1.64 & 0.032 & Decrease \\
Theta Relative Power & 24 & 0.98 & 0.493 & NS \\
Alpha Relative Power & 24 & 0.710 & 0.841 & NS \\
Low Beta Relative Power & 24 & 0.88 & 0.633 & NS \\
High Beta Relative Power & 24 & 1.58 & 0.045 & Increase \\
Gamma Relative Power & 24 & 1.66 & 0.029 & Increase \\
Theta/Low Beta Ratio & 24 & 2.12 & 0.002 & Decrease \\
Theta/High Beta Ratio & 24 & 6.11 & $<0.001$ & Decrease \\
Theta/Beta Ratio & 24 & 4.82 & $<0.001$ & Decrease \\
Theta/Alpha Ratio & 24 & 2.05 & 0.003 & Decrease \\
"Focus" Measure & 24 & 4.35 & $<0.001$ & Increase \\
"Alertness" Measure & 24 & 4.83 & $<0.001$ & Increase \\
\hline
\end{tabular}

Changes were determined to be either increasing or decreasing based on the trend the data exhibited when charted. Therefore, from minute 1-25 Theta/Low Beta ratio and Theta/Alpha ratio was shown to be significantly decreasing. An increase is seen from minute 1-25 with "Focus" measure. As with the changes seen across sessions, changes in Theta/Low Beta ratio, Theta/Alpha ratio, and "Focus" measure across minute of session were of particular interest. To gain an understanding of these changes in Theta/Low Beta ratio, Theta/Alpha ratio, and "Focus" measure depending on minute of neurofeedback session, the average value for each minute of each EEG measure were plotted from minute 1-25. Figures 8-10 display the changes in average Theta/Low Beta ratio, Theta/Alpha ratio, and "Focus" measures, respectively, from minute 1-25. With regard to changes within a session of neurofeedback, a logarithmic relationship was deemed to 
be a better fit than a linear relationship. For instance, in addition to visual inspection, the $\mathrm{R}^{2}$ value for a linear relationship between "Focus" measure and minute $\left(\mathrm{R}^{2}=0.3281\right)$ was much lower than the $\mathrm{R}^{2}$ value seen in Figure 10 associated with the logarithmic relationship.

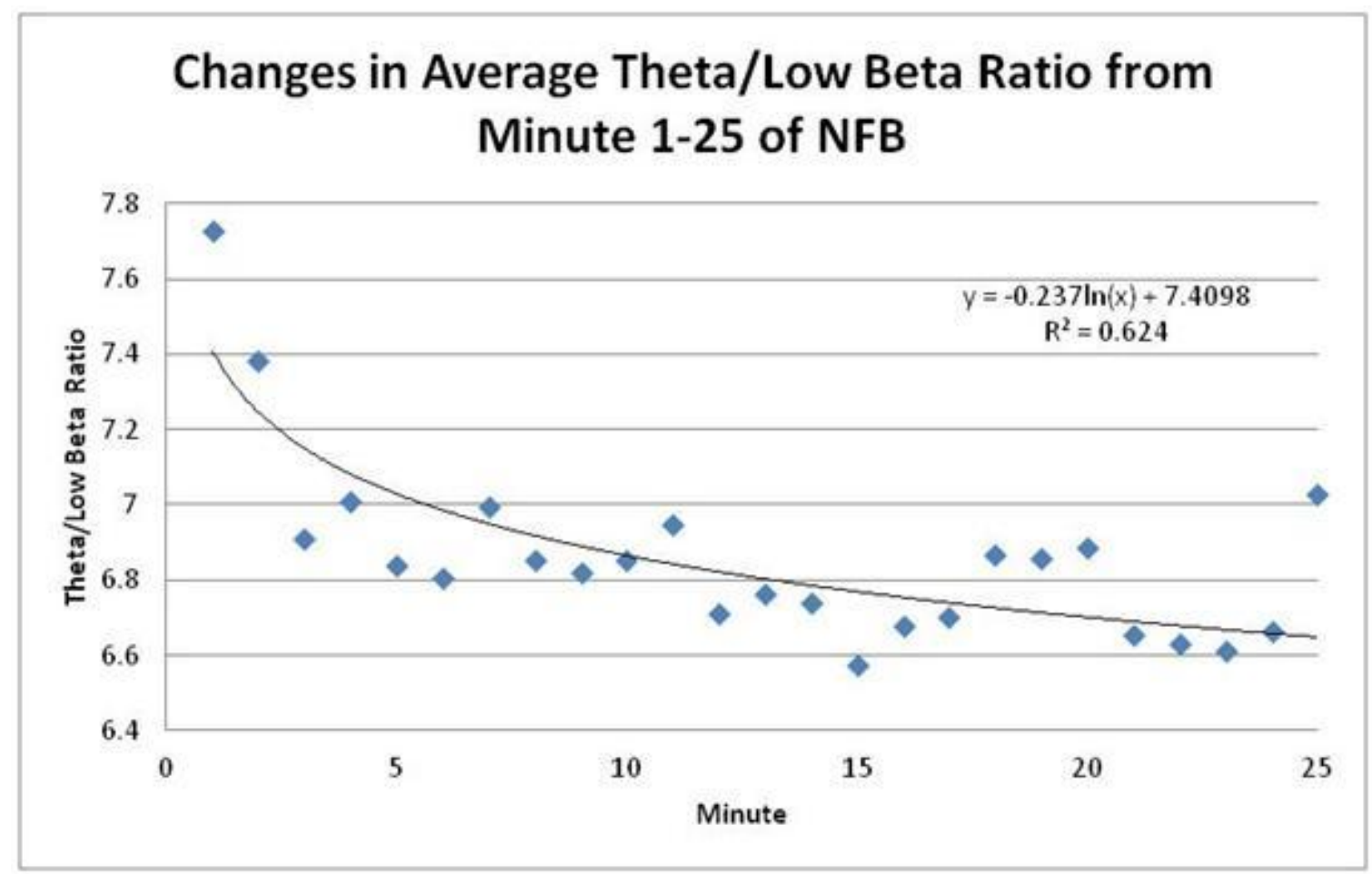

FIGURE 8: Plot of average Theta/Low Beta ratios (averaged across all sessions) for each minute of Neurofeedback (1-25) indicating a decreasing Theta/Low Beta ratio as minute of NFB within a session increases. $\mathrm{R}^{2}$ value and equation for logarithmic relationship included on the plot. 


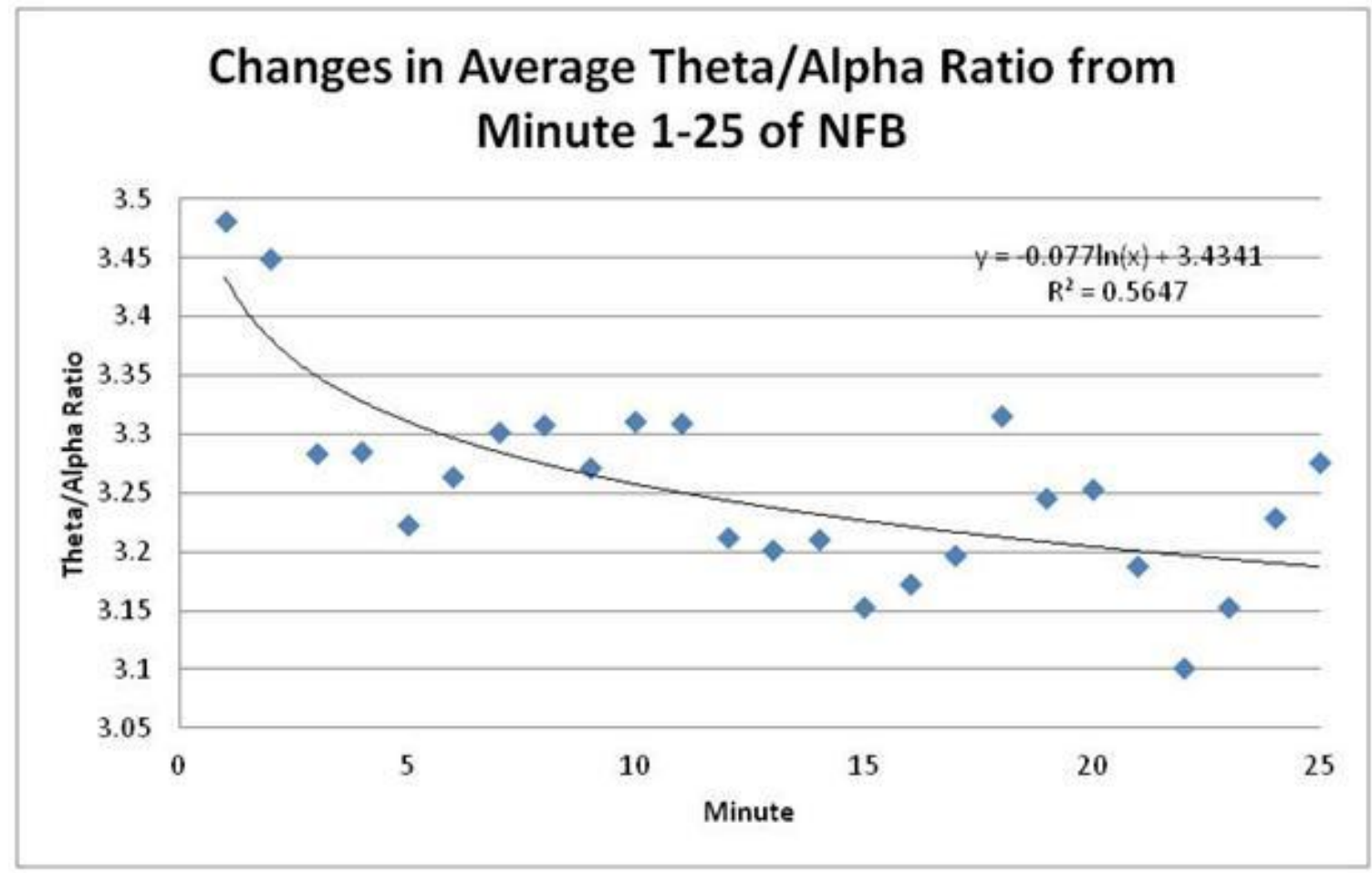

FIGURE 9: Plot of average Theta/Alpha ratios (averaged across all sessions) for each minute of Neurofeedback (1-25) indicating a decreasing Theta/Alpha ratio as minute of NFB within a session increases. $\mathrm{R}^{2}$ value and equation for logarithmic relationship included on the plot. 


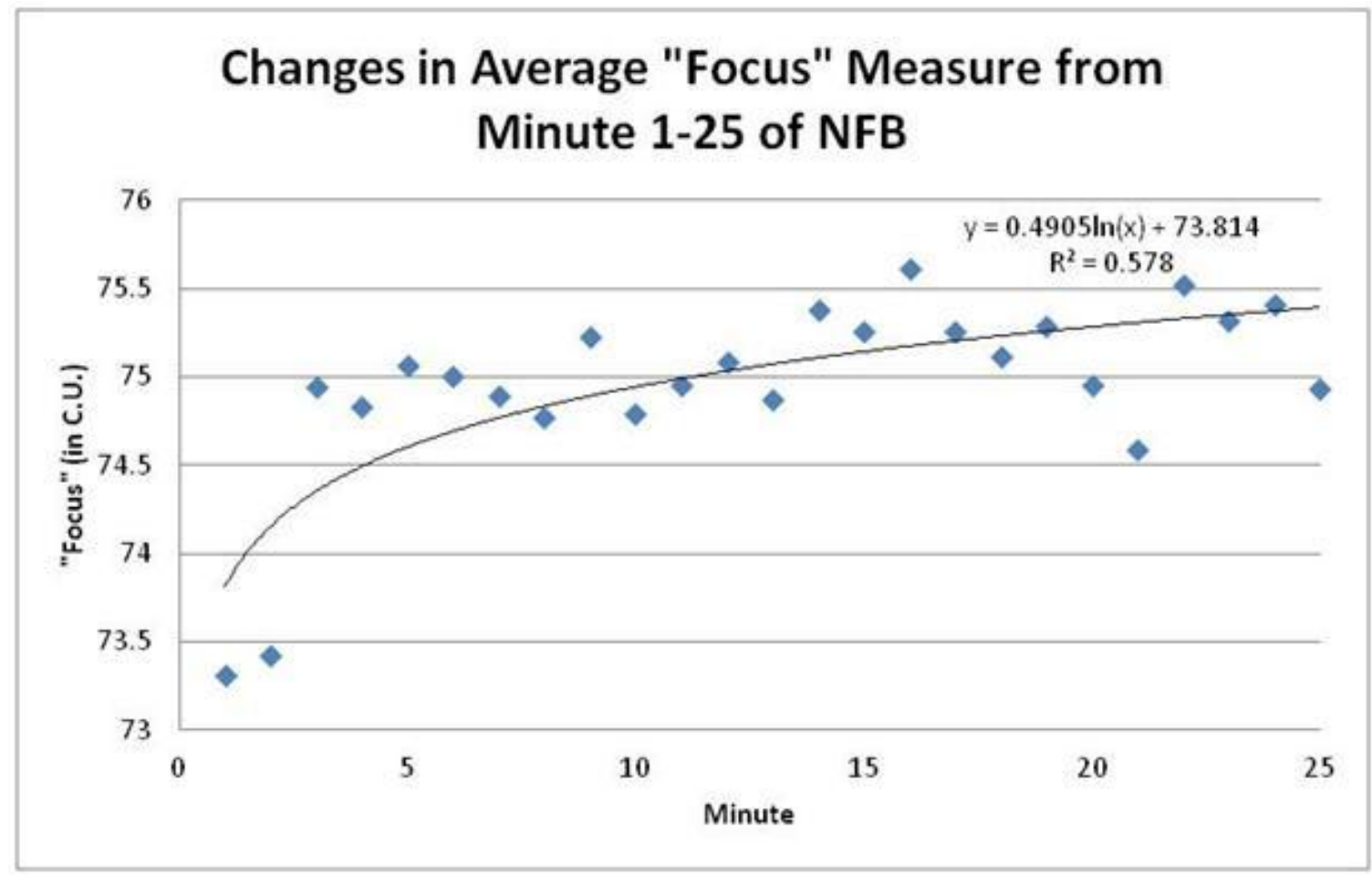

FIGURE 10: Plot of average "Focus" values (averaged across all sessions) for each minute of Neurofeedback (1-25) indicating an increasing "Focus" measure as minute of NFB within a session increases. $\mathrm{R}^{2}$ value and equation for logarithmic relationship included on the plot.

\section{Correlation between "Focus" Measure and EEG Band Relative Powers/Ratios}

The results of the Pearson Correlation, using the corresponding average values for any interested EEG measures (Theta relative power, Alpha relative power, Low Beta relative power, High Beta relative power, Theta/Low Beta ratio, Theta/High Beta ratio, Theta/Beta ratio, and Theta/Alpha ratio) and for "Focus" calculated for changes in minute 1-25 and session 1-12, showed possible correlations in multiple EEG band relative power and EEG band ratios with the "Focus" measure. Specifically, a significant correlation existed between "Focus" and the Theta/Low Beta ratio (Pearson Correlation Coefficient $=$ 
-0.633, $\left.\mathrm{p}<0.001, \mathrm{R}^{2}=0.401\right)$. Additionally, a significant correlation existed between "Focus" and the Theta/Alpha ratio (Pearson Correlation Coefficient $=-0.676, \mathrm{p}<0.001, \mathrm{R}^{2}$ $=0.457)$. Table 3 fully summarizes the results of the Pearson Correlation test and gives the linear regression equation of the correlation between all significant measures and the "Focus" measure with appropriate $\mathrm{R}^{2}$ values.

\section{TABLE III}

SUMMARY OF RESULTS OF PEARSON CORRELATION TEST USING CORRESPONDING AVERAGE VALUES OF EEG BAND RELATIVE POWERS AND EEG BAND RATIOS WITH "FOCUS" MEASURE (P<0.05 SIGNIFICANT)

\begin{tabular}{|c|c|c|c|c|c|c|c|c|c|}
\hline & & $\begin{array}{l}\text { Theta } \\
\text { Relative } \\
\text { Power }\end{array}$ & $\begin{array}{l}\text { Alpha } \\
\text { Relative } \\
\text { Power } \\
\end{array}$ & $\begin{array}{l}\text { Low Beta } \\
\text { Relative } \\
\text { Power }\end{array}$ & $\begin{array}{l}\text { High Beta } \\
\text { Relative } \\
\text { Power }\end{array}$ & $\begin{array}{l}\text { Theta/ } \\
\text { Low Beta } \\
\text { Ratio }\end{array}$ & $\begin{array}{l}\text { Theta/ } \\
\text { High Beta } \\
\text { Ratio }\end{array}$ & $\begin{array}{l}\text { Theta/ } \\
\text { Beta } \\
\text { Ratio }\end{array}$ & $\begin{array}{l}\text { Theta/ } \\
\text { Alpha } \\
\text { Ratio } \\
\end{array}$ \\
\hline \multirow{4}{*}{ "Focus" } & $\begin{array}{c}\text { Pearson } \\
\text { Correlation } \\
\text { Coefficient }\end{array}$ & -0.197 & 0.444 & 0.423 & 0.373 & -0.633 & -0.577 & -0.612 & -0.676 \\
\hline & $p$-value & 0.242 & 0.006 & 0.009 & 0.023 & $<0.001$ & $<0.001$ & $<0.001$ & $<0.001$ \\
\hline & Equation & $\begin{array}{c}y= \\
-68.179 x+ \\
80.618\end{array}$ & $\begin{array}{c}y= \\
194.17 x+ \\
69.304\end{array}$ & $\begin{array}{c}y= \\
283.31 x+ \\
70.576\end{array}$ & $\begin{array}{c}y= \\
76.68 x+ \\
72.227\end{array}$ & $\begin{array}{c}y= \\
-1.5496 x \\
+85.584\end{array}$ & $\begin{array}{c}y= \\
-1.2722 \mathrm{x}+ \\
80.056\end{array}$ & $\begin{array}{c}y= \\
-2.7701 x \\
+81.765\end{array}$ & $\begin{array}{c}y= \\
-3.9262 x \\
+87.736\end{array}$ \\
\hline & $R^{2}$ Value & 0.0389 & 0.1968 & 0.1792 & 0.1388 & 0.4005 & 0.3334 & 0.3742 & 0.4573 \\
\hline
\end{tabular}


Additionally, Figure 11 plots the correlation for the Theta/Low Beta ratio vs. "Focus," while Figure 12 plots the correlation for the Theta/Alpha ratio vs. "Focus."

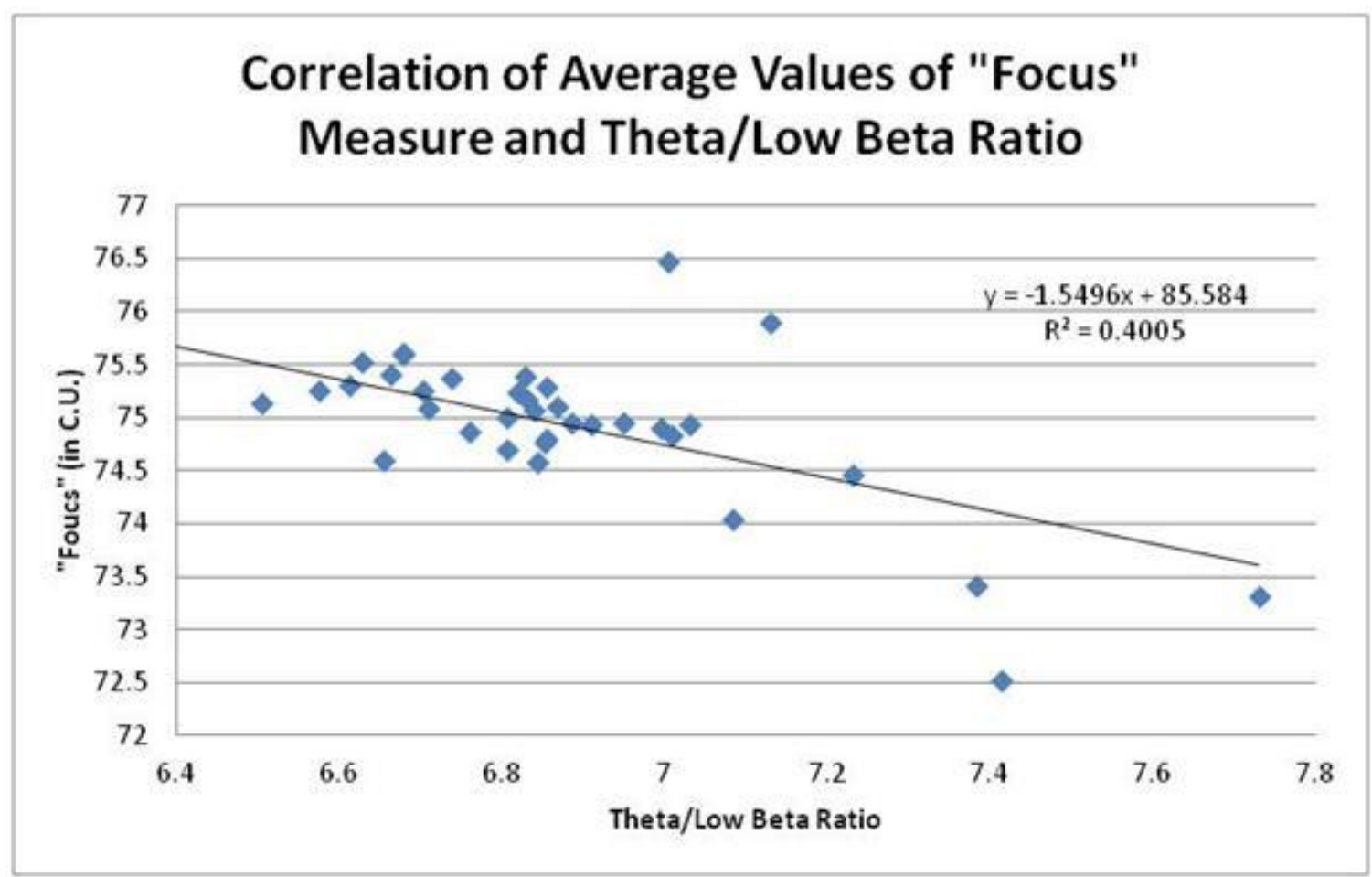

FIGURE 11: Plot of correlation between corresponding average "Focus" values and Theta/Low Beta ratios for Sessions 1-12 and Minute 1-25 of NFB within a session. 


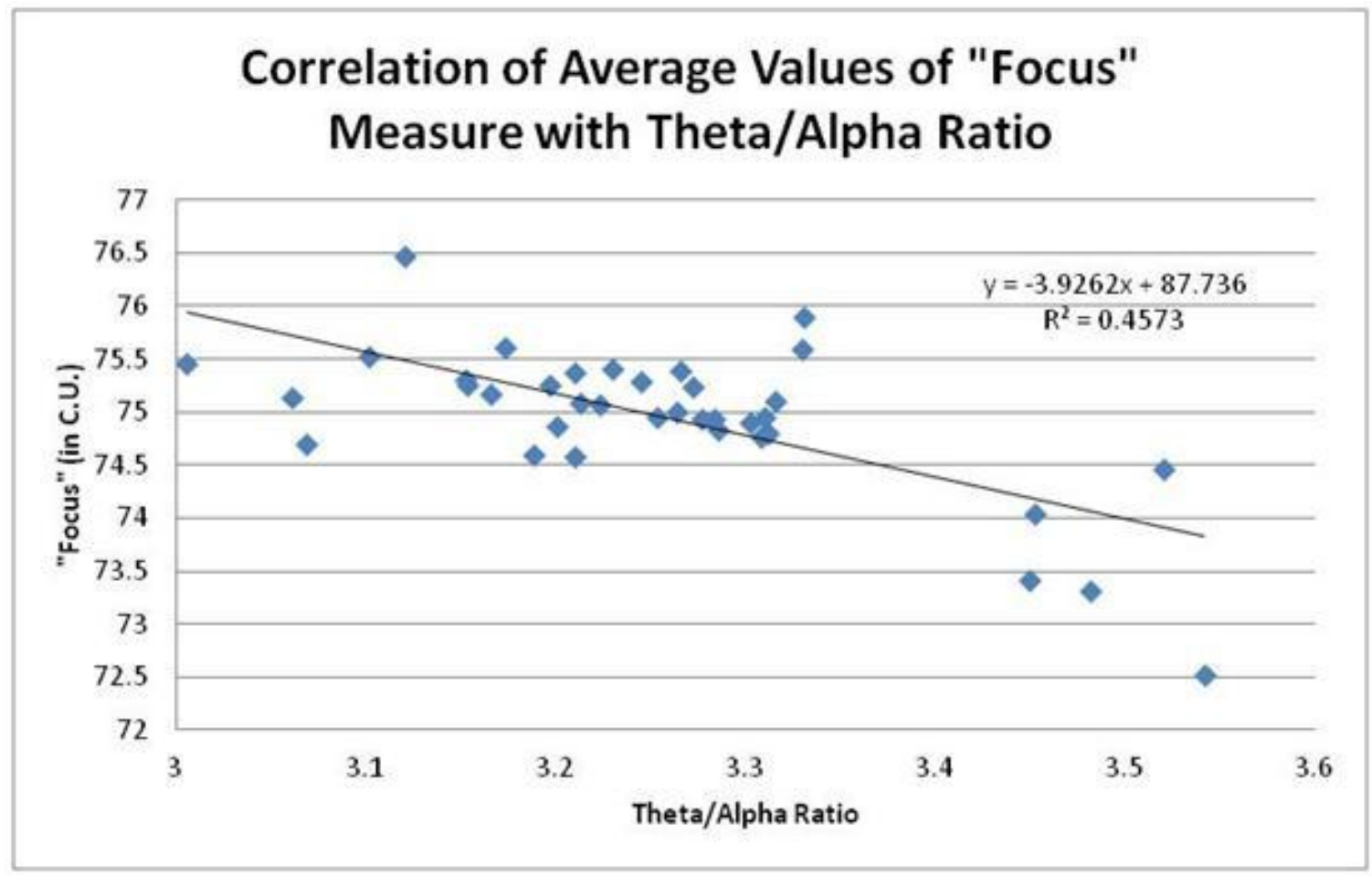

FIGURE 12: Plot of correlation between corresponding average "Focus" values and Theta/Alpha ratios for Sessions 1-12 and Minute 1-25 of NFB within a session.

\section{IVA+ and ABC Survey - Pre- and Post-Neurofeedback}

The student t-test performed on the results of the IVA+ yielded multiple measures showing a significant change from pre- to post-neurofeedback for each subject. The Attention Quotient showed a significant change from pre-neurofeedback $(78.00 \pm 6.33)$ to post-neurofeedback $(87.22 \pm 5.68) ; \mathrm{t}(17)=-2.576, \mathrm{p}=0.020$. The Attention Quotient - Visual showed a significant change from pre-neurofeedback $(89.89 \pm 4.40)$ to postneurofeedback $(97.89 \pm 3.31) ; \mathrm{t}(17)=-2.285, \mathrm{p}=0.035$. The Sustained Visual Attention Quotient showed a significant change from pre-neurofeedback $(83.44 \pm 5.64)$ to postneurofeedback $(97.83 \pm 4.92) ; \mathrm{t}(17)=-2.721, \mathrm{p}=0.015$. The Visual Reaction Time $(\mathrm{ms})$ showed a significant change from pre-neurofeedback $(490.78 \pm 22.87)$ to post- 
neurofeedback $(468.94 \pm 19.45) ; \mathrm{t}(17)=2.379, \mathrm{p}=0.029$. Table 4 fully summarizes the IVA+t-test results.

TABLE IV

SUMMARY OF SIGNIFICANT CHANGES WITHIN THE IVA+PLUS TEST FROM COMPARING PRE- AND POST- NEUROFEEDBACK ( $\mathrm{P}<0.05$ SIGNIFICANT)

\begin{tabular}{|c|c|c|c|c|c|}
\hline Measure & $\begin{array}{c}\text { Pre-NFB } \\
\text { Mean } \pm \\
\text { SE } \\
\end{array}$ & $\begin{array}{c}\text { Post-NFB } \\
\text { Mean } \pm \\
\text { SE }\end{array}$ & t-statistic & p-value & $\begin{array}{c}\text { Change from } \\
\text { Pre-NFB to } \\
\text { Post-NFB } \\
\end{array}$ \\
\hline Attention Quotient & $\begin{array}{l}78.00 \pm \\
6.33\end{array}$ & $\begin{array}{l}87.22 \pm \\
5.68\end{array}$ & -2.576 & 0.020 & Increase \\
\hline $\begin{array}{l}\text { Attention Quotient - } \\
\text { Auditory }\end{array}$ & $\begin{array}{l}70.39 \pm \\
7.62\end{array}$ & $\begin{array}{c}79.06 \pm \\
7.94\end{array}$ & -2.012 & 0.060 & NS \\
\hline $\begin{array}{c}\text { Attention Quotient - } \\
\text { Visual }\end{array}$ & $\begin{array}{c}89.89 \pm \\
4.40\end{array}$ & $\begin{array}{c}97.89 \pm \\
3.31\end{array}$ & -2.285 & 0.035 & Increase \\
\hline $\begin{array}{l}\text { Sustained Auditory } \\
\text { Attention Quotient }\end{array}$ & $\begin{array}{c}60.83 \pm \\
9.44\end{array}$ & $\begin{array}{c}74.11 \pm \\
9.41\end{array}$ & -2.009 & 0.061 & NS \\
\hline $\begin{array}{l}\text { Sustained Visual } \\
\text { Attention Quotient }\end{array}$ & $\begin{array}{c}83.44 \pm \\
5.64\end{array}$ & $\begin{array}{c}97.83 \pm \\
4.92\end{array}$ & -2.721 & 0.015 & Increase \\
\hline $\begin{array}{l}\text { Auditory Reaction } \\
\text { Time (ms) }\end{array}$ & $\begin{array}{c}735.56 \pm \\
30.54\end{array}$ & $\begin{array}{c}699.00 \pm \\
31.98\end{array}$ & 1.812 & 0.088 & NS \\
\hline $\begin{array}{c}\text { Visual Reaction Time } \\
(\mathrm{ms})\end{array}$ & $\begin{array}{l}490.78 \pm \\
22.87\end{array}$ & $\begin{array}{l}468.94 \pm \\
19.45\end{array}$ & 2.379 & 0.029 & Decrease \\
\hline
\end{tabular}

All $\mathrm{ABC}$ survey measures showed significant changes from pre- to postneurofeedback. Specifically, Hyperactivity and Inappropriate Speech showed the most 
significant changes. Hyperactivity showed a significant change from pre-neurofeedback $(15.28 \pm 3.24)$ to post-neurofeedback $(10.83 \pm 2.44) ; \mathrm{t}(17)=3.189, \mathrm{p}=0.005$.

Inappropriate Speech showed a significant change from pre-neurofeedback $(2.94 \pm 0.75)$ to post-neurofeedback $(1.94 \pm 0.64) ; \mathrm{t}(17)=4.675, \mathrm{p}<0.001$. Table 5 fully summarizes the results of the t-test for the $\mathrm{ABC}$ outcomes.

\section{TABLE V}

SUMMARY OF SIGNIFICANT CHANGES IN CLINICAL MEASURE AS INDICATED BY THE ABBERANT BEHAVIOR CHECKLIST SURVEY FROM COMPARING DATA FROM PRE- AND POST- NEUROFEEDBACK $(\mathrm{P}<0.05$ SIGNIFICANT)

\begin{tabular}{|c|c|c|c|c|c|}
\hline Measure & $\begin{array}{c}\text { Pre-NFB } \\
\text { Mean } \pm \\
\text { SE }\end{array}$ & $\begin{array}{c}\text { Post-NFB } \\
\text { Mean } \pm \\
\text { SE }\end{array}$ & t-statistic & p-value & $\begin{array}{c}\text { Change from } \\
\text { Pre-NFB to } \\
\text { Post-NFB }\end{array}$ \\
\hline Irritability & $\begin{array}{c}11.67 \pm \\
2.16\end{array}$ & $\begin{array}{c}8.33 \pm \\
2.01\end{array}$ & 3.602 & 0.002 & Decrease \\
\hline Lethargy & $\begin{array}{c}8.00 \pm \\
2.04\end{array}$ & $\begin{array}{c}3.94 \pm \\
1.25\end{array}$ & 2.366 & 0.030 & Decrease \\
\hline Stereotypy & $\begin{array}{c}3.89 \pm \\
1.37\end{array}$ & $\begin{array}{c}2.56 \pm \\
1.01\end{array}$ & 2.515 & 0.022 & Decrease \\
\hline Hyperactivity & $\begin{array}{c}15.28 \pm \\
3.24\end{array}$ & $\begin{array}{c}10.83 \pm \\
2.44\end{array}$ & 3.189 & 0.005 & Decrease \\
\hline Inappropriate Speech & $\begin{array}{c}2.94 \pm \\
0.75\end{array}$ & $\begin{array}{c}1.94 \pm \\
0.64\end{array}$ & 4.675 & $<0.001$ & Decrease \\
\hline
\end{tabular}




\section{CONCLUSIONS}

The results outlined in Tables 1 and 2 indicate outcomes which were primarily expected with regards to changes in the relative power of interested bands and the change in ratios. For instance, the Theta band is shown to decrease across sessions and minute within a session, while the Alpha band is shown to increase for both criteria. Therefore, it would appear that the Theta/Alpha band should decrease for both session and minute within a session. This is evidenced in Figure 6 and 9. However, several bands (High Beta and Gamma) and "Alertness" measure show what appear to be counterintuitive results at first glance. Upon further inspection of the protocol and the changes within each band though, this discrepancy can be rationalized and explained. The High Beta band shows an increase in relative power within session, but a decrease from session to session. However, the session to session changes indicate a very low correlation. Additionally, neurofeedback doesn't specifically target the 18-30 Hz range encompassed by the High Beta designation in this protocol. The Gamma measure is also not noted for being specifically targeted by this application. However, the increase within session observed in the Gamma range could be the result of an increase in a subjective sense of achievement attained through mastery of the assigned skill (i.e. increasing ability to focus attention). It has been suggested that an increase in the prefrontal Gamma activity could be tied to emotional responses and the effort associated with learning (Rubik 2011). Therefore, the decrease in Gamma activity from session to session could be the result of the subject 
having a lower effort to mastering this skill of concentration of attention. Finally, "Alertness" indicates a decrease from session 1-12, while indicating an increase from minute 1-25 within a session. This is not unexpected since "Alertness" was not to be enhanced or suppressed in this protocol, but simply maintained within a broad range. In the later stages of the neurofeedback training course the ability to focus attention does not require general arousal, resulting in dissociation of two measures and lower correlation of "Focus" and "Alertness".

As evidenced in Tables 1-2 and Figures 5, 6, 8, and 9 the most notable indications of this analysis are a decrease in the Theta/Low Beta and Theta/Alpha proportions from session to session and from minute 1 to minute 25 within a session. These results show consistency with the overall aims and goals of neurofeedback which have been described earlier (Monastra 2005). Specifically, this claim can be made regarding the decrease in the Theta/Low Beta ratio. A net reduction in Theta/Low Beta ratio was seen across both sessions and minute within a session. These findings support the treatment of EEG irregularities within the ADHD population (Barry, Clarke, and Johnstone 2003) with neurofeedback techniques. Figure 13 provides visual illustration of the observed changes, as a result of session number and minute within a session, through utilization of a surface chart representing a three dimensional view of the data. 


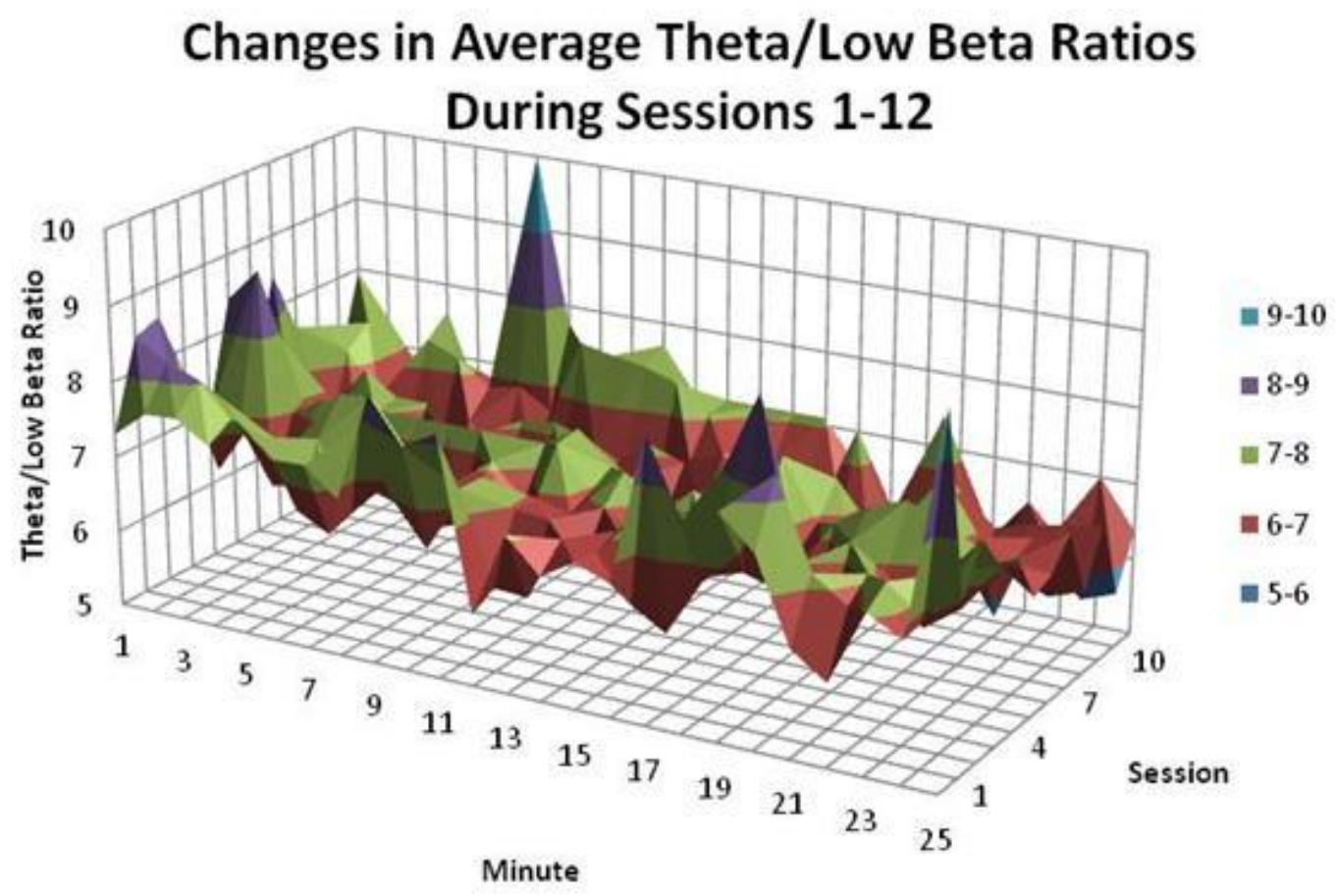

FIGURE 13: The surface chart provides evidence supporting the decrease in the Theta/Low Beta ratio with regards to increasing session number and increasing minute of each session. As is consistent with the results of the ANOVA, Session trends, and Minute trend analysis, a general decrease is seen from (Session 1, Minute 1) through (Session 12, Minute 25) for the Theta/Low Beta ratio. The legend on the right side of the figure gives the color-coded ranges for the Theta/Low Beta ratio, as seen in the chart.

In this study, the Theta band was characterized by the EEG signals collected between 4-8 $\mathrm{Hz}$ whereas the Alpha signal was characterized via the signals collected between 8-13

Hz. A reduction in the Theta/Alpha proportion was seen across both sessions and minute within a session. As with the evidence provided for changing Theta/Low Beta ratio values, visual illustration of a decrease in Theta/Alpha ratio as a function of session number and minute within a session is provided in Figure 14. 


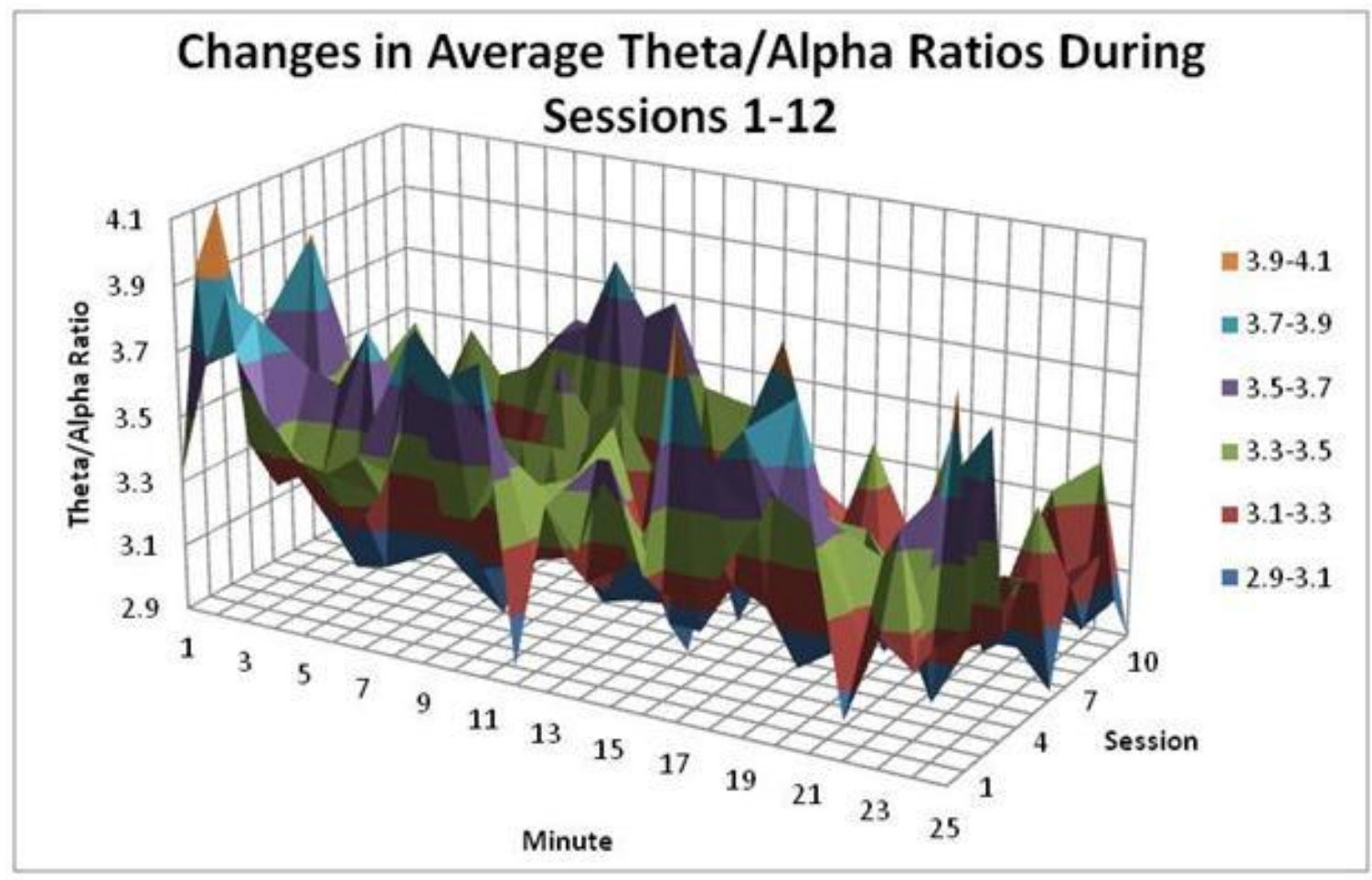

FIGURE 14: The surface chart provides evidence supporting the decrease in the Theta/Alpha ratio with regards to increasing session number and increasing minute of each session. As is consistent with the results of the ANOVA, Session trends, and Minute trend analysis, a general decrease is seen from (Session 1, Minute 1) through (Session 12, Minute 25) for the Theta/Alpha ratio. The legend on the right side of the figure gives the color-coded ranges for the Theta/Alpha ratio, as seen in the chart.

Also, the decrease of Theta/Alpha and Theta/Low Beta ratios indicate a potential link between these ratios and the targeted desynchronized measure of "Focus" recorded at the prefrontal site, since "Focus" showed an increase across session number and minute within a session (Fig. 15). 


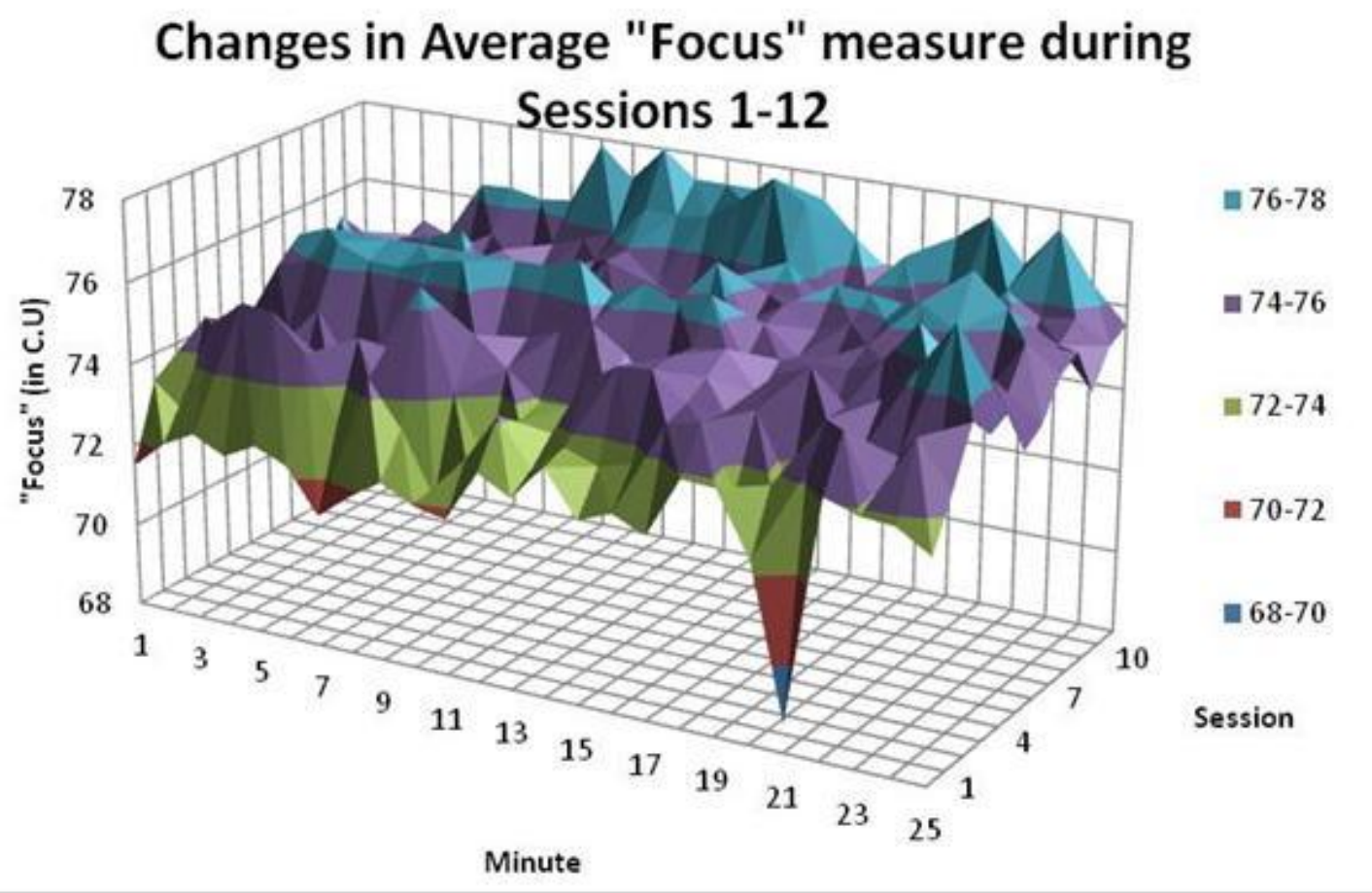

FIGURE 15: The surface chart provides anecdotal evidence supporting the increase in the "Focus" measure with regards to increasing session number and increasing minute of each session. As is consistent with the results of the ANOVA, Session trends, and Minute trend analysis, a general increase is seen from (Session 1, Minute 1) through (Session 12, Minute 25) for the "Focus" measure. The legend on the right side of the figure gives the color-coded ranges for the "Focus" measure, as seen in the chart.

As previously mentioned, ADHD subjects, especially subjects presenting with Inattentive ADHD subtype, have similar expressions of EEG characteristics. This is specifically evident in the Theta/Beta proportion being similar in the first session to that encountered in other studies involving ADHD subjects (Barry et al. 2009; Lansbergen et al. 2011; Ogrim, Kropotov, and Hestad 2012). In this analysis, the average session one value for the Theta/Low Beta proportion was 7.4, which is similar to the baseline value of 6.4-6.6 reported by Monastra (2008) for Theta/Beta values encompassing similar frequencies 
current data of Ogrim, Kropotov, and Hestad (2012) ( 7.02-7.08 for young ADHD group and 6.21for adult ADHD group).

Due to the improvements in clinical and functional outcomes indicated through IVA+Plus and $\mathrm{ABC}$, there is also discussion to be held as to whether training of the "Focus" measure or the Theta/Beta and Theta/Alpha ratios are more fundamental to functional improvement. Determination of the measure more fundamental to treatment of ADHD would increase the efficiency and aid in the delivery of neurofeedback treatment methods.

Similar to prior work in the treatment of ADHD with neurofeedback, this study indicates the efficacy of neurofeedback for altering the EEG characteristics associated with the disorder (Arns et al. 2009; Gevensleben et al. 2009; Holtmann and Stadler 2006; Monastra 2005; Sherlin et al. 2010a, 2010b; Sokhadze 2012). The positive effects of the increase in "Focus" during neurofeedback corresponded to an improvement in the clinical measures and functional outcomes seen in the IVA+Plus test and the ABC survey. Since this exploratory study did not use a controlled design we are not claiming any clinical efficiency results, but rather consider it as an investigation of EEG bands' relative powers and their ratios across 12 session neurofeedback training course aimed to enhance focused attention. This is a methodological study that uses EEG analysis in ADHD children enrolled in neurofeedback treatment using a specialist device and software.

However, this analysis differs from those prior studies in the consideration of what is transpiring not only from session to session, but also within each session. Therefore, improvement can be indicated within a shorter number of sessions (i.e. 12) compared to previous protocols that required 30-40 sessions per subject to statistically 
indicate significant improvement either in EEG or clinical behavioral measures (Gevensleben et al. 2009). Probably more than 12 sessions might contribute to better consolidation of results of operant conditioning using neurofeedback and currently we have study in progress that will compare outcomes of 12 vs. 18 sessions of neurofeedback using the same protocol. 


\section{FUTURE WORK AND APPLICATIONS}

Based on the application developed for more efficiently processing data from neurofeedback sessions, a great deal of future research is brought to the forefront of discussion. The first extension of this research involves the use of a controlled study to demonstrate these changes. In this study, the results clearly demonstrated changes in certain bands and band ratios during neurofeedback even though specific bands were not targeted in the protocol. Therefore, a study incorporating a control group of non-ADHD subjects contrasted with a group consisting of ADHD subjects with each group undergoing neurofeedback sessions to increase "Focus" would be beneficial. The ADHD group could be further broken down into positive and negative for comorbid diagnosis, or medicated vs. non-medicated subjects. Additionally, one shortcoming of the current study involved the use of a neurofeedback system without a calibration measure. In a controlled study, a system with calibration capabilities would increase the ability for a wide-ranging analysis. Assumptions based on resistance, derived from general electrical principles, could be bypassed and the true total power of the EEG signal could be calculated and compared across different subjects with regard to session and minute of neurofeedback. Other measures such as relative amplitude of the signal in bands and band ratios could also be more accurately considered.

This study also utilized band-pass filtering to analyze the differences and changes within EEG bands and band ratios. Band-pass filtering, although with its advantages, does have larger affinity for error due to multiple filters being necessary to develop the interested relative powers and band ratios. A spectral analysis of each could produce 
results with greater accuracy than seen with a band-pass based analysis. Spectral analysis would involve only filtering the signal from $2-45 \mathrm{~Hz}$ and then calculating power of measures from the integration of the results expressed in the frequency domain following a fast Fourier transform (FFT).

In addition to changing the form of analysis, there is also a viable extension of this protocol to a different patient population. Many neurophysiological disorders present with abnormal EEG patterns (Pliszka 1998). As a result, an extension of this protocol to autistic subjects seems logical. Such a study would be the first of its kind to examine the EEG changes occurring within neurofeedback treatment of autistic subjects. Results of this analysis would be integral to determine any efficacy or benefit of treatment of autism with neurofeedback protocols. 


\section{REFERENCES}

Aman, M.G. and Singh, N.N. (1994). Aberrant Behavior Checklist - Community. Supplementary Manual. East Aurora, NY: Slosson Ed. Publications.

American Psychiatric, A. and D.-I. American Psychiatric Association. Task Force on (2000). Diagnostic and statistical manual of mental disorders : DSM-IV-TR. Washington, DC, American Psychiatric Association.

Arns, M., de Ridder, S., Strehl, U., Breteler, M., and Coenen, A. 2009. Efficacy of neurofeedback treatment in ADHD: The effects on inattention, impulsivity and hyperactivity: A meta-analysis. Clinical EEG \& Neuroscience 40(3): 180-189.

Banaschewski, T., Coghill, D., Santosh, P., Zuddas, A., et al. 2006. Long-acting medications for the hyperkinetic disorders. European Child \& Adolescent Psychiatry 15(8): 476-495.

Barry, R. J., Clarke, A. R., and Johnstone, S.J.. 2003. A review of electrophysiology in attention-deficit/hyperactivity disorder: I. Qualitative and quantitative electroencephalography. Clinical Neurophysiology 114(2): 171-183.

Barry, R. J., Clarke, A.R., Johnstone, S.J., McCarthy, R., and Selikowitz, M. 2009. Electroencephalogram theta/beta ratio and arousal in attention-deficit/hyperactivity disorder: evidence of independent processes. Biological Psychiatry 66(4): 398-401.

Biederman, J., Milberger, S., Faraone, S.V., Kiely, K., et al. 1995. Family-environment risk factors for attention-deficit hyperactivity disorder: a test of Rutter's indicators of adversity. Archives of General Psychiatry 52(6): 464-470.

Biederman, J. 2005. Attention-deficit/hyperactivity disorder: a selective overview. Biological Psychiatry 57(11): 1215-1220.

Clarke, A. R., Barry, R. J., McCarthy, R., and Selikowitz, M. 1998. EEG analysis in attention-deficit/hyperactivity disorder: a comparative study of two subtypes. Psychiatry Research 81(1): 19-29.

Clarke, A. R., Barry, R. J., McCarthy, R., and Selikowitz, M. 2001. EEG-defined subtypes of children with attention-deficit/hyperactivity disorder. Clinical Neurophysiology 112(11): 2098-2105.

Clarke, A. R., Barry, R. J., McCarthy, R., Selikowitz, M., and Brown, C.R. 2002. EEG evidence for a new conceptualisation of attention deficit hyperactivity disorder. Clinical Neurophysiology 113(7): 1036-1044. 
Clarke, A. R., Barry, R.J., Dupuy, F.E., McCarthy, R., et al. 2010. Childhood EEG as a predictor of adult attention-deficit/hyperactivity disorder. Clinical Neurophysiology 122(1): 73-80.

Clarke, A. R., Barry, R.J., Irving, A.M., McCarthy, R., and Selikowitz, M. 2011 a. Children with attention-deficit/hyperactivity disorder and autistic features: EEG evidence for comorbid disorders. Psychiatry Research 185(1-2): 225-231.

Clarke, A. R., Barry, R.J., Dupuy, F.E., Heckel, L.D., et al. 2011b. Behavioural differences between EEG-defined subgroups of children with attentiondeficit/hyperactivity disorder. Clinical Neurophysiology 122(7): 1333-1341.

Cortese, S. 2012. The neurobiology and genetics of attention-deficit/hyperactivity disorder (ADHD): What every clinician should know. European Journal of Paediatric Neurology doi:10.1016/j.ejpn.2012.01.009.

Cowan J.D. and Albers, S. Manual for The Peak Achievement Trainer. Goshen, KY: NeuroTek LLC; 2008.

Faraone, S.V., Sergeant, J., Gillberg, C., and Biederman, J. 2003. The worldwide prevalence of ADHD: is it an American condition? World Psychiatry 2:104-113.

Faraone, S. V., Perlis, R.H., Doyle, A.E., and Smoller, J.W., et al. 2005. Molecular Genetics of attention-deficit/hyperactivity disorder. Biological Psychiatry 57(11): 13131323.

Faraone, S. V. and Mick, E. 2010. Molecular genetics of attention deficit hyperactivity disorder. The Psychiatric Clinics of North America 33(1): 159-180.

Ferguson, J. H. 2000. National Institutes of Health consensus development conference statement: diagnosis and treatment of attention-deficit/hyperactivity disorder (ADHD). Journal of the American Academy of Child \& Adolescent Psychiatry 39(2): 182-193.

Fuchs, T., Birbaumer, N., Lutzenberger, W., Gruzelier, J.H., and Kaiser, J. 2003. Neurofeedback treatment for attention-deficit/hyperactivity disorder in children: a comparison with methylphenidate. Applied Psychophysiology and Biofeedback 28(1): 112.

Gevensleben, H., Holl, B., Albrecht, B., Vogel, C., et al. 2009. Is neurofeedback an efficacious treatment for ADHD? A randomised controlled clinical trial. Journal of Child Psychology and Psychiatry 50(7): 780-789.

Gillberg, C., Gillberg, I.C., Rasmussen, P., Kadesjö, B., et al. 2004. Co-existing disorders in ADHD - implications for diagnosis and intervention. European Child \& Adolescent Psychiatry 13(0): 80-92. 
Greenhill, L. L., Halperin, J. M., and Abikoff, H. 1999. Stimulant medications. Journal of the American Academy of Child \& Adolescent Psychiatry 38(5): 503-512.

Greenhill, L. L., Swanson, J.M., Vitiello, B., Davies, M., et al. 2001. Impairment and deportment responses to different methylphenidate doses in children with ADHD: the MTA titration trial. Journal of the American Academy of Child \& Adolescent Psychiatry 40(2): 180-187.

Holtmann, M. and Stadler, C. 2006. Electroencephalographic biofeedback for the treatment of attention-deficit hyperactivity disorder in childhood and adolescence. Expert Review of Neurotherapeutics 6(4): 533-540.

Lansbergen, M. M., Arns, M., van Dongen-Boomsma, M., Spronk, D., and Buitelaar, J.K. 2011. The increase in theta/beta ratio on resting-state EEG in boys with attentiondeficit/hyperactivity disorder is mediated by slow alpha peak frequency. Progress in Neuro-Psychopharmacology and Biological Psychiatry 35(1): 47-52.

Linden, M., Habib, T., and Radojevic, V. 1996. A controlled study of the effects of EEG biofeedback on cognition and behavior of children with attention deficit disorder and learning disabilities. Biofeedback and Self-regulation 21(1): 35-49.

Lofthouse, N., Arnold, L. E. and Hurt, E. 2010 A Comment on Sherlin, Arns, Lubar, and Sokhadze, 2010. Journal of Neurotherapy 14(4): 301-306.

Lubar, J.F. and Shouse, M. N. 1976. EEG and behavioral changes in a hyperkinetic child concurrent with training of the sensorimotor rhythm (SMR): A preliminary report. Biofeedback and Self-regulation, 1(3), 293-306.

Mick, E., Biederman, J., Faraone, S.V., Sayer, J., and Kleinman, S. 2002. Case-control study of attention-deficit hyperactivity disorder and maternal smoking, alcohol use, and drug use during pregnancy. Journal of the American Academy of Child \& Adolescent Psychiatry 41(4): 378-385.

Miller, R. 2007. Theory of the normal waking EEG: from single neurones to waveforms in the alpha, beta and gamma frequency ranges. International Journal of Psychophysiology 64(1): 18-23.

Monastra, V. J. 2005. Electroencephalographic biofeedback (neurotherapy) as a treatment for attention deficit hyperactivity disorder: rationale and empirical foundation. Child and Adolescent Psychiatric Clinics of North America 14(1): 55-82.

Monastra, V.J. 2008. Quantitative electroencephalography and attentiondeficit/hyperactivity disorder: implications for clinical practice. Current Psychiatry Reports 10(5): 432-438. 
Neale, B. M., Medland, S.E., Ripke, S., Asherson, P., et al. 2010. Meta-analysis of genome-wide association studies of attention-deficit/hyperactivity disorder. Journal of the American Academy of Child \& Adolescent Psychiatry 49(9): 884-897.

Ogrim, G., Kropotov, J., and Hestad, K. 2012. The QEEG theta/beta ratio in ADHD and normal Performance Tests. Psychiatry Research doi: 10.1016/j.psychres.2011.12.041

Pliszka, S. R. 1998. Comorbidity of attention-deficit/hyperactivity disorder with psychiatric disorder: an overview. The Journal of Clinical Psychiatry 59 Suppl 7: 50-8.

Rossiter, D. and La Vaque, T.J. 1995. A comparison of EEG biofeedback and psychostimulants in treating attention deficit/hyperactivity disorders. Journal of Neurotherapy 1(1): 48-59.

Rubik, B. 2011. Neurofeedback-enhanced gamma brainwaves from the prefrontal cortical region of meditators and non-meditators and associated subjective experiences. Journal of Alternative \& Complementary Medicine 17(2): 109-115.

Sandford, J.A. IVA+ Plus IVA-AE. Integrated Visual and Auditory Continuous Performance Test (CPT).

Sherlin, L., Arns, M., Lubar, J., and Sohkadze, E. 2010a. A position paper on neurofeedback for the treatment of ADHD. Journal of Neurotherapy 14(2): 66-78.

Sherlin, L., Arns, M., Lubar, J., and Sohkadze, E. 2010b. A reply to Lofthouse, Arnold, and Hurt (2010). Journal of Neurotherapy 14(4): 307-311.

Sokhadze E. 2012. Peak performance training using prefrontal EEG biofeedback. Biofeedback 40 (in press).

Taylor, E., Döpfner, M., Sergeant, J., Asherson, P., et al. 2004. European clinical guidelines for hyperkinetic disorder - first upgrade. European Child \& Adolescent Psychiatry 13(0): 7-30.

The MTA Cooperative Group. 1999. A 14-month randomized clinical trial of treatment strategies for attention-deficit/hyperactivity disorder. Archives of General Psychiatry 56(12): 1073-1086.

Van den Bergh, W. 2010. Neurofeedback and State Regulation in ADHD: A Therapy Without Medication. BMED Press.

Wood, A.C., Buitelaar, J., Rijsdijk, F., Asherson, P., and Kuntoi, J. 2009. Rethinking shared environment as a source of variance underlying attention-deficit/hyperactivity disorder symptoms: comment on Burt. Psychological Bulletin 2010;136:331e40. 
Wyrwicka, W. and Sterman, M. B. 1968. Instrumental conditioning of sensorimotor cortex EEG spindles in the waking cat. Physiology and Behavior 3(5): 703-707.

Zhou, K., Dempfle, A., Arcos-Burgos, M., Bakker, S.C., et al. 2008. Meta-analysis of genome-wide linkage scans of attention deficit hyperactivity disorder. American Journal of Medical Genetics Part B: Neuropsychiatric Genetics 147B(8): 1392-1398. 


\title{
APPENDIX I: MATLAB CODES
}

\author{
A. EEG Signal Processing Main Code
}

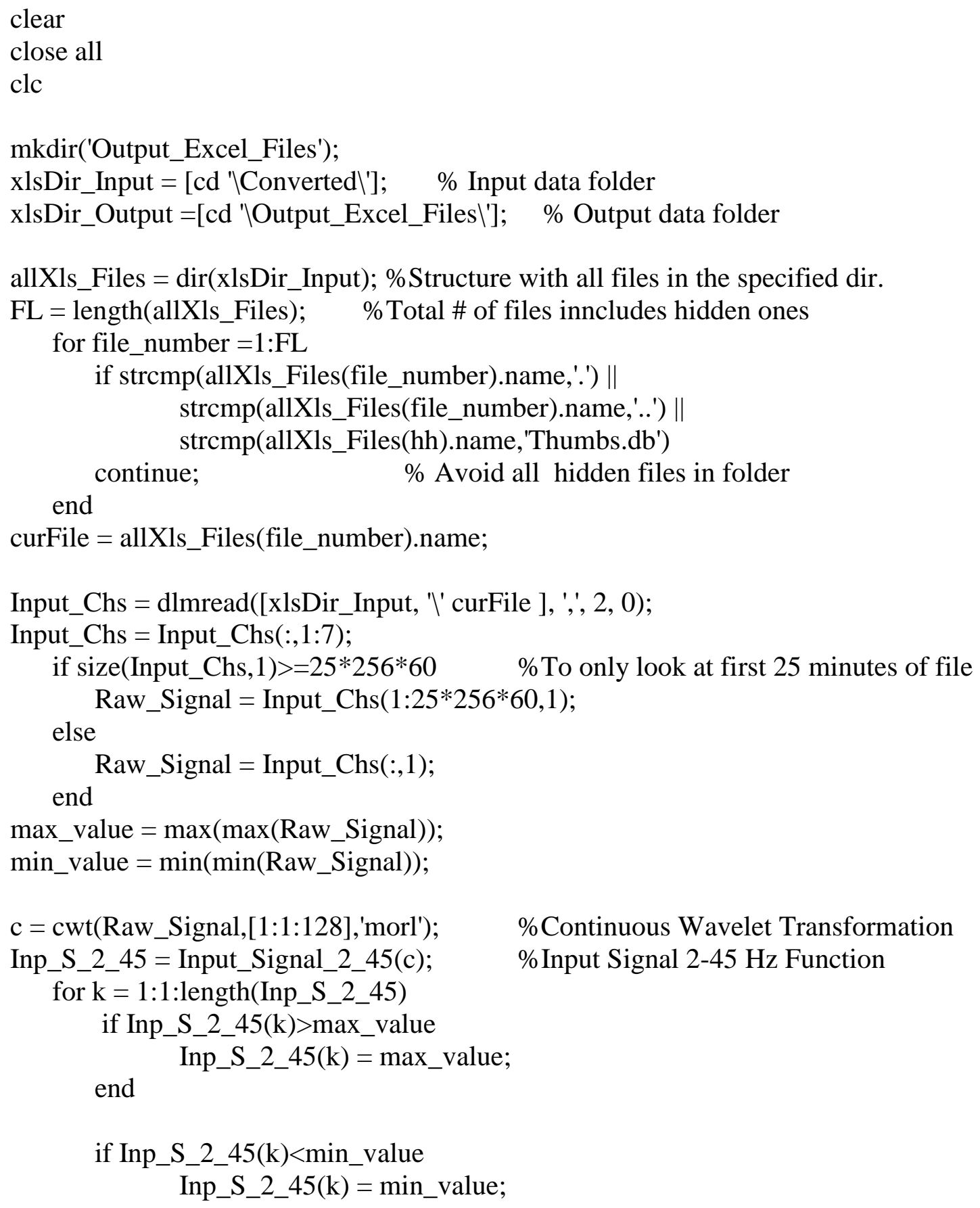


end

end

Delta_Signal = Input_Chs(:,2);

Theta_Signal = Input_Chs $(:, 3)$;

Alpha_Signal = Input_Chs $(:, 4)$;

Low_Beta $=$ Input_Chs $(:, 5)$;

High_Beta $=$ Input_Chs $(:, 6)$;

Gamma_Signal = Input_Chs $(:, 7)$;

No_Minutes $=$ fix $(($ length $($ Inp_S_2_45) $)$./15360)

for $\mathrm{k}=1: 1:$ No_Minutes

Start_In $=(\mathrm{k}-1){ }^{*} 15360+1$;

End_In = k.*15360;

D_S = Delta_Signal(Start_In:1:End_In);

T_S = Theta_Signal(Start_In:1:End_In);

A_S = Alpha_Signal(Start_In:1:End_In);

L_B = Low_Beta(Start_In:1:End_In);

H_B $=$ High_Beta(Start_In:1:End_In);

G_S = Gamma_Signal(Start_In:1:End_In);

I_S = Inp_S_2_45(Start_In:1:End_In);

R_D_S(k) = sum(D_S.^2)./sum(I_S.^2);

R_T_S(k) = sum(T_S.^2)./sum(I_S.^2);

R_A_S(k) = sum(A_S.^2)./sum(I_S.^2);

R_L_B(k) $=\operatorname{sum}\left(\mathrm{L} \_B .^{\wedge} 2\right) . / \operatorname{sum}\left(I \_S .^{\wedge} 2\right)$;

R_H_B(k) $=\operatorname{sum}\left(H \_B .^{\wedge} 2\right) . / \operatorname{sum}\left(I \_S .^{\wedge} 2\right)$;

R_G_S $(k)=\operatorname{sum}\left(G \_S .{ }^{\wedge} 2\right) . / \operatorname{sum}\left(I \_S .{ }^{\wedge} 2\right)$;

Ratio_T_L_B $(\mathrm{k})=\mathrm{R} \_\mathrm{T} \_\mathrm{S}(\mathrm{k})$./R_L_B(k);

Ratio_T_H_B(k) = R_T_S(k)./R_H_B(k);

Ratio_T_B(k) = R_T_S(k)./(R_L_B(k) + R_H_B(k));

Ratio_T_A(k)=R_T_S(k)./R_A_S $(k)$

end

Start_In $=1$;

End_In = No_Minutes.*15360;

D_S = Delta_Signal(Start_In:1:End_In);

T_S = Theta_Signal(Start_In:1:End_In);

A_S = Alpha_Signal(Start_In:1:End_In);

L_B = Low_Beta(Start_In:1:End_In);

H_B $=$ High_Beta(Start_In:1:End_In);

G_S = Gamma_Signal(Start_In:1:End_In);

I_S = Inp_S_2_45(Start_In:1:End_In);

R_D_S(No_Minutes + 1) $=\operatorname{sum}($ D_S.^2)./sum(I_S.^2);

R_T_S(No_Minutes +1$)=\operatorname{sum}\left(T \_S .^{\wedge} 2\right)$./sum(I_S.^2); 
R_A_S(No_Minutes +1$)=\operatorname{sum}\left(A \_S .^{\wedge} 2\right) . / \operatorname{sum}\left(I \_S .^{\wedge} 2\right)$;

R_L_B(No_Minutes +1$)=\operatorname{sum}\left(\right.$ L_B.^2)./sum $\left(I \_S . \wedge 2\right)$;

R_H_B(No_Minutes +1$)=\operatorname{sum}\left(H \_B .^{\wedge} 2\right) . / \operatorname{sum}\left(I \_S .^{\wedge} 2\right)$;

R_G_S(No_Minutes +1$)=\operatorname{sum}\left(\right.$ G_S.^2)./sum $\left(I \_S . \wedge 2\right)$;

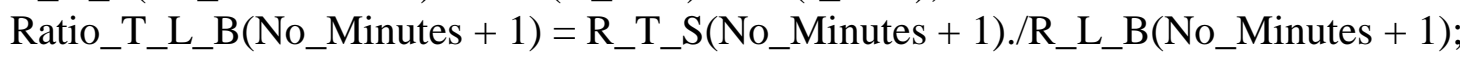

Ratio_T_H_B(No_Minutes +1$)=$ R_T_S $($ No_Minutes +1$)$./R_H_B $($ No_Minutes +1$)$

Ratio_T_B(No_Minutes +1$)=$ R_T_S $($ No_Minutes +1$)$./(R_L_B $($ No_Minutes +1$)+$ R_H_B(No_Minutes + 1));

Ratio_T_A(No_Minutes +1$)=$ R_T_S(No_Minutes +1)./R_A_S(No_Minutes + 1);

X $=$ [R_D_S' R_T_S' R_A_S' R_L_B' R_H_B' R_G_S' Ratio_T_L_B' Ratio_T_H_B' Ratio_T_B' Ratio_T_A'];

curFile $=$ curFile $(1$ :end -4$)$;

xlswrite([ xlsDir_Output 'IResult_' curFile '.xlsx'],X)

end 


\section{B. Input Signal Filtering Function}

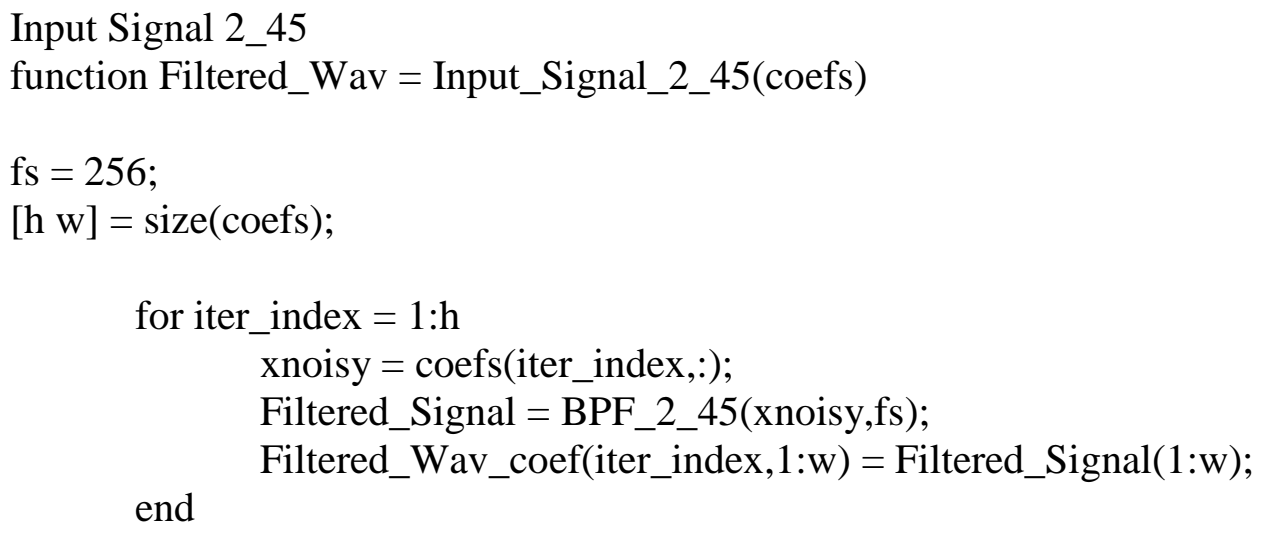

Filtered_Wav $=$ sum $($ Filtered_Wav_coef $) . / 128$; 


\section{2-45 Hz Band-pass Filter Function}

BPF_2_45

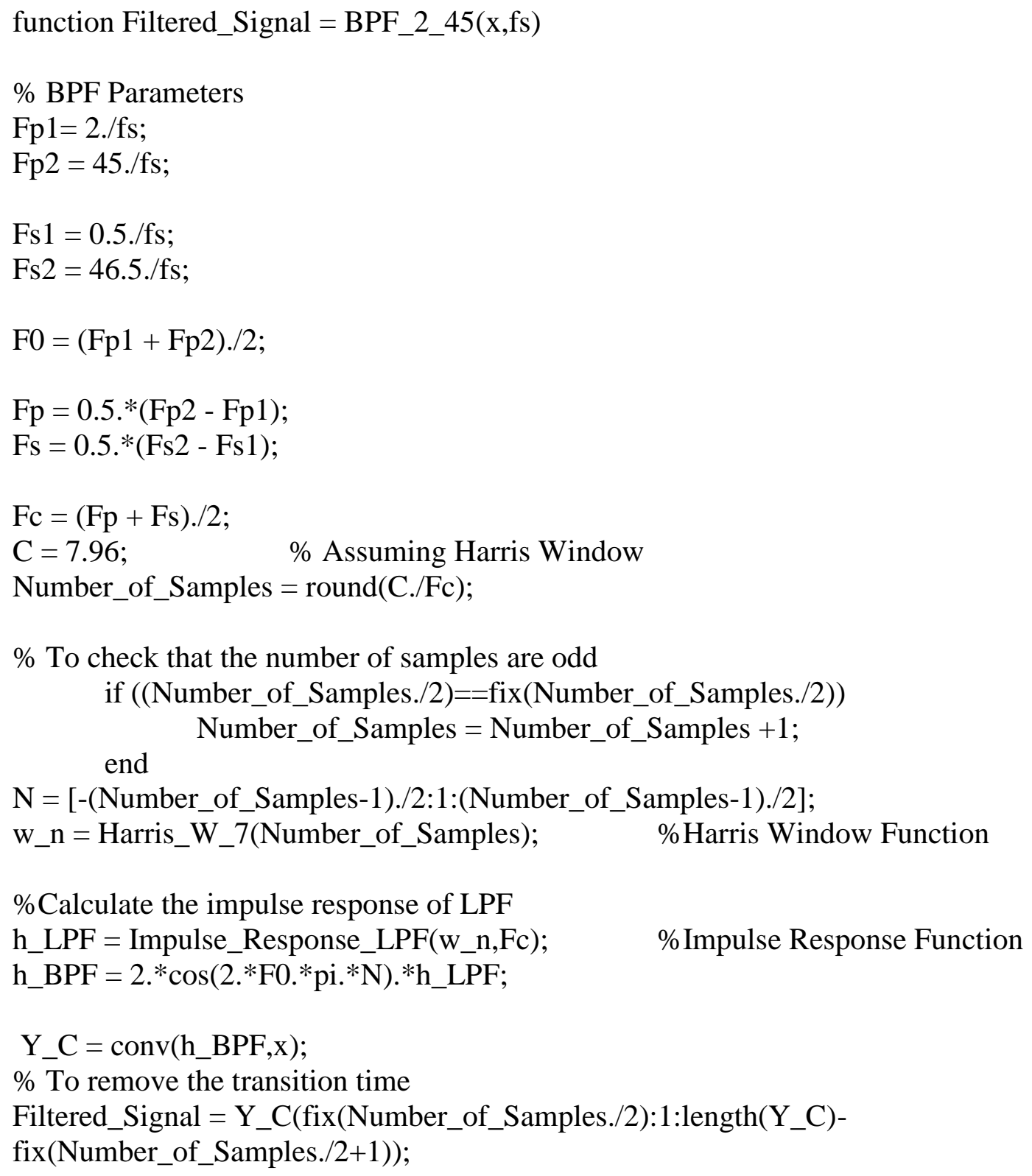




\section{Harris Window Function}

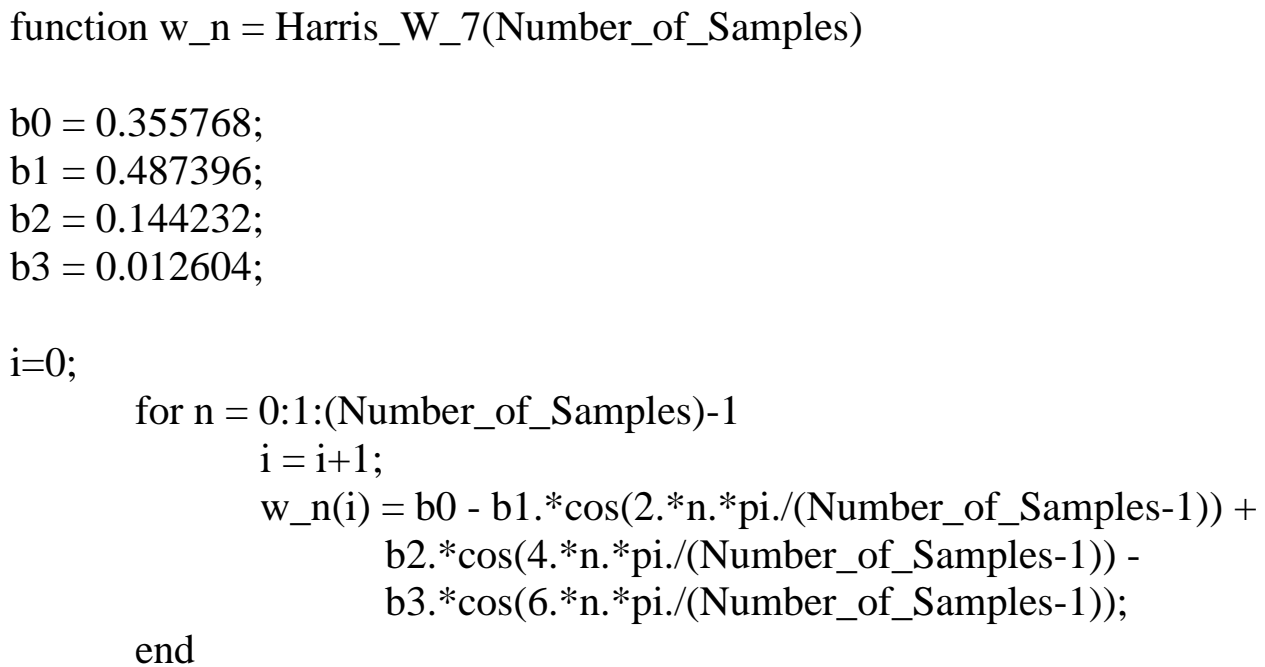




\section{E. Impulse Response LPF Function}

function $\mathrm{h} \_\mathrm{LPF}=$ Impulse_Response_LPF $\left(\mathrm{w} \_\mathrm{n}, \mathrm{Fc}\right)$

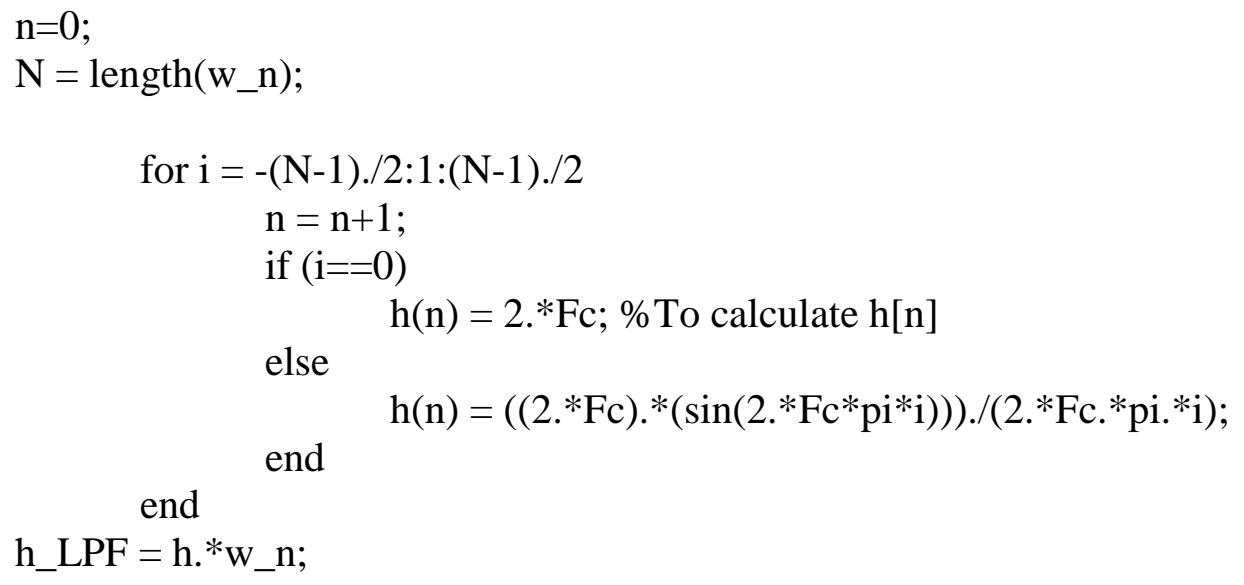




\section{F. Main Analysis Code}

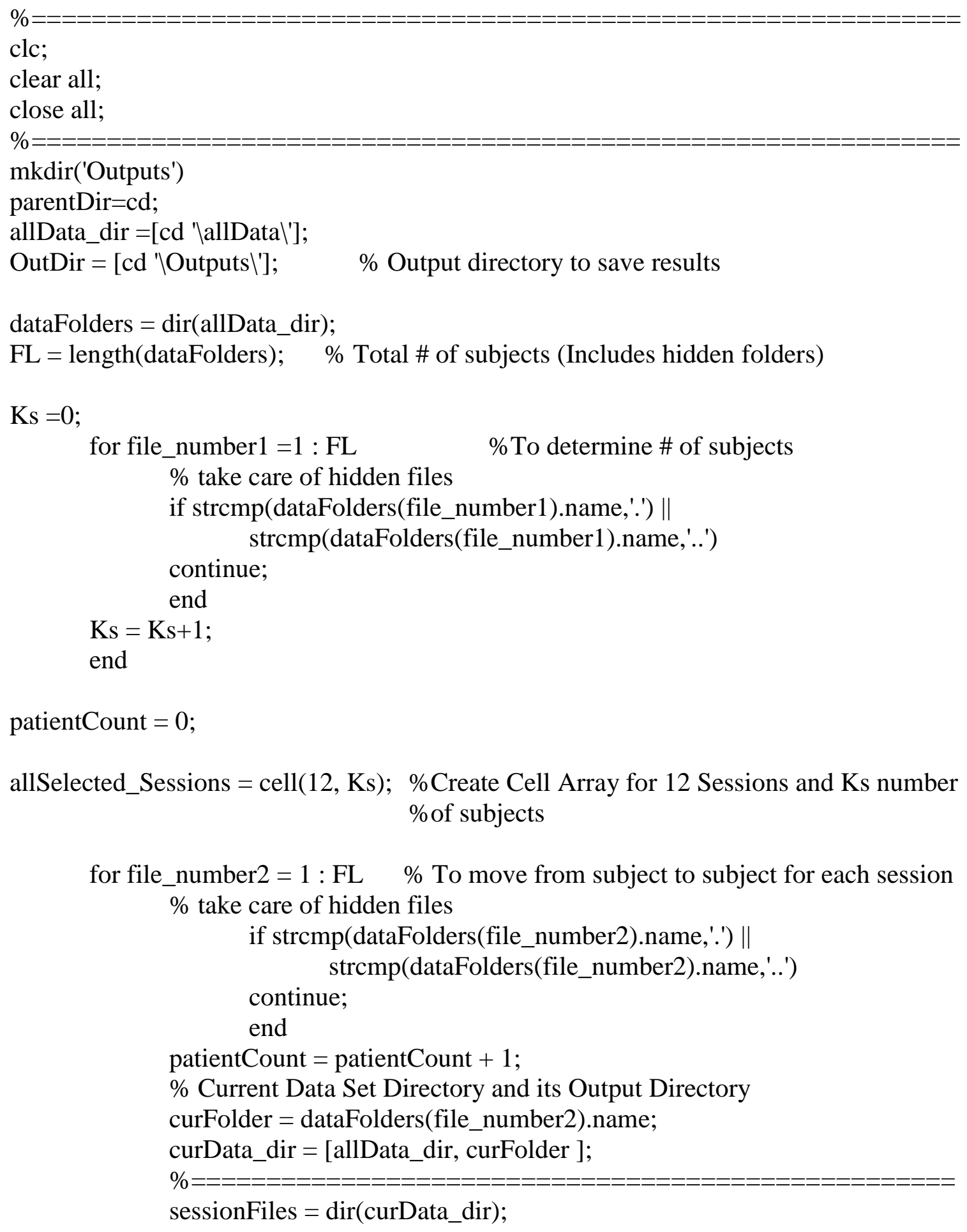

for file_number2 $=1:$ FL $\%$ To move from subject to subject for each session $\%$ take care of hidden files if strcmp(dataFolders(file_number2).name,'.') \| 


$$
\begin{aligned}
& \text { FL2 = length(sessionFiles); \% Total \# of Sessions (Includes hidden } \\
& \% \text { folders) }
\end{aligned}
$$

$\mathrm{Ks} 2=0$

for file_number3 $=1$ : FL $\%$ To move from subject to subject while $\%$ getting FL2 session file

$\%$ take care of hidden files

if strcmp(sessionFiles(file_number3).name,'.') \| strcmp(sessionFiles(file_number3).name,'..')

continue;

end

$\mathrm{Ks} 2=\mathrm{Ks} 2+1$

end

allSessions $=\operatorname{cell}(1, \mathrm{Ks} 2)$;

sessionCount $=0$;

for file_number4 $=1:$ FL2 \%To move from session to session across all \%subjects

$\%$ take care of hidden files

if strcmp(sessionFiles(file_number4).name, '.') \| strcmp(sessionFiles(file_number4).name,'..') continue;

end

sessionCount $=$ sessionCount +1 ;

$\%$ Current Data Set Directory and its Output Directory curFile $=$ sessionFiles(file_number4).name; curData = xlsread $([$ curData_dir 'l' curFile $])$; allSessions $\{$ sessionCount $\}=$ curData;

end

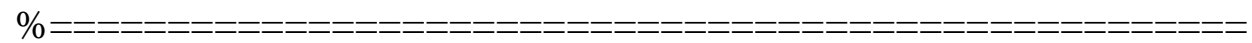

$\%=================================================$

allSelected_Sessions $\{1$,patientCount $\}=\operatorname{allSessions}\{1\}$;

allSelected_Sessions $\{2$,patientCount $\}=\operatorname{allSessions}\{2\}$;

allSelected_Sessions $\{3$,patientCount $\}=\operatorname{allSessions}\{3\}$;

allSelected_Sessions $\{4$,patientCount $\}=\operatorname{allSessions}\{4\}$;

allSelected_Sessions $\{5$,patientCount $\}=$ allSessions $\{5\}$;

allSelected_Sessions $\{6$,patientCount $\}=\operatorname{allSessions}\{6\}$;

allSelected_Sessions $\{7$,patientCount $\}=\operatorname{allSessions}\{7\}$;

allSelected_Sessions $\{$, patientCount $\}=\operatorname{allSessions}\{8\}$;

allSelected_Sessions $\{9$,patientCount $\}=$ allSessions $\{9\}$;

allSelected_Sessions $\{10$,patientCount $\}=$ allSessions $\{10\}$;

allSelected_Sessions $\{11$,patientCount $\}=\operatorname{allSessions}\{11\}$;

allSelected_Sessions $\{12$,patientCount $\}=\operatorname{allSessions}\{12\}$;

end

\% The First Session 


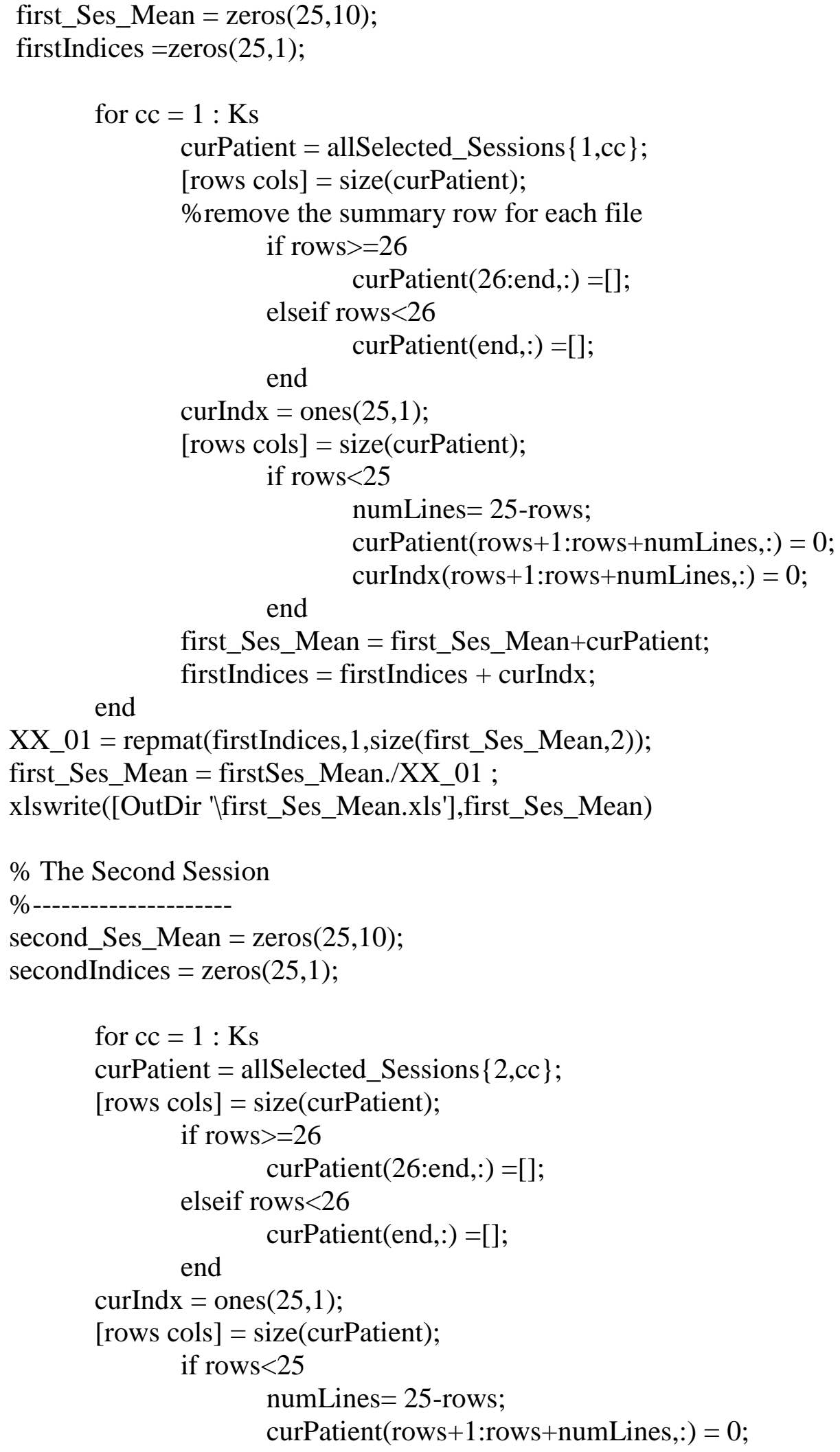


end curIndx(rows+1:rows+numLines,: $)=0$;

second_Ses_Mean = second_Ses_Mean+curPatient; secondIndices $=$ secondIndices + curIndx;

end

XX_02 = repmat $($ secondIndices,1,size $($ second_Ses_Mean,2) $)$; second_Ses_Mean $=$ second_Ses_Mean./XX_02 ;

xlswrite([OutDir 'Isecond_Ses_Mean.xls'],second_Ses_Mean)

$\%$ The Third Session

$\%$

third_Ses_Mean $=$ zeros $(25,10)$;

thirdIndices $=$ zeros $(25,1)$;

for $\mathrm{cc}=1: \mathrm{Ks}$

curPatient $=$ allSelected_Sessions $\{3, \mathrm{cc}\}$;

[rows cols] $=\operatorname{size}($ curPatient $)$;

if rows $>=26$ curPatient $(26:$ end,: $)=[]$;

elseif rows $<26$ curPatient(end,:) $=[]$;

end

curIndx $=$ ones $(25,1)$;

[rows cols] $=\operatorname{size}($ curPatient $)$;

if rows $<25$

numLines $=25$-rows;

curPatient(rows+1:rows+numLines,: $)=0$;

end curIndx $($ rows +1 :rows+numLines,: $)=0$;

third_Ses_Mean $=$ third_Ses_Mean+curPatient;

thirdIndices $=$ thirdIndices + curIndx;

end

XX_03 = repmat $($ thirdIndices, 1 ,size(third_Ses_Mean,2));

third_Ses_Mean $=$ third_Ses_Mean./XX_03 ;

xlswrite([OutDir 'Ithird_Ses_Mean.xls'],third_Ses_Mean)

$\%$ The Fourth Session

\%-------------------

fourth_Ses_Mean $=\operatorname{zeros}(25,10)$;

fourthIndices $=$ zeros $(25,1)$;

for $\mathrm{cc}=1: \mathrm{Ks}$

curPatient $=$ allSelected_Sessions $\{4, \mathrm{cc}\}$;

[rows cols] $=$ size $($ curPatient $)$; 


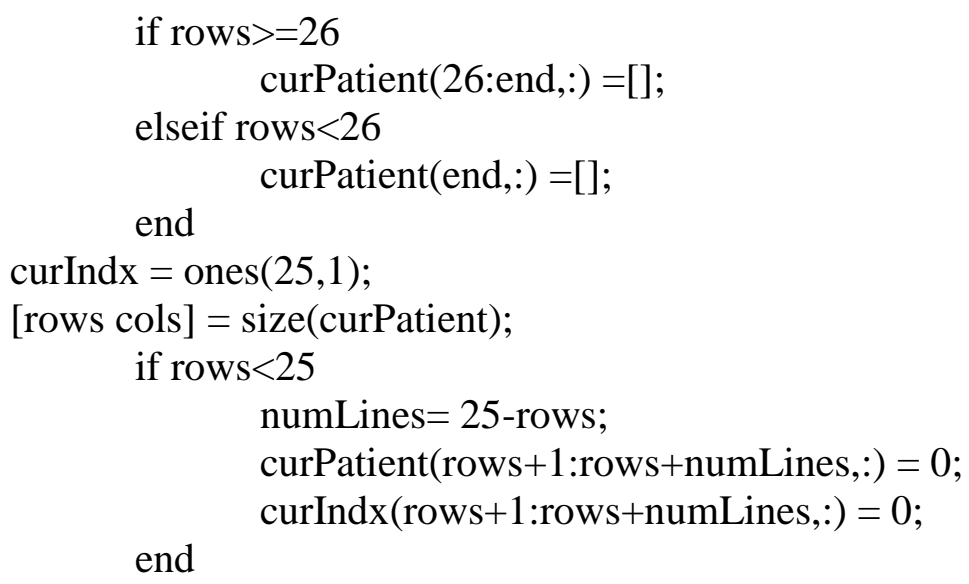




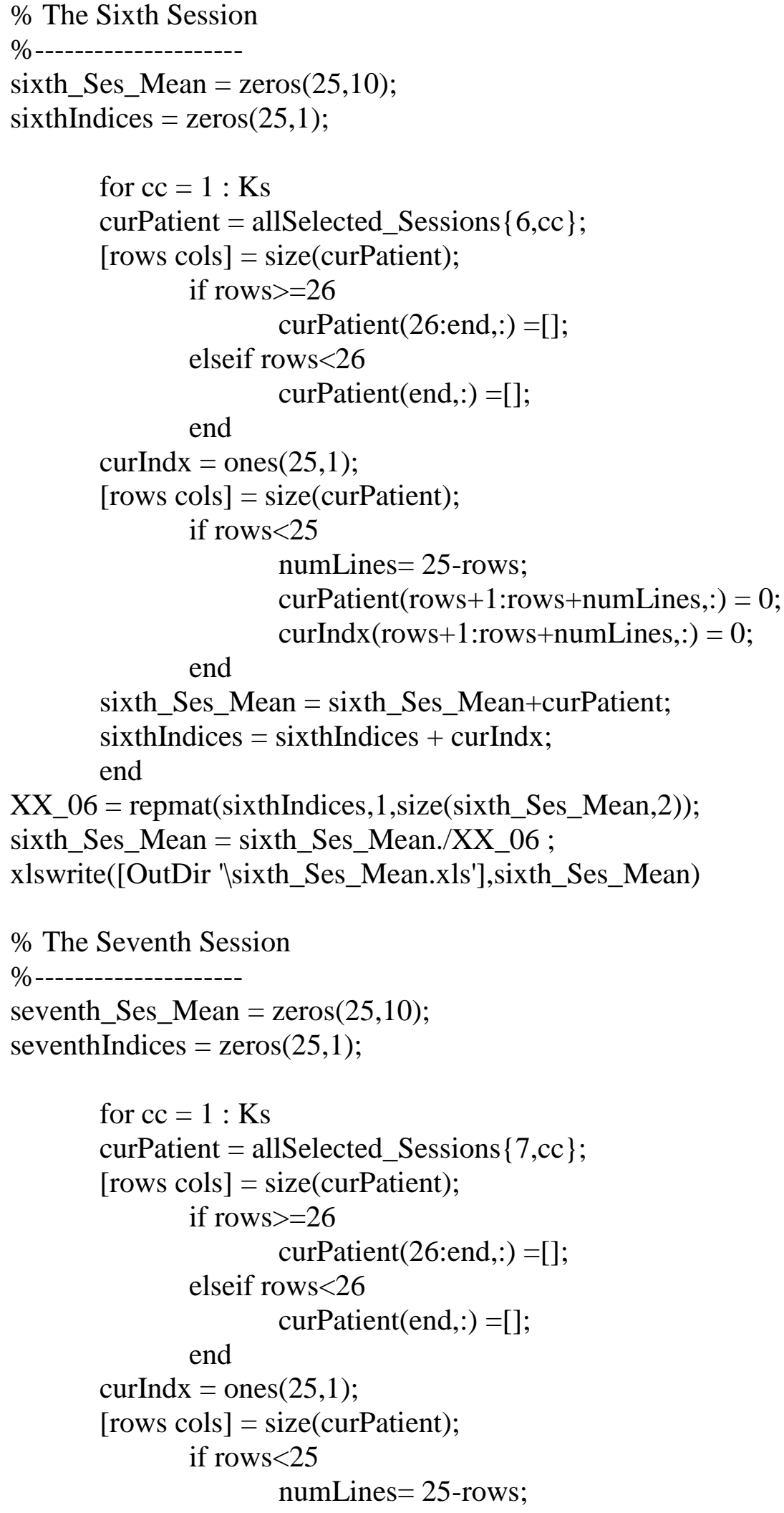




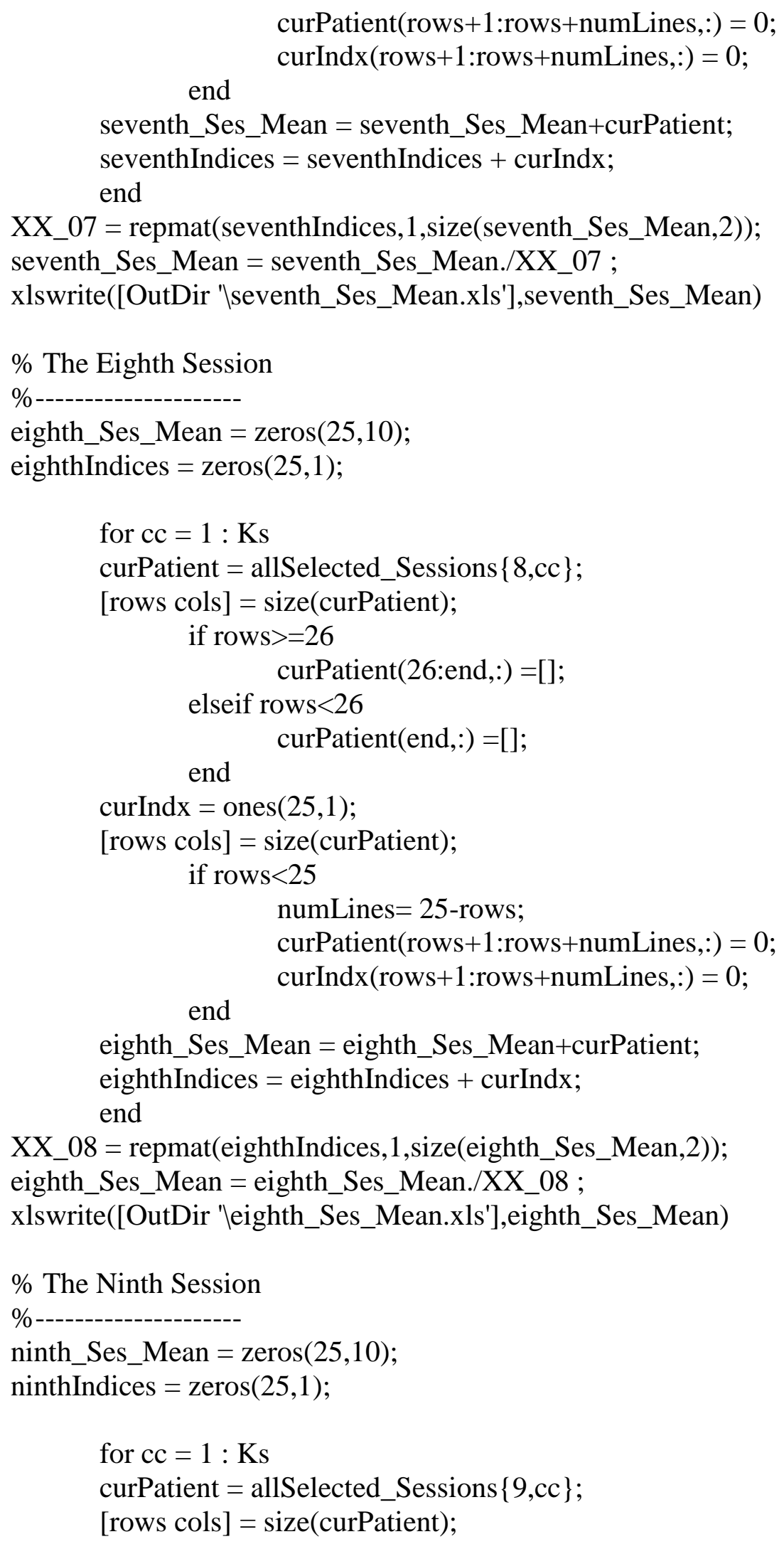




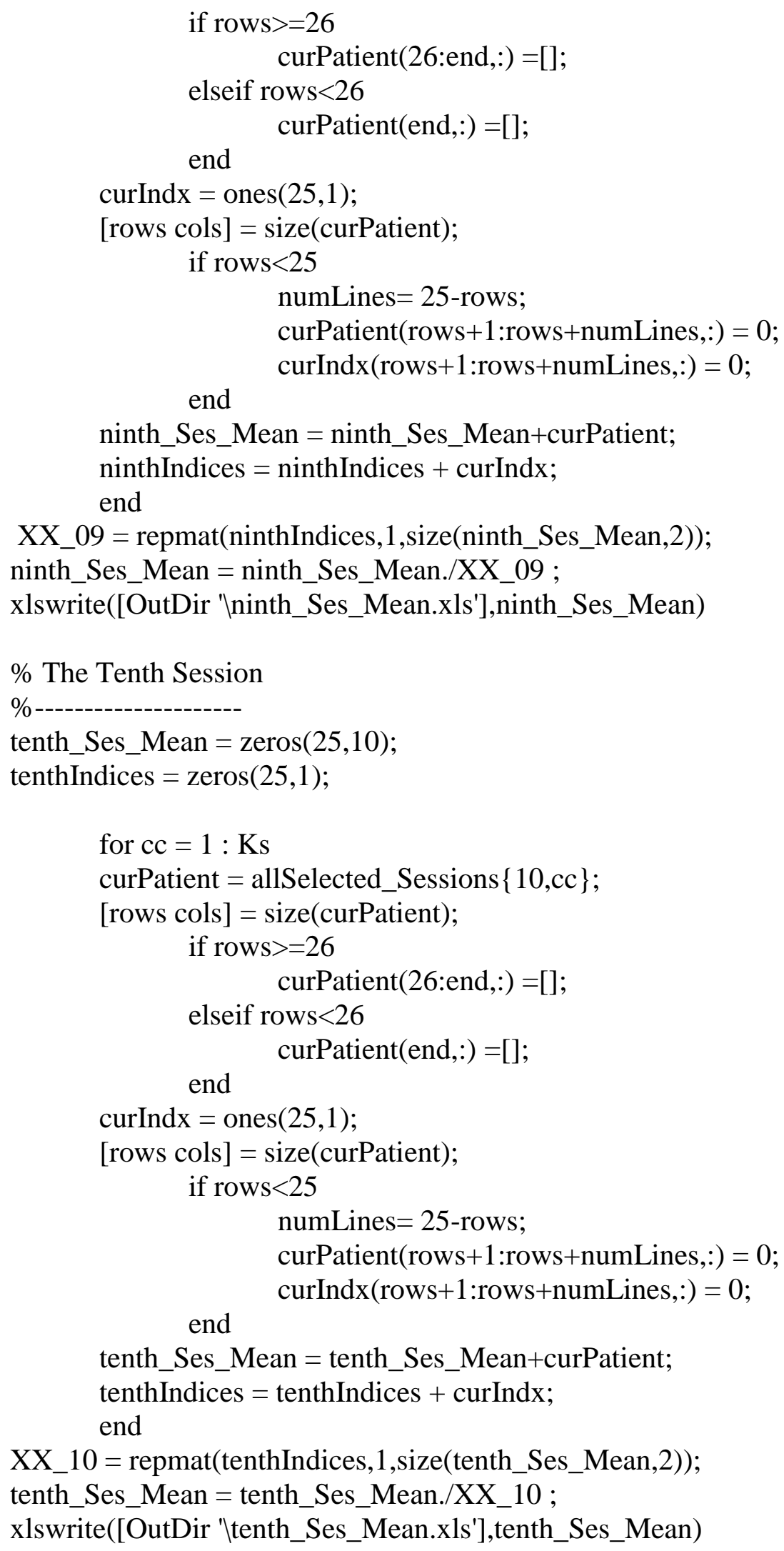


$\%$ The Eleventh Session

$\%$---------------------

eleventh_Ses_Mean $=\operatorname{zeros}(25,10)$;

eleventhIndices $=$ zeros $(25,1)$;

for $\mathrm{cc}=1: \mathrm{Ks}$

curPatient $=$ allSelected_Sessions $\{11, \mathrm{cc}\}$;

[rows cols] $=$ size $($ curPatient $)$;

if rows $>=26$ curPatient $(26:$ end,:) $=[]$;

elseif rows $<26$ curPatient $($ end,: $)=[]$;

end

curIndx $=$ ones $(25,1)$;

[rows cols] $=$ size $($ curPatient $)$;

if rows $<25$

numLines $=25$-rows;

curPatient(rows+1:rows+numLines,: $)=0$; curIndx (rows+1:rows+numLines,:) $=0$;

end

eleventh_Ses_Mean $=$ eleventh_Ses_Mean+curPatient;

eleventhIndices $=$ eleventhIndices + curIndx;

end

XX_11 = repmat (eleventhIndices,1,size(eleventh_Ses_Mean,2));

eleventh_Ses_Mean = eleventh_Ses_Mean./XX_11 ;

xlswrite([OutDir 'leleventh_Ses_Mean.xls'],eleventh_Ses_Mean)

$\%$ The Twelfth Session

$\%$---------------------

twelfth_Ses_Mean $=\operatorname{zeros}(25,10)$;

twelveIndices $=$ zeros $(25,1)$;

for $\mathrm{cc}=1: \mathrm{Ks}$

curPatient $=$ allSelected_Sessions $\{12, \mathrm{cc}\}$;

[rows cols] $=$ size $($ curPatient $)$;

if rows $>=26$ curPatient $(26:$ end,: $)=[]$;

elseif rows $<26$

curPatient $(\mathrm{end},:)=[]$;

end

curIndx $=$ ones $(25,1)$;

[rows cols] $=$ size $($ curPatient $)$; 
if rows $<25$

numLines $=25$-rows;

curPatient(rows+1:rows+numLines,: $)=0$;

curIndx (rows+1:rows+numLines,: $)=0$;

end

twelfth_Ses_Mean $=$ twelfth_Ses_Mean+curPatient;

twelveIndices $=$ twelveIndices + curIndx;

end

XX_12 = repmat $($ twelveIndices, 1,size(twelfth_Ses_Mean,2));

twelfth_Ses_Mean $=$ twelfth_Ses_Mean./XX_12 ;

xlswrite([OutDir 'Itwelfth_Ses_Mean.xls'],twelfth_Ses_Mean) 


\title{
APPENDIX II: DATA TABLES
}

\author{
A. Raw Data for Analysis
}

TABLE VI

RAW DATA FOR SESSION 1

\begin{tabular}{|c|c|c|c|c|c|c|c|c|c|c|c|c|}
\hline Minute & $\begin{array}{l}\text { Delta } \\
\text { Relative } \\
\text { Power }\end{array}$ & $\begin{array}{l}\text { Theta } \\
\text { Relative } \\
\text { Power }\end{array}$ & $\begin{array}{l}\text { Alpha } \\
\text { Relative } \\
\text { Power }\end{array}$ & $\begin{array}{c}\text { Low Beta } \\
\text { Relative } \\
\text { Power }\end{array}$ & $\begin{array}{c}\text { High Beta } \\
\text { Relative } \\
\text { Power }\end{array}$ & $\begin{array}{c}\text { Gamma } \\
\text { Relative } \\
\text { Power }\end{array}$ & $\begin{array}{l}\text { Theta/ } \\
\text { Low Beta } \\
\text { Ratio }\end{array}$ & $\begin{array}{c}\text { Theta/ } \\
\text { High Beta } \\
\text { Ratio }\end{array}$ & $\begin{array}{c}\text { Theta/ } \\
\text { Beta Ratio }\end{array}$ & $\begin{array}{l}\text { Theta/ } \\
\text { Alpha } \\
\text { Ratio }\end{array}$ & "Focus" & "Alertness" \\
\hline 1 & 0.145 & 0.084 & 0.027 & 0.013 & 0.027 & 0.026 & 7.306 & 4.501 & 2.73 & 3.323 & 71.501 & 38.594 \\
\hline 2 & 0.15 & 0.082 & 0.024 & 0.012 & 0.029 & 0.027 & 7.655 & 4.846 & 2.858 & 3.676 & 72.178 & 38.133 \\
\hline 3 & 0.138 & 0.079 & 0.023 & 0.012 & 0.025 & 0.027 & 7.682 & 4.672 & 2.809 & 3.733 & 72.58 & 38.2 \\
\hline 4 & 0.137 & 0.084 & 0.026 & 0.013 & 0.029 & 0.033 & 7.407 & 4.576 & 2.739 & 3.552 & 72.196 & 38.913 \\
\hline 5 & 0.141 & 0.087 & 0.031 & 0.015 & 0.032 & 0.031 & 7.807 & 4.701 & 2.86 & 3.44 & 72.603 & 39.189 \\
\hline 6 & 0.135 & 0.078 & 0.024 & 0.012 & 0.03 & 0.04 & 7.405 & 4.025 & 2.545 & 3.42 & 72.286 & 38.884 \\
\hline 7 & 0.136 & 0.084 & 0.027 & 0.014 & 0.036 & 0.047 & 7.418 & 4.23 & 2.617 & 3.491 & 71.214 & 38.864 \\
\hline 8 & 0.133 & 0.081 & 0.026 & 0.014 & 0.035 & 0.046 & 7.058 & 3.96 & 2.473 & 3.459 & 71.838 & 38.243 \\
\hline 9 & 0.143 & 0.085 & 0.023 & 0.014 & 0.036 & 0.047 & 8.504 & 4.83 & 3 & 3.903 & 72.352 & 38.541 \\
\hline 10 & 0.141 & 0.08 & 0.023 & 0.012 & 0.027 & 0.031 & 7.925 & 4.375 & 2.761 & 3.778 & 71.956 & 38.364 \\
\hline 11 & 0.137 & 0.091 & 0.026 & 0.013 & 0.03 & 0.032 & 8.169 & 4.81 & 2.92 & 3.843 & 71.789 & 37.127 \\
\hline 12 & 0.125 & 0.075 & 0.027 & 0.016 & 0.039 & 0.045 & 5.931 & 3.376 & 2.095 & 2.95 & 73.068 & 38.462 \\
\hline 13 & 0.14 & 0.082 & 0.026 & 0.015 & 0.032 & 0.035 & 7.06 & 3.87 & 2.435 & 3.46 & 72.64 & 38.115 \\
\hline 14 & 0.142 & 0.084 & 0.028 & 0.017 & 0.032 & 0.033 & 6.622 & 3.972 & 2.439 & 3.339 & 73.527 & 38.376 \\
\hline 15 & 0.134 & 0.081 & 0.026 & 0.015 & 0.037 & 0.041 & 6.895 & 4.486 & 2.634 & 3.634 & 72.438 & 38.631 \\
\hline 16 & 0.139 & 0.09 & 0.029 & 0.017 & 0.042 & 0.043 & 6.724 & 3.932 & 2.417 & 3.316 & 72.763 & 39.227 \\
\hline 17 & 0.138 & 0.08 & 0.02 & 0.011 & 0.029 & 0.033 & 8.682 & 4.645 & 2.943 & 4.068 & 72.414 & 37.487 \\
\hline 18 & 0.142 & 0.08 & 0.023 & 0.013 & 0.033 & 0.035 & 7.721 & 4.434 & 2.744 & 3.669 & 73.895 & 38.324 \\
\hline 19 & 0.142 & 0.081 & 0.023 & 0.015 & 0.037 & 0.039 & 7.908 & 4.476 & 2.761 & 3.793 & 73.846 & 40.133 \\
\hline 20 & 0.136 & 0.074 & 0.022 & 0.014 & 0.033 & 0.036 & 7.489 & 3.576 & 2.326 & 3.616 & 72.337 & 39.841 \\
\hline 21 & 0.135 & 0.082 & 0.025 & 0.016 & 0.045 & 0.057 & 6.394 & 3.326 & 2.114 & 3.565 & 68.69 & 40.593 \\
\hline 22 & 0.136 & 0.082 & 0.029 & 0.016 & 0.047 & 0.061 & 6.071 & 3.377 & 2.077 & 3.017 & 74.133 & 40.317 \\
\hline 23 & 0.126 & 0.079 & 0.024 & 0.014 & 0.043 & 0.053 & 7.044 & 3.561 & 2.285 & 3.281 & 73.867 & 40.64 \\
\hline 24 & 0.125 & 0.076 & 0.026 & 0.016 & 0.051 & 0.063 & 6.806 & 3.454 & 2.241 & 3.203 & 73.799 & 39.199 \\
\hline 25 & 0.144 & 0.087 & 0.03 & 0.016 & 0.044 & 0.047 & 9.698 & 6.307 & 3.704 & 4.02 & 73.28 & 37.095 \\
\hline
\end{tabular}


TABLE VII

RAW DATA FOR SESSION 2

\begin{tabular}{|c|c|c|c|c|c|c|c|c|c|c|c|c|}
\hline Minute & $\begin{array}{l}\text { Delta } \\
\text { Relative } \\
\text { Power }\end{array}$ & $\begin{array}{l}\text { Theta } \\
\text { Relative } \\
\text { Power }\end{array}$ & $\begin{array}{l}\text { Alpha } \\
\text { Relative } \\
\text { Power }\end{array}$ & $\begin{array}{c}\text { Low Beta } \\
\text { Relative } \\
\text { Power }\end{array}$ & $\begin{array}{l}\text { High Beta } \\
\text { Relative } \\
\text { Power }\end{array}$ & $\begin{array}{c}\text { Gamma } \\
\text { Relative } \\
\text { Power }\end{array}$ & $\begin{array}{l}\text { Theta/ Low } \\
\text { Beta Ratio }\end{array}$ & $\begin{array}{l}\text { Theta/ } \\
\text { High Beta } \\
\text { Ratio }\end{array}$ & $\begin{array}{c}\text { Theta/ Beta } \\
\text { Ratio }\end{array}$ & $\begin{array}{l}\text { Theta/ } \\
\text { Alpha } \\
\text { Ratio }\end{array}$ & "Focus" & "Alertness" \\
\hline 1 & 0.142 & 0.081 & 0.022 & 0.011 & 0.026 & 0.03 & 8.449 & 5.57 & 3.279 & 3.93 & 73.338 & 37.982 \\
\hline 2 & 0.146 & 0.084 & 0.025 & 0.013 & 0.031 & 0.039 & 8.2 & 5.461 & 3.191 & 3.864 & 72.687 & 39.025 \\
\hline 3 & 0.145 & 0.076 & 0.022 & 0.011 & 0.023 & 0.026 & 8.049 & 4.71 & 2.928 & 3.811 & 75.021 & 38.235 \\
\hline 4 & 0.149 & 0.083 & 0.029 & 0.016 & 0.042 & 0.047 & 7.607 & 4.26 & 2.677 & 3.412 & 75.681 & 40.102 \\
\hline 5 & 0.138 & 0.079 & 0.025 & 0.013 & 0.03 & 0.028 & 7.464 & 4.287 & 2.663 & 3.336 & 75.598 & 38.192 \\
\hline 6 & 0.158 & 0.082 & 0.028 & 0.015 & 0.037 & 0.043 & 6.57 & 3.675 & 2.268 & 3.199 & 74.726 & 38.942 \\
\hline 7 & 0.139 & 0.079 & 0.027 & 0.015 & 0.041 & 0.045 & 6.339 & 3.504 & 2.166 & 3.341 & 73.283 & 39.594 \\
\hline 8 & 0.154 & 0.084 & 0.025 & 0.014 & 0.033 & 0.038 & 7.861 & 4.618 & 2.808 & 3.825 & 74.421 & 39.404 \\
\hline 9 & 0.146 & 0.082 & 0.027 & 0.015 & 0.041 & 0.046 & 6.97 & 3.617 & 2.306 & 3.32 & 73.367 & 39.614 \\
\hline 10 & 0.157 & 0.101 & 0.033 & 0.021 & 0.056 & 0.071 & 6.428 & 3.762 & 2.282 & 3.32 & 71.871 & 38.956 \\
\hline 11 & 0.157 & 0.095 & 0.032 & 0.019 & 0.053 & 0.064 & 7.306 & 5.044 & 2.816 & 3.561 & 72.961 & 39.804 \\
\hline 12 & 0.145 & 0.08 & 0.027 & 0.016 & 0.04 & 0.044 & 6.104 & 3.627 & 2.225 & 3.24 & 74.146 & 39.329 \\
\hline 13 & 0.142 & 0.083 & 0.027 & 0.017 & 0.042 & 0.057 & 6.076 & 3.429 & 2.135 & 3.268 & 73.025 & 40.039 \\
\hline 14 & 0.144 & 0.085 & 0.026 & 0.016 & 0.047 & 0.053 & 6.931 & 3.591 & 2.302 & 3.583 & 73.708 & 40.203 \\
\hline 15 & 0.14 & 0.081 & 0.026 & 0.017 & 0.049 & 0.059 & 6.86 & 3.53 & 2.275 & 3.303 & 73.416 & 40.315 \\
\hline 16 & 0.138 & 0.082 & 0.027 & 0.016 & 0.046 & 0.067 & 6.273 & 3.496 & 2.197 & 3.225 & 73.629 & 39.284 \\
\hline 17 & 0.141 & 0.083 & 0.028 & 0.018 & 0.043 & 0.058 & 6.004 & 3.373 & 2.098 & 3.202 & 74.729 & 39.347 \\
\hline 18 & 0.135 & 0.078 & 0.025 & 0.014 & 0.031 & 0.038 & 6.753 & 4.139 & 2.507 & 3.353 & 74.914 & 38.782 \\
\hline 19 & 0.137 & 0.08 & 0.027 & 0.016 & 0.04 & 0.05 & 7.194 & 4.309 & 2.644 & 3.509 & 73.477 & 38.667 \\
\hline 20 & 0.142 & 0.079 & 0.024 & 0.013 & 0.03 & 0.037 & 8.297 & 5.062 & 3.084 & 3.871 & 73.793 & 38.146 \\
\hline 21 & 0.146 & 0.087 & 0.027 & 0.015 & 0.04 & 0.043 & 7.16 & 4.258 & 2.618 & 3.538 & 74.263 & 38.38 \\
\hline 22 & 0.146 & 0.082 & 0.028 & 0.017 & 0.042 & 0.051 & 6.846 & 3.964 & 2.452 & 3.211 & 75.356 & 38.04 \\
\hline 23 & 0.152 & 0.084 & 0.028 & 0.016 & 0.04 & 0.046 & 7.251 & 4.334 & 2.644 & 3.555 & 73.652 & 37.042 \\
\hline 24 & 0.141 & 0.089 & 0.031 & 0.018 & 0.046 & 0.051 & 6.887 & 4.318 & 2.559 & 3.23 & 75.513 & 36.348 \\
\hline 25 & 0.14 & 0.086 & 0.029 & 0.015 & 0.035 & 0.041 & 7.207 & 4.197 & 2.574 & 3.311 & 74.453 & 36.102 \\
\hline
\end{tabular}


TABLE VIII

RAW DATA FOR SESSION 3

\begin{tabular}{|c|c|c|c|c|c|c|c|c|c|c|c|c|}
\hline Minute & $\begin{array}{c}\text { Delta } \\
\text { Relative } \\
\text { Power }\end{array}$ & $\begin{array}{c}\text { Theta } \\
\text { Relative } \\
\text { Power }\end{array}$ & $\begin{array}{l}\text { Alpha } \\
\text { Relative } \\
\text { Power }\end{array}$ & $\begin{array}{c}\text { Low } \\
\text { Beta } \\
\text { Relative } \\
\text { Power }\end{array}$ & $\begin{array}{c}\text { High } \\
\text { Beta } \\
\text { Relative } \\
\text { Power }\end{array}$ & $\begin{array}{c}\text { Gamma } \\
\text { Relative } \\
\text { Power }\end{array}$ & $\begin{array}{c}\text { Theta/ } \\
\text { Low } \\
\text { Beta } \\
\text { Ratio }\end{array}$ & $\begin{array}{c}\text { Theta/ } \\
\text { High } \\
\text { Beta } \\
\text { Ratio }\end{array}$ & $\begin{array}{c}\text { Theta/ } \\
\text { Beta } \\
\text { Ratio }\end{array}$ & $\begin{array}{c}\text { Theta/ } \\
\text { Alpha } \\
\text { Ratio }\end{array}$ & "Focus" & "Alertness" \\
\hline 1 & 0.148 & 0.091 & 0.024 & 0.011 & 0.021 & 0.022 & 8.579 & 6.309 & 3.514 & 4.094 & 73.712 & 34.095 \\
\hline 2 & 0.136 & 0.083 & 0.025 & 0.013 & 0.027 & 0.029 & 7.537 & 4.473 & 2.72 & 3.544 & 74.791 & 36.5 \\
\hline 3 & 0.138 & 0.094 & 0.029 & 0.014 & 0.028 & 0.026 & 7.642 & 4.485 & 2.731 & 3.502 & 74.849 & 37.909 \\
\hline 4 & 0.141 & 0.083 & 0.026 & 0.013 & 0.031 & 0.032 & 7.138 & 3.763 & 2.371 & 3.64 & 74.001 & 39.879 \\
\hline 5 & 0.13 & 0.081 & 0.027 & 0.014 & 0.035 & 0.03 & 7.108 & 3.626 & 2.335 & 3.607 & 73.367 & 39.215 \\
\hline 6 & 0.138 & 0.085 & 0.028 & 0.015 & 0.035 & 0.03 & 7.363 & 3.829 & 2.447 & 3.786 & 74.221 & 39.265 \\
\hline 7 & 0.138 & 0.085 & 0.028 & 0.016 & 0.042 & 0.036 & 6.453 & 3.312 & 2.131 & 3.481 & 74.997 & 39.98 \\
\hline 8 & 0.136 & 0.075 & 0.026 & 0.013 & 0.032 & 0.031 & 6.895 & 3.393 & 2.199 & 3.454 & 73.072 & 38.831 \\
\hline 9 & 0.132 & 0.079 & 0.027 & 0.014 & 0.033 & 0.026 & 6.523 & 3.457 & 2.185 & 3.458 & 76.504 & 36.843 \\
\hline 10 & 0.135 & 0.084 & 0.039 & 0.014 & 0.033 & 0.031 & 6.69 & 3.184 & 2.09 & 3.359 & 74.125 & 36.388 \\
\hline 11 & 0.137 & 0.085 & 0.028 & 0.013 & 0.03 & 0.04 & 7.297 & 3.972 & 2.45 & 3.401 & 72.526 & 37.482 \\
\hline 12 & 0.133 & 0.083 & 0.027 & 0.015 & 0.034 & 0.035 & 6.967 & 3.781 & 2.397 & 3.386 & 73.727 & 38.771 \\
\hline 13 & 0.136 & 0.082 & 0.035 & 0.017 & 0.046 & 0.071 & 6.919 & 3.848 & 2.409 & 3.158 & 73.604 & 38.985 \\
\hline 14 & 0.14 & 0.078 & 0.027 & 0.013 & 0.028 & 0.027 & 6.44 & 3.79 & 2.314 & 3.21 & 75.019 & 37.82 \\
\hline 15 & 0.132 & 0.081 & 0.028 & 0.015 & 0.029 & 0.024 & 6.97 & 4.172 & 2.559 & 3.308 & 75.497 & 37.498 \\
\hline 16 & 0.141 & 0.089 & 0.029 & 0.016 & 0.034 & 0.028 & 7.4 & 4.467 & 2.722 & 3.585 & 75.56 & 38.46 \\
\hline 17 & 0.134 & 0.083 & 0.036 & 0.016 & 0.04 & 0.033 & 7.381 & 4.34 & 2.651 & 3.33 & 74.934 & 37.648 \\
\hline 18 & 0.132 & 0.09 & 0.029 & 0.016 & 0.038 & 0.036 & 8.029 & 4.55 & 2.805 & 3.736 & 74.807 & 38.332 \\
\hline 19 & 0.146 & 0.1 & 0.032 & 0.017 & 0.038 & 0.039 & 9.059 & 5.339 & 3.31 & 3.984 & 75.077 & 39.12 \\
\hline 20 & 0.136 & 0.081 & 0.032 & 0.016 & 0.042 & 0.041 & 6.99 & 4.074 & 2.494 & 3.499 & 73.442 & 38.528 \\
\hline 21 & 0.131 & 0.086 & 0.032 & 0.018 & 0.043 & 0.048 & 6.408 & 4.247 & 2.457 & 3.133 & 75.173 & 38.69 \\
\hline 22 & 0.131 & 0.082 & 0.03 & 0.016 & 0.036 & 0.03 & 7.077 & 4.45 & 2.665 & 3.416 & 74.617 & 38.491 \\
\hline 23 & 0.127 & 0.087 & 0.03 & 0.015 & 0.03 & 0.03 & 6.855 & 3.978 & 2.44 & 3.403 & 74.636 & 38.872 \\
\hline 24 & 0.122 & 0.079 & 0.028 & 0.015 & 0.035 & 0.036 & 7.271 & 4.29 & 2.593 & 3.693 & 73.784 & 38.417 \\
\hline 25 & 0.133 & 0.087 & 0.028 & 0.014 & 0.031 & 0.029 & 7.781 & 4.737 & 2.843 & 3.847 & 75.727 & 38.108 \\
\hline
\end{tabular}




\section{TABLE IX}

RAW DATA FOR SESSION 4

\begin{tabular}{|c|c|c|c|c|c|c|c|c|c|c|c|c|}
\hline Minute & $\begin{array}{l}\text { Delta } \\
\text { Relative } \\
\text { Power }\end{array}$ & $\begin{array}{l}\text { Theta } \\
\text { Relative } \\
\text { Power }\end{array}$ & $\begin{array}{l}\text { Alpha } \\
\text { Relative } \\
\text { Power }\end{array}$ & $\begin{array}{l}\text { Low Beta } \\
\text { Relative } \\
\text { Power }\end{array}$ & $\begin{array}{c}\text { High Beta } \\
\text { Relative } \\
\text { Power }\end{array}$ & $\begin{array}{c}\text { Gamma } \\
\text { Relative } \\
\text { Power }\end{array}$ & $\begin{array}{l}\text { Theta/ Low } \\
\text { Beta Ratio }\end{array}$ & $\begin{array}{c}\text { Theta/ } \\
\text { High Beta } \\
\text { Ratio }\end{array}$ & $\begin{array}{c}\text { Theta/ Beta } \\
\text { Ratio }\end{array}$ & $\begin{array}{l}\text { Theta/ } \\
\text { Alpha } \\
\text { Ratio }\end{array}$ & "Focus" & "Alertness" \\
\hline 1 & 0.132 & 0.084 & 0.026 & 0.013 & 0.027 & 0.028 & 7.675 & 5.348 & 3.091 & 3.322 & 71.642 & 35.893 \\
\hline 2 & 0.137 & 0.08 & 0.027 & 0.015 & 0.035 & 0.04 & 6.437 & 4.034 & 2.41 & 3.201 & 71.305 & 38.589 \\
\hline 3 & 0.141 & 0.078 & 0.026 & 0.013 & 0.03 & 0.035 & 7.077 & 4.399 & 2.63 & 3.326 & 73.45 & 38.523 \\
\hline 4 & 0.135 & 0.081 & 0.028 & 0.015 & 0.033 & 0.033 & 7.007 & 4.24 & 2.604 & 3.306 & 74.448 & 38.279 \\
\hline 5 & 0.132 & 0.082 & 0.029 & 0.016 & 0.037 & 0.035 & 6.789 & 4.198 & 2.554 & 3.165 & 75.154 & 39.355 \\
\hline 6 & 0.134 & 0.079 & 0.025 & 0.014 & 0.035 & 0.035 & 7.807 & 4.847 & 2.892 & 3.508 & 73.932 & 38.947 \\
\hline 7 & 0.136 & 0.08 & 0.027 & 0.015 & 0.038 & 0.035 & 7.85 & 4.992 & 2.992 & 3.491 & 74.597 & 39.313 \\
\hline 8 & 0.144 & 0.082 & 0.029 & 0.016 & 0.043 & 0.039 & 7.28 & 4.457 & 2.695 & 3.313 & 74.326 & 40.145 \\
\hline 9 & 0.132 & 0.081 & 0.028 & 0.014 & 0.04 & 0.044 & 6.762 & 3.512 & 2.252 & 3.076 & 74.468 & 39.863 \\
\hline 10 & 0.129 & 0.079 & 0.029 & 0.016 & 0.044 & 0.041 & 6.693 & 3.575 & 2.281 & 3.11 & 75.251 & 40.297 \\
\hline 11 & 0.132 & 0.079 & 0.026 & 0.015 & 0.035 & 0.032 & 6.387 & 3.429 & 2.193 & 3.187 & 74.58 & 39.94 \\
\hline 12 & 0.141 & 0.08 & 0.025 & 0.013 & 0.032 & 0.03 & 6.946 & 3.77 & 2.386 & 3.417 & 73.92 & 39.062 \\
\hline 13 & 0.14 & 0.077 & 0.028 & 0.015 & 0.044 & 0.042 & 6.838 & 3.614 & 2.302 & 3.092 & 73.962 & 39.108 \\
\hline 14 & 0.136 & 0.077 & 0.025 & 0.014 & 0.041 & 0.035 & 7.004 & 4.093 & 2.544 & 3.303 & 74.454 & 38.51 \\
\hline 15 & 0.133 & 0.078 & 0.027 & 0.015 & 0.054 & 0.087 & 6.753 & 3.932 & 2.422 & 3.033 & 72.996 & 39.488 \\
\hline 16 & 0.128 & 0.083 & 0.029 & 0.016 & 0.038 & 0.042 & 5.866 & 3.227 & 2.037 & 3.031 & 75.623 & 40.239 \\
\hline 17 & 0.132 & 0.088 & 0.029 & 0.016 & 0.042 & 0.039 & 6.38 & 3.899 & 2.358 & 3.193 & 75.26 & 38.83 \\
\hline 18 & 0.125 & 0.082 & 0.028 & 0.015 & 0.036 & 0.035 & 6.534 & 3.989 & 2.38 & 3.15 & 73.979 & 38.815 \\
\hline 19 & 0.132 & 0.081 & 0.028 & 0.015 & 0.033 & 0.041 & 6.4 & 3.676 & 2.277 & 2.985 & 75.626 & 37.926 \\
\hline 20 & 0.141 & 0.082 & 0.029 & 0.016 & 0.04 & 0.041 & 6.265 & 3.818 & 2.312 & 3.052 & 75.968 & 39.135 \\
\hline 21 & 0.143 & 0.092 & 0.03 & 0.016 & 0.036 & 0.046 & 7.211 & 4.28 & 2.616 & 3.442 & 75.196 & 37.58 \\
\hline 22 & 0.128 & 0.091 & 0.029 & 0.015 & 0.036 & 0.055 & 6.895 & 4.681 & 2.713 & 3.208 & 75.505 & 37.346 \\
\hline 23 & 0.129 & 0.079 & 0.028 & 0.014 & 0.034 & 0.045 & 6.311 & 4.036 & 2.407 & 2.97 & 76.38 & 35.761 \\
\hline 24 & 0.13 & 0.089 & 0.03 & 0.015 & 0.03 & 0.024 & 6.647 & 4.409 & 2.577 & 3.155 & 77.544 & 35.07 \\
\hline 25 & 0.138 & 0.075 & 0.024 & 0.012 & 0.026 & 0.023 & 7.291 & 4.615 & 2.733 & 3.212 & 75.154 & 37.609 \\
\hline
\end{tabular}


TABLE X

RAW DATA FOR SESSION 5

\begin{tabular}{|c|c|c|c|c|c|c|c|c|c|c|c|c|}
\hline Minute & $\begin{array}{l}\text { Delta } \\
\text { Relative } \\
\text { Power }\end{array}$ & $\begin{array}{l}\text { Theta } \\
\text { Relative } \\
\text { Power }\end{array}$ & $\begin{array}{l}\text { Alpha } \\
\text { Relative } \\
\text { Power }\end{array}$ & $\begin{array}{c}\text { Low Beta } \\
\text { Relative } \\
\text { Power }\end{array}$ & $\begin{array}{l}\text { High Beta } \\
\text { Relative } \\
\text { Power }\end{array}$ & $\begin{array}{l}\text { Gamma } \\
\text { Relative } \\
\text { Power }\end{array}$ & $\begin{array}{l}\text { Theta/ Low } \\
\text { Beta Ratio }\end{array}$ & $\begin{array}{l}\text { Theta/ } \\
\text { High Beta } \\
\text { Ratio }\end{array}$ & $\begin{array}{c}\text { Theta/ Beta } \\
\text { Ratio }\end{array}$ & $\begin{array}{l}\text { Theta/ } \\
\text { Alpha } \\
\text { Ratio }\end{array}$ & "Focus" & "Alertness" \\
\hline 1 & 0.139 & 0.104 & 0.035 & 0.02 & 0.034 & 0.036 & 6.976 & 4.948 & 2.819 & 3.67 & 73.445 & 37.632 \\
\hline 2 & 0.146 & 0.088 & 0.031 & 0.018 & 0.035 & 0.036 & 6.869 & 4.567 & 2.693 & 3.194 & 74.314 & 37.077 \\
\hline 3 & 0.144 & 0.083 & 0.029 & 0.017 & 0.033 & 0.031 & 6.147 & 3.838 & 2.316 & 3.074 & 75.721 & 37.527 \\
\hline 4 & 0.138 & 0.092 & 0.036 & 0.02 & 0.047 & 0.056 & 6.23 & 3.629 & 2.228 & 2.942 & 75.974 & 38.003 \\
\hline 5 & 0.132 & 0.083 & 0.032 & 0.018 & 0.046 & 0.054 & 6.231 & 3.65 & 2.245 & 2.963 & 76.56 & 40.897 \\
\hline 6 & 0.133 & 0.08 & 0.031 & 0.016 & 0.036 & 0.034 & 6.399 & 3.414 & 2.17 & 3.01 & 76.234 & 39.863 \\
\hline 7 & 0.141 & 0.089 & 0.036 & 0.019 & 0.042 & 0.043 & 6.268 & 3.593 & 2.22 & 3.054 & 76.213 & 39.384 \\
\hline 8 & 0.129 & 0.083 & 0.031 & 0.017 & 0.038 & 0.036 & 6.011 & 3.329 & 2.102 & 2.976 & 76.488 & 39.943 \\
\hline 9 & 0.129 & 0.076 & 0.029 & 0.015 & 0.031 & 0.03 & 6.158 & 3.529 & 2.193 & 2.884 & 76.63 & 39.462 \\
\hline 10 & 0.142 & 0.085 & 0.03 & 0.015 & 0.039 & 0.049 & 7.098 & 4.022 & 2.513 & 3.161 & 74.935 & 38.993 \\
\hline 11 & 0.137 & 0.09 & 0.033 & 0.018 & 0.054 & 0.076 & 6.669 & 3.868 & 2.376 & 3.239 & 75.059 & 39.409 \\
\hline 12 & 0.14 & 0.073 & 0.024 & 0.014 & 0.038 & 0.042 & 7.507 & 4.537 & 2.779 & 3.463 & 75.371 & 39.727 \\
\hline 13 & 0.142 & 0.08 & 0.029 & 0.016 & 0.037 & 0.035 & 6.958 & 4.206 & 2.555 & 3.193 & 75.709 & 38.924 \\
\hline 14 & 0.13 & 0.081 & 0.028 & 0.016 & 0.041 & 0.052 & 7.309 & 4.531 & 2.74 & 3.108 & 75.13 & 38.699 \\
\hline 15 & 0.137 & 0.079 & 0.03 & 0.017 & 0.042 & 0.048 & 6.512 & 4.063 & 2.433 & 2.908 & 74.121 & 38.314 \\
\hline 16 & 0.137 & 0.086 & 0.028 & 0.016 & 0.042 & 0.046 & 7.25 & 4.631 & 2.759 & 3.311 & 75.551 & 38.842 \\
\hline 17 & 0.136 & 0.082 & 0.03 & 0.019 & 0.056 & 0.07 & 6.529 & 4.052 & 2.45 & 3.283 & 75.662 & 39.252 \\
\hline 18 & 0.149 & 0.086 & 0.027 & 0.016 & 0.042 & 0.058 & 7.167 & 4.377 & 2.663 & 3.545 & 74.708 & 38.977 \\
\hline 19 & 0.131 & 0.08 & 0.031 & 0.017 & 0.047 & 0.055 & 6.721 & 4.116 & 2.486 & 3.132 & 74.628 & 39.241 \\
\hline 20 & 0.139 & 0.083 & 0.029 & 0.015 & 0.04 & 0.05 & 7.188 & 4.683 & 2.761 & 3.224 & 74.307 & 39.331 \\
\hline 21 & 0.133 & 0.085 & 0.031 & 0.017 & 0.047 & 0.067 & 7.499 & 4.418 & 2.718 & 3.049 & 72.788 & 38.651 \\
\hline 22 & 0.141 & 0.086 & 0.03 & 0.016 & 0.046 & 0.046 & 7.66 & 4.534 & 2.788 & 3.213 & 74.279 & 39.8 \\
\hline 23 & 0.13 & 0.084 & 0.032 & 0.018 & 0.047 & 0.059 & 7.488 & 4.707 & 2.832 & 3.081 & 75.226 & 38.113 \\
\hline 24 & 0.135 & 0.085 & 0.036 & 0.02 & 0.052 & 0.056 & 6.697 & 3.789 & 2.377 & 3.134 & 75.032 & 38.533 \\
\hline 25 & 0.135 & 0.081 & 0.027 & 0.015 & 0.038 & 0.045 & 7.212 & 4.134 & 2.581 & 3.338 & 75.375 & 39.098 \\
\hline
\end{tabular}


TABLE XI

RAW DATA FOR SESSION 6

\begin{tabular}{|c|c|c|c|c|c|c|c|c|c|c|c|c|}
\hline Minute & $\begin{array}{l}\text { Delta } \\
\text { Relative } \\
\text { Power }\end{array}$ & $\begin{array}{l}\text { Theta } \\
\text { Relative } \\
\text { Power }\end{array}$ & $\begin{array}{l}\text { Alpha } \\
\text { Relative } \\
\text { Power }\end{array}$ & $\begin{array}{l}\text { Low Beta } \\
\text { Relative } \\
\text { Power }\end{array}$ & $\begin{array}{l}\text { High Beta } \\
\text { Relative } \\
\text { Power }\end{array}$ & $\begin{array}{l}\text { Gamma } \\
\text { Relative } \\
\text { Power }\end{array}$ & $\begin{array}{l}\text { Theta/ } \\
\text { Low Beta } \\
\text { Ratio }\end{array}$ & $\begin{array}{l}\text { Theta/ } \\
\text { High Beta } \\
\text { Ratio }\end{array}$ & $\begin{array}{c}\text { Theta/ } \\
\text { Beta Ratio }\end{array}$ & $\begin{array}{l}\text { Theta/ } \\
\text { Alpha } \\
\text { Ratio }\end{array}$ & "Focus" & "Alertness" \\
\hline 1 & 0.128 & 0.08 & 0.023 & 0.011 & 0.021 & 0.02 & 8.406 & 5.886 & 3.361 & 3.665 & 73.686 & 35.895 \\
\hline 2 & 0.133 & 0.081 & 0.022 & 0.01 & 0.019 & 0.019 & 8.858 & 5.455 & 3.282 & 3.931 & 73.381 & 35.593 \\
\hline 3 & 0.125 & 0.083 & 0.029 & 0.014 & 0.028 & 0.023 & 6.989 & 4.29 & 2.571 & 3.301 & 76.244 & 37.257 \\
\hline 4 & 0.133 & 0.09 & 0.05 & 0.027 & 0.061 & 0.053 & 6.787 & 3.988 & 2.439 & 3.258 & 77.404 & 36.773 \\
\hline 5 & 0.14 & 0.098 & 0.071 & 0.041 & 0.094 & 0.083 & 6.585 & 3.686 & 2.306 & 3.215 & 77.11 & 36.064 \\
\hline 6 & 0.137 & 0.098 & 0.067 & 0.04 & 0.096 & 0.086 & 6.74 & 3.597 & 2.282 & 3.265 & 77.008 & 36.609 \\
\hline 7 & 0.132 & 0.098 & 0.065 & 0.041 & 0.097 & 0.087 & 6.298 & 3.406 & 2.156 & 3.164 & 76.549 & 36.425 \\
\hline 8 & 0.143 & 0.107 & 0.083 & 0.047 & 0.109 & 0.093 & 6.583 & 3.647 & 2.296 & 2.97 & 77.073 & 35.959 \\
\hline 9 & 0.14 & 0.092 & 0.075 & 0.043 & 0.102 & 0.097 & 6.374 & 3.199 & 2.072 & 3.14 & 76.545 & 37.138 \\
\hline 10 & 0.134 & 0.097 & 0.066 & 0.039 & 0.091 & 0.083 & 6.628 & 3.534 & 2.25 & 3.116 & 76.33 & 37.193 \\
\hline 11 & 0.153 & 0.109 & 0.102 & 0.054 & 0.127 & 0.107 & 7.529 & 3.947 & 2.515 & 3.486 & 75.906 & 35.741 \\
\hline 12 & 0.134 & 0.087 & 0.029 & 0.014 & 0.031 & 0.026 & 7.547 & 4.451 & 2.695 & 3.511 & 76.827 & 36.59 \\
\hline 13 & 0.14 & 0.094 & 0.033 & 0.016 & 0.034 & 0.026 & 7.129 & 4.169 & 2.579 & 3.19 & 76.158 & 38.245 \\
\hline 14 & 0.125 & 0.078 & 0.028 & 0.015 & 0.035 & 0.034 & 6.619 & 3.714 & 2.313 & 3.204 & 76.541 & 39.349 \\
\hline 15 & 0.139 & 0.082 & 0.028 & 0.015 & 0.033 & 0.031 & 6.691 & 3.729 & 2.346 & 3.292 & 76.222 & 38.987 \\
\hline 16 & 0.126 & 0.08 & 0.03 & 0.016 & 0.034 & 0.028 & 6.453 & 3.779 & 2.335 & 2.983 & 76.532 & 39.245 \\
\hline 17 & 0.13 & 0.08 & 0.027 & 0.015 & 0.031 & 0.026 & 6.813 & 3.771 & 2.392 & 3.185 & 75.117 & 37.639 \\
\hline 18 & 0.142 & 0.084 & 0.027 & 0.015 & 0.029 & 0.025 & 7.708 & 4.489 & 2.814 & 3.418 & 75.282 & 37.044 \\
\hline 19 & 0.136 & 0.089 & 0.032 & 0.017 & 0.039 & 0.038 & 6.933 & 3.936 & 2.459 & 3.148 & 75.362 & 38.658 \\
\hline 20 & 0.129 & 0.09 & 0.034 & 0.018 & 0.045 & 0.045 & 6.701 & 3.919 & 2.401 & 3.238 & 75.35 & 38.478 \\
\hline 21 & 0.126 & 0.078 & 0.028 & 0.016 & 0.035 & 0.035 & 6.93 & 3.879 & 2.443 & 3.224 & 75.722 & 38.551 \\
\hline 22 & 0.13 & 0.082 & 0.031 & 0.017 & 0.04 & 0.04 & 6.12 & 3.797 & 2.294 & 2.931 & 76.739 & 39.297 \\
\hline 23 & 0.136 & 0.094 & 0.033 & 0.018 & 0.044 & 0.044 & 6.76 & 4.111 & 2.498 & 3.217 & 75.972 & 38.48 \\
\hline 24 & 0.127 & 0.091 & 0.03 & 0.017 & 0.043 & 0.043 & 6.883 & 4.085 & 2.497 & 3.294 & 75.778 & 39.364 \\
\hline 25 & 0.134 & 0.084 & 0.029 & 0.016 & 0.036 & 0.036 & 6.545 & 3.827 & 2.366 & 3.292 & 74.213 & 37.304 \\
\hline
\end{tabular}


TABLE XII

RAW DATA FOR SESSION 7

\begin{tabular}{|c|c|c|c|c|c|c|c|c|c|c|c|c|}
\hline Minute & $\begin{array}{l}\text { Delta } \\
\text { Relative } \\
\text { Power }\end{array}$ & $\begin{array}{l}\text { Theta } \\
\text { Relative } \\
\text { Power }\end{array}$ & $\begin{array}{l}\text { Alpha } \\
\text { Relative } \\
\text { Power }\end{array}$ & $\begin{array}{l}\text { Low Beta } \\
\text { Relative } \\
\text { Power }\end{array}$ & $\begin{array}{l}\text { High Beta } \\
\text { Relative } \\
\text { Power }\end{array}$ & $\begin{array}{c}\text { Gamma } \\
\text { Relative } \\
\text { Power }\end{array}$ & $\begin{array}{l}\text { Theta/ } \\
\text { Low Beta } \\
\text { Ratio }\end{array}$ & $\begin{array}{l}\text { Theta/ } \\
\text { High Beta } \\
\text { Ratio }\end{array}$ & $\begin{array}{l}\text { Theta/ } \\
\text { Beta Ratio }\end{array}$ & $\begin{array}{l}\text { Theta/ } \\
\text { Alpha } \\
\text { Ratio }\end{array}$ & "Focus" & "Alertness" \\
\hline 1 & 0.139 & 0.079 & 0.028 & 0.013 & 0.024 & 0.022 & 7.126 & 4.947 & 2.873 & 3.098 & 72.748 & 36.313 \\
\hline 2 & 0.14 & 0.088 & 0.025 & 0.013 & 0.025 & 0.024 & 7.751 & 5.219 & 3.067 & 3.64 & 73.173 & 36.783 \\
\hline 3 & 0.138 & 0.08 & 0.027 & 0.014 & 0.027 & 0.025 & 6.461 & 4.086 & 2.434 & 3.09 & 74.488 & 37.943 \\
\hline 4 & 0.126 & 0.087 & 0.033 & 0.016 & 0.037 & 0.038 & 6.777 & 3.943 & 2.437 & 2.99 & 74.597 & 38.22 \\
\hline 5 & 0.138 & 0.08 & 0.026 & 0.014 & 0.029 & 0.029 & 7.011 & 4.215 & 2.58 & 3.232 & 74.746 & 39.239 \\
\hline 6 & 0.146 & 0.088 & 0.031 & 0.016 & 0.032 & 0.036 & 6.368 & 3.845 & 2.316 & 3.053 & 74.429 & 39.284 \\
\hline 7 & 0.141 & 0.083 & 0.029 & 0.015 & 0.031 & 0.032 & 7.037 & 4.391 & 2.638 & 3.282 & 74.458 & 39.486 \\
\hline 8 & 0.139 & 0.09 & 0.04 & 0.021 & 0.043 & 0.044 & 6.916 & 3.784 & 2.369 & 2.942 & 74.384 & 39.947 \\
\hline 9 & 0.136 & 0.089 & 0.034 & 0.019 & 0.044 & 0.05 & 6.072 & 3.505 & 2.124 & 2.997 & 74.853 & 40.275 \\
\hline 10 & 0.14 & 0.094 & 0.035 & 0.02 & 0.048 & 0.05 & 5.756 & 3.462 & 2.079 & 3.035 & 74.602 & 40.1 \\
\hline 11 & 0.137 & 0.079 & 0.033 & 0.017 & 0.042 & 0.042 & 6.337 & 3.681 & 2.262 & 2.776 & 74.897 & 40.422 \\
\hline 12 & 0.138 & 0.09 & 0.044 & 0.022 & 0.052 & 0.055 & 6.568 & 3.819 & 2.355 & 2.927 & 74.354 & 39.321 \\
\hline 13 & 0.135 & 0.081 & 0.035 & 0.017 & 0.035 & 0.031 & 6.817 & 4.116 & 2.487 & 2.937 & 74.769 & 38.788 \\
\hline 14 & 0.135 & 0.09 & 0.039 & 0.021 & 0.049 & 0.051 & 6.419 & 3.563 & 2.238 & 2.886 & 75.575 & 40.341 \\
\hline 15 & 0.13 & 0.086 & 0.036 & 0.019 & 0.045 & 0.044 & 6.817 & 3.77 & 2.373 & 3.036 & 74.947 & 40.026 \\
\hline 16 & 0.133 & 0.078 & 0.03 & 0.016 & 0.031 & 0.03 & 7.078 & 4.009 & 2.503 & 3.142 & 75.477 & 40.025 \\
\hline 17 & 0.138 & 0.091 & 0.039 & 0.02 & 0.045 & 0.041 & 6.869 & 3.829 & 2.43 & 2.924 & 75.733 & 39.954 \\
\hline 18 & 0.141 & 0.084 & 0.032 & 0.019 & 0.038 & 0.041 & 6.67 & 4.105 & 2.496 & 3.098 & 75.097 & 40.532 \\
\hline 19 & 0.136 & 0.084 & 0.031 & 0.016 & 0.033 & 0.03 & 7.343 & 4.141 & 2.614 & 3.266 & 75.021 & 37.839 \\
\hline 20 & 0.156 & 0.086 & 0.033 & 0.018 & 0.033 & 0.026 & 6.801 & 4.3 & 2.604 & 2.935 & 75.665 & 36.801 \\
\hline 21 & 0.141 & 0.091 & 0.035 & 0.018 & 0.031 & 0.026 & 7.163 & 4.591 & 2.757 & 3.09 & 74.755 & 38.404 \\
\hline 22 & 0.153 & 0.088 & 0.029 & 0.015 & 0.026 & 0.023 & 7.645 & 5.529 & 3.142 & 3.335 & 74.479 & 38.932 \\
\hline 23 & 0.138 & 0.079 & 0.029 & 0.017 & 0.029 & 0.026 & 6.955 & 4.515 & 2.702 & 3.033 & 74.532 & 38.434 \\
\hline 24 & 0.142 & 0.084 & 0.033 & 0.018 & 0.031 & 0.03 & 6.751 & 4.378 & 2.593 & 3.038 & 75.1 & 38.911 \\
\hline 25 & 0.13 & 0.088 & 0.035 & 0.019 & 0.033 & 0.03 & 6.662 & 4.456 & 2.606 & 2.928 & 74.549 & 38.54 \\
\hline
\end{tabular}


TABLE XIII

RAW DATA FOR SESSION 8

\begin{tabular}{|c|c|c|c|c|c|c|c|c|c|c|c|c|}
\hline Minute & $\begin{array}{l}\text { Delta } \\
\text { Relative } \\
\text { Power }\end{array}$ & $\begin{array}{l}\text { Theta } \\
\text { Relative } \\
\text { Power }\end{array}$ & $\begin{array}{l}\text { Alpha } \\
\text { Relative } \\
\text { Power }\end{array}$ & $\begin{array}{l}\text { Low Beta } \\
\text { Relative } \\
\text { Power }\end{array}$ & $\begin{array}{l}\text { High Beta } \\
\text { Relative } \\
\text { Power }\end{array}$ & $\begin{array}{l}\text { Gamma } \\
\text { Relative } \\
\text { Power }\end{array}$ & $\begin{array}{l}\text { Theta/ Low } \\
\text { Beta Ratio }\end{array}$ & $\begin{array}{l}\text { Theta/ } \\
\text { High Beta } \\
\text { Ratio }\end{array}$ & $\begin{array}{c}\text { Theta/ Beta } \\
\text { Ratio }\end{array}$ & $\begin{array}{l}\text { Theta/ } \\
\text { Alpha } \\
\text { Ratio }\end{array}$ & "Focus" & "Alertness" \\
\hline 1 & 0.135 & 0.101 & 0.028 & 0.013 & 0.019 & 0.017 & 8.448 & 6.36 & 3.545 & 3.7 & 74.524 & 35.839 \\
\hline 2 & 0.136 & 0.071 & 0.022 & 0.011 & 0.019 & 0.018 & 7.118 & 4.421 & 2.691 & 3.377 & 74.264 & 36.606 \\
\hline 3 & 0.13 & 0.075 & 0.026 & 0.012 & 0.027 & 0.024 & 6.817 & 3.733 & 2.362 & 3.158 & 76.237 & 38.611 \\
\hline 4 & 0.143 & 0.073 & 0.024 & 0.011 & 0.023 & 0.02 & 7.379 & 4.28 & 2.642 & 3.195 & 75.235 & 38.588 \\
\hline 5 & 0.139 & 0.086 & 0.028 & 0.014 & 0.033 & 0.03 & 7.078 & 4.039 & 2.473 & 3.298 & 75.949 & 38.345 \\
\hline 6 & 0.142 & 0.078 & 0.025 & 0.013 & 0.028 & 0.026 & 7.078 & 3.97 & 2.422 & 3.435 & 76.118 & 38.102 \\
\hline 7 & 0.135 & 0.081 & 0.028 & 0.014 & 0.033 & 0.028 & 6.354 & 3.568 & 2.197 & 3.122 & 76.369 & 39.232 \\
\hline 8 & 0.134 & 0.073 & 0.025 & 0.012 & 0.03 & 0.028 & 6.796 & 3.556 & 2.255 & 3.188 & 75.015 & 40.697 \\
\hline 9 & 0.136 & 0.087 & 0.028 & 0.015 & 0.039 & 0.04 & 7.089 & 3.487 & 2.253 & 3.582 & 74.378 & 41.524 \\
\hline 10 & 0.14 & 0.081 & 0.026 & 0.013 & 0.036 & 0.032 & 7.159 & 3.39 & 2.226 & 3.43 & 74.63 & 40.809 \\
\hline 11 & 0.14 & 0.07 & 0.021 & 0.011 & 0.028 & 0.025 & 7.025 & 3.24 & 2.147 & 3.495 & 74.365 & 40.434 \\
\hline 12 & 0.148 & 0.076 & 0.024 & 0.012 & 0.031 & 0.026 & 6.804 & 3.716 & 2.281 & 3.318 & 74.625 & 39.972 \\
\hline 13 & 0.139 & 0.073 & 0.022 & 0.011 & 0.026 & 0.025 & 7.096 & 3.562 & 2.3 & 3.467 & 74.143 & 40.606 \\
\hline 14 & 0.143 & 0.083 & 0.028 & 0.014 & 0.033 & 0.027 & 6.948 & 3.737 & 2.349 & 3.333 & 74.987 & 40.206 \\
\hline 15 & 0.138 & 0.084 & 0.031 & 0.016 & 0.035 & 0.028 & 6.066 & 3.208 & 2.05 & 3 & 76.677 & 39.033 \\
\hline 16 & 0.139 & 0.086 & 0.03 & 0.013 & 0.027 & 0.022 & 7.472 & 4.658 & 2.794 & 3.149 & 75.181 & 38.515 \\
\hline 17 & 0.128 & 0.082 & 0.029 & 0.015 & 0.03 & 0.028 & 6.926 & 3.922 & 2.441 & 3.087 & 75.92 & 39.034 \\
\hline 18 & 0.134 & 0.079 & 0.027 & 0.013 & 0.031 & 0.028 & 6.698 & 3.146 & 2.097 & 3.221 & 75.471 & 39.191 \\
\hline 19 & 0.138 & 0.077 & 0.026 & 0.013 & 0.029 & 0.023 & 6.475 & 3.299 & 2.136 & 3.106 & 75.769 & 39.031 \\
\hline 20 & 0.138 & 0.08 & 0.031 & 0.018 & 0.038 & 0.034 & 5.887 & 3.338 & 2.074 & 3.036 & 76.002 & 39.597 \\
\hline 21 & 0.131 & 0.076 & 0.029 & 0.016 & 0.038 & 0.031 & 5.932 & 3.463 & 2.117 & 2.996 & 76.554 & 41.447 \\
\hline 22 & 0.139 & 0.073 & 0.028 & 0.015 & 0.032 & 0.027 & 6.441 & 3.412 & 2.193 & 3.231 & 76.011 & 38.774 \\
\hline 23 & 0.135 & 0.073 & 0.026 & 0.014 & 0.032 & 0.028 & 5.741 & 2.956 & 1.919 & 3.073 & 74.782 & 40.507 \\
\hline 24 & 0.146 & 0.079 & 0.025 & 0.013 & 0.03 & 0.03 & 6.864 & 3.626 & 2.314 & 3.427 & 76.025 & 41.262 \\
\hline 25 & 0.147 & 0.076 & 0.028 & 0.014 & 0.033 & 0.032 & 7.019 & 4.561 & 2.676 & 3.221 & 75.415 & 40.442 \\
\hline
\end{tabular}


TABLE XIV

RAW DATA FOR SESSION 9

\begin{tabular}{|c|c|c|c|c|c|c|c|c|c|c|c|c|}
\hline Minute & $\begin{array}{l}\text { Delta } \\
\text { Relative } \\
\text { Power }\end{array}$ & $\begin{array}{l}\text { Theta } \\
\text { Relative } \\
\text { Power }\end{array}$ & $\begin{array}{l}\text { Alpha } \\
\text { Relative } \\
\text { Power }\end{array}$ & $\begin{array}{c}\text { Low Beta } \\
\text { Relative } \\
\text { Power }\end{array}$ & $\begin{array}{l}\text { High Beta } \\
\text { Relative } \\
\text { Power }\end{array}$ & $\begin{array}{c}\text { Gamma } \\
\text { Relative } \\
\text { Power }\end{array}$ & $\begin{array}{l}\text { Theta/ } \\
\text { Low Beta } \\
\text { Ratio }\end{array}$ & $\begin{array}{l}\text { Theta/ } \\
\text { High Beta } \\
\text { Ratio }\end{array}$ & $\begin{array}{l}\text { Theta/ } \\
\text { Beta Ratio }\end{array}$ & $\begin{array}{l}\text { Theta/ } \\
\text { Alpha } \\
\text { Ratio }\end{array}$ & "Focus" & "Alertness" \\
\hline 1 & 0.15 & 0.092 & 0.03 & 0.013 & 0.025 & 0.024 & 7.586 & 4.712 & 2.854 & 3.345 & 73.691 & 36.066 \\
\hline 2 & 0.149 & 0.093 & 0.034 & 0.019 & 0.034 & 0.033 & 6.18 & 3.952 & 2.337 & 3.169 & 73.835 & 37.678 \\
\hline 3 & 0.145 & 0.091 & 0.032 & 0.017 & 0.03 & 0.029 & 6.027 & 3.563 & 2.164 & 3.186 & 75.605 & 37.669 \\
\hline 4 & 0.145 & 0.091 & 0.033 & 0.017 & 0.031 & 0.029 & 6.121 & 3.666 & 2.221 & 3.156 & 74.44 & 38.222 \\
\hline 5 & 0.135 & 0.101 & 0.041 & 0.021 & 0.043 & 0.039 & 5.595 & 3.239 & 1.992 & 2.896 & 74.53 & 38.177 \\
\hline 6 & 0.132 & 0.098 & 0.043 & 0.022 & 0.04 & 0.035 & 5.377 & 3.203 & 1.959 & 2.68 & 74.972 & 37.909 \\
\hline 7 & 0.133 & 0.096 & 0.04 & 0.02 & 0.035 & 0.034 & 5.557 & 3.202 & 1.992 & 2.804 & 75.475 & 38.897 \\
\hline 8 & 0.134 & 0.1 & 0.042 & 0.023 & 0.045 & 0.051 & 5.632 & 3.203 & 1.989 & 3.01 & 74.718 & 38.917 \\
\hline 9 & 0.13 & 0.085 & 0.032 & 0.018 & 0.042 & 0.04 & 5.901 & 3.267 & 2.068 & 2.973 & 75.289 & 38.38 \\
\hline 10 & 0.138 & 0.084 & 0.028 & 0.015 & 0.038 & 0.036 & 6.333 & 3.28 & 2.12 & 3.228 & 74.886 & 38.929 \\
\hline 11 & 0.124 & 0.082 & 0.033 & 0.02 & 0.043 & 0.039 & 5.41 & 2.805 & 1.816 & 2.752 & 75.933 & 39.897 \\
\hline 12 & 0.132 & 0.084 & 0.033 & 0.02 & 0.041 & 0.035 & 5.526 & 3.158 & 1.97 & 2.796 & 75.639 & 39.531 \\
\hline 13 & 0.133 & 0.089 & 0.034 & 0.021 & 0.046 & 0.043 & 5.527 & 3.008 & 1.898 & 2.858 & 75.41 & 39.187 \\
\hline 14 & 0.134 & 0.087 & 0.032 & 0.019 & 0.042 & 0.041 & 5.866 & 3.462 & 2.114 & 3.011 & 75.612 & 38.895 \\
\hline 15 & 0.127 & 0.081 & 0.029 & 0.018 & 0.039 & 0.039 & 5.388 & 2.919 & 1.856 & 2.969 & 76.096 & 39.199 \\
\hline 16 & 0.143 & 0.083 & 0.03 & 0.019 & 0.048 & 0.049 & 6.196 & 3.377 & 2.127 & 3.154 & 75.796 & 39.286 \\
\hline 17 & 0.133 & 0.086 & 0.035 & 0.019 & 0.047 & 0.042 & 5.926 & 3.301 & 2.039 & 3.045 & 75.801 & 38.165 \\
\hline 18 & 0.129 & 0.071 & 0.026 & 0.015 & 0.031 & 0.028 & 6.122 & 3.22 & 2.058 & 3.074 & 76.309 & 37.985 \\
\hline 19 & 0.126 & 0.078 & 0.032 & 0.019 & 0.041 & 0.036 & 5.748 & 3.05 & 1.95 & 2.87 & 76.242 & 38.135 \\
\hline 20 & 0.131 & 0.078 & 0.034 & 0.017 & 0.033 & 0.028 & 5.98 & 3.246 & 2.079 & 2.874 & 76.121 & 37.865 \\
\hline 21 & 0.137 & 0.099 & 0.032 & 0.017 & 0.033 & 0.028 & 7.288 & 4.635 & 2.779 & 3.358 & 75.939 & 38.393 \\
\hline 22 & 0.131 & 0.081 & 0.033 & 0.017 & 0.037 & 0.032 & 5.946 & 3.228 & 2.061 & 2.839 & 77.192 & 38.635 \\
\hline 23 & 0.136 & 0.084 & 0.034 & 0.02 & 0.05 & 0.05 & 6.103 & 3.314 & 2.108 & 2.975 & 76.434 & 38.973 \\
\hline 24 & 0.129 & 0.084 & 0.032 & 0.02 & 0.047 & 0.047 & 5.926 & 3.247 & 2.061 & 3.08 & 74.686 & 38.132 \\
\hline 25 & 0.136 & 0.08 & 0.031 & 0.018 & 0.044 & 0.04 & 6.085 & 3.059 & 2.011 & 3.04 & 75.696 & 38.676 \\
\hline
\end{tabular}


TABLE XV

RAW DATA FOR SESSION 10

\begin{tabular}{|c|c|c|c|c|c|c|c|c|c|c|c|c|}
\hline Minute & $\begin{array}{l}\text { Delta } \\
\text { Relative } \\
\text { Power }\end{array}$ & $\begin{array}{l}\text { Theta } \\
\text { Relative } \\
\text { Power }\end{array}$ & $\begin{array}{l}\text { Alpha } \\
\text { Relative } \\
\text { Power }\end{array}$ & $\begin{array}{c}\text { Low Beta } \\
\text { Relative } \\
\text { Power }\end{array}$ & $\begin{array}{l}\text { High Beta } \\
\text { Relative } \\
\text { Power }\end{array}$ & $\begin{array}{c}\text { Gamma } \\
\text { Relative } \\
\text { Power }\end{array}$ & $\begin{array}{l}\text { Theta/ Low } \\
\text { Beta Ratio }\end{array}$ & $\begin{array}{l}\text { Theta/ } \\
\text { High Beta } \\
\text { Ratio }\end{array}$ & $\begin{array}{c}\text { Theta/ Beta } \\
\text { Ratio }\end{array}$ & $\begin{array}{l}\text { Theta/ } \\
\text { Alpha } \\
\text { Ratio }\end{array}$ & "Focus" & "Alertness" \\
\hline 1 & 0.137 & 0.088 & 0.029 & 0.014 & 0.024 & 0.028 & 7.46 & 5.052 & 2.936 & 3.33 & 74.341 & 34.761 \\
\hline 2 & 0.133 & 0.078 & 0.035 & 0.012 & 0.022 & 0.024 & 7.186 & 4.601 & 2.778 & 3.068 & 73.64 & 36.375 \\
\hline 3 & 0.128 & 0.092 & 0.034 & 0.017 & 0.038 & 0.035 & 6.622 & 3.964 & 2.419 & 3.062 & 75.155 & 37.737 \\
\hline 4 & 0.128 & 0.085 & 0.032 & 0.016 & 0.036 & 0.033 & 6.189 & 3.627 & 2.238 & 3.05 & 75.42 & 38.159 \\
\hline 5 & 0.12 & 0.081 & 0.028 & 0.015 & 0.031 & 0.032 & 6.086 & 3.413 & 2.158 & 2.956 & 75.031 & 37.754 \\
\hline 6 & 0.14 & 0.095 & 0.033 & 0.017 & 0.031 & 0.028 & 6.52 & 3.896 & 2.382 & 3.057 & 74.71 & 37.738 \\
\hline 7 & 0.138 & 0.088 & 0.034 & 0.016 & 0.032 & 0.028 & 6.066 & 3.67 & 2.222 & 3.052 & 75.427 & 38.281 \\
\hline 8 & 0.122 & 0.076 & 0.028 & 0.014 & 0.032 & 0.034 & 6.094 & 3.009 & 1.982 & 2.993 & 74.714 & 38.244 \\
\hline 9 & 0.131 & 0.083 & 0.029 & 0.015 & 0.03 & 0.03 & 6.325 & 3.539 & 2.204 & 3.065 & 74.831 & 37.76 \\
\hline 10 & 0.139 & 0.09 & 0.03 & 0.015 & 0.029 & 0.027 & 6.557 & 4.068 & 2.426 & 3.136 & 75.565 & 38.257 \\
\hline 11 & 0.13 & 0.086 & 0.03 & 0.015 & 0.032 & 0.029 & 6.288 & 3.804 & 2.287 & 3.205 & 75.937 & 38.762 \\
\hline 12 & 0.131 & 0.088 & 0.033 & 0.017 & 0.038 & 0.038 & 6.114 & 3.353 & 2.104 & 2.952 & 75.24 & 38.007 \\
\hline 13 & 0.133 & 0.086 & 0.029 & 0.015 & 0.031 & 0.028 & 6.567 & 4.075 & 2.43 & 3.22 & 74.864 & 37.519 \\
\hline 14 & 0.128 & 0.083 & 0.032 & 0.015 & 0.032 & 0.035 & 6.762 & 4.116 & 2.503 & 2.999 & 75.226 & 37.231 \\
\hline 15 & 0.133 & 0.081 & 0.03 & 0.015 & 0.031 & 0.028 & 6.253 & 3.551 & 2.188 & 2.948 & 74.854 & 38.923 \\
\hline 16 & 0.129 & 0.087 & 0.035 & 0.018 & 0.039 & 0.036 & 6.042 & 3.601 & 2.189 & 2.874 & 76.314 & 39.037 \\
\hline 17 & 0.124 & 0.087 & 0.031 & 0.016 & 0.034 & 0.031 & 6.339 & 3.889 & 2.355 & 2.986 & 75.691 & 38.261 \\
\hline 18 & 0.131 & 0.085 & 0.026 & 0.014 & 0.027 & 0.022 & 7.431 & 4.601 & 2.744 & 3.434 & 75.737 & 37.944 \\
\hline 19 & 0.127 & 0.089 & 0.032 & 0.017 & 0.035 & 0.034 & 6.348 & 4.054 & 2.425 & 3.02 & 75.267 & 38.763 \\
\hline 20 & 0.146 & 0.101 & 0.085 & 0.049 & 0.112 & 0.097 & 6.056 & 3.541 & 2.182 & 2.928 & 75.586 & 38.693 \\
\hline 21 & 0.137 & 0.096 & 0.071 & 0.042 & 0.094 & 0.085 & 6.32 & 3.882 & 2.346 & 3.158 & 76.042 & 37.917 \\
\hline 22 & 0.146 & 0.103 & 0.095 & 0.053 & 0.12 & 0.101 & 6.627 & 4.141 & 2.509 & 3.107 & 74.892 & 36.537 \\
\hline 23 & 0.131 & 0.077 & 0.028 & 0.014 & 0.028 & 0.025 & 6.607 & 4.092 & 2.434 & 2.983 & 74.993 & 37.768 \\
\hline 24 & 0.132 & 0.085 & 0.028 & 0.015 & 0.03 & 0.029 & 6.69 & 3.693 & 2.352 & 3.15 & 75.435 & 37.654 \\
\hline 25 & 0.123 & 0.072 & 0.026 & 0.014 & 0.029 & 0.025 & 6.783 & 3.877 & 2.4 & 3.228 & 74.483 & 37.552 \\
\hline
\end{tabular}


TABLE XVI

RAW DATA FOR SESSION 11

\begin{tabular}{|c|c|c|c|c|c|c|c|c|c|c|c|c|}
\hline Minute & $\begin{array}{l}\text { Delta } \\
\text { Relative } \\
\text { Power }\end{array}$ & $\begin{array}{l}\text { Theta } \\
\text { Relative } \\
\text { Power }\end{array}$ & $\begin{array}{l}\text { Alpha } \\
\text { Relative } \\
\text { Power }\end{array}$ & $\begin{array}{c}\text { Low Beta } \\
\text { Relative } \\
\text { Power }\end{array}$ & $\begin{array}{l}\text { High Beta } \\
\text { Relative } \\
\text { Power }\end{array}$ & $\begin{array}{c}\text { Gamma } \\
\text { Relative } \\
\text { Power }\end{array}$ & $\begin{array}{l}\text { Theta/ Low } \\
\text { Beta Ratio }\end{array}$ & $\begin{array}{l}\text { Theta/ } \\
\text { High Beta } \\
\text { Ratio }\end{array}$ & $\begin{array}{c}\text { Theta/ Beta } \\
\text { Ratio }\end{array}$ & $\begin{array}{l}\text { Theta/ } \\
\text { Alpha } \\
\text { Ratio }\end{array}$ & "Focus" & "Alertness" \\
\hline 1 & 0.164 & 0.089 & 0.031 & 0.015 & 0.027 & 0.022 & 6.803 & 4.66 & 2.698 & 3.141 & 74.025 & 34.773 \\
\hline 2 & 0.14 & 0.081 & 0.026 & 0.014 & 0.031 & 0.031 & 7.446 & 4.822 & 2.84 & 3.502 & 73.925 & 37.519 \\
\hline 3 & 0.136 & 0.075 & 0.026 & 0.013 & 0.031 & 0.029 & 6.67 & 3.921 & 2.394 & 3.299 & 74.799 & 39.197 \\
\hline 4 & 0.157 & 0.083 & 0.027 & 0.014 & 0.03 & 0.028 & 7.358 & 4.037 & 2.542 & 3.509 & 74.649 & 39.11 \\
\hline 5 & 0.148 & 0.086 & 0.026 & 0.014 & 0.029 & 0.028 & 7.179 & 4.094 & 2.51 & 3.38 & 74.358 & 38.859 \\
\hline 6 & 0.142 & 0.078 & 0.025 & 0.013 & 0.03 & 0.026 & 6.841 & 3.496 & 2.26 & 3.424 & 75.455 & 39.009 \\
\hline 7 & 0.132 & 0.085 & 0.026 & 0.014 & 0.036 & 0.033 & 6.938 & 3.247 & 2.134 & 3.543 & 73.967 & 38.914 \\
\hline 8 & 0.143 & 0.08 & 0.025 & 0.014 & 0.037 & 0.034 & 6.68 & 3.26 & 2.092 & 3.587 & 75.452 & 38.707 \\
\hline 9 & 0.141 & 0.079 & 0.022 & 0.011 & 0.025 & 0.025 & 7.711 & 4.102 & 2.623 & 3.814 & 75.727 & 36.127 \\
\hline 10 & 0.141 & 0.077 & 0.022 & 0.011 & 0.024 & 0.025 & 7.618 & 4.037 & 2.572 & 3.652 & 76.038 & 36.539 \\
\hline 11 & 0.137 & 0.072 & 0.022 & 0.012 & 0.03 & 0.034 & 7.546 & 3.874 & 2.519 & 3.715 & 76.735 & 36.883 \\
\hline 12 & 0.137 & 0.072 & 0.023 & 0.012 & 0.029 & 0.031 & 7.396 & 3.345 & 2.252 & 3.466 & 76.695 & 37.787 \\
\hline 13 & 0.136 & 0.077 & 0.025 & 0.014 & 0.035 & 0.037 & 7.053 & 3.268 & 2.195 & 3.443 & 76.798 & 37.696 \\
\hline 14 & 0.134 & 0.073 & 0.025 & 0.013 & 0.031 & 0.033 & 6.838 & 3.518 & 2.284 & 3.425 & 77.363 & 36.802 \\
\hline 15 & 0.132 & 0.073 & 0.026 & 0.014 & 0.033 & 0.033 & 6.61 & 3.805 & 2.374 & 3.286 & 78.498 & 37.545 \\
\hline 16 & 0.129 & 0.073 & 0.026 & 0.014 & 0.034 & 0.035 & 6.292 & 3.354 & 2.147 & 3.178 & 77.522 & 37.317 \\
\hline 17 & 0.135 & 0.076 & 0.027 & 0.014 & 0.036 & 0.038 & 6.081 & 3.318 & 2.07 & 2.954 & 75.218 & 38.298 \\
\hline 18 & 0.136 & 0.078 & 0.027 & 0.016 & 0.035 & 0.04 & 5.668 & 3.235 & 2.001 & 3.076 & 75.253 & 38.338 \\
\hline 19 & 0.141 & 0.084 & 0.031 & 0.018 & 0.041 & 0.041 & 5.838 & 3.22 & 2.028 & 3.059 & 76.636 & 39.676 \\
\hline 20 & 0.14 & 0.078 & 0.025 & 0.014 & 0.034 & 0.045 & 7.626 & 4.653 & 2.833 & 3.493 & 74.279 & 37.926 \\
\hline 21 & 0.14 & 0.076 & 0.027 & 0.017 & 0.032 & 0.029 & 5.47 & 2.845 & 1.831 & 3.077 & 73.256 & 39.237 \\
\hline 22 & 0.142 & 0.072 & 0.028 & 0.014 & 0.029 & 0.029 & 5.872 & 3.304 & 2.052 & 2.897 & 76.213 & 36.81 \\
\hline 23 & 0.137 & 0.071 & 0.023 & 0.012 & 0.026 & 0.025 & 6.194 & 3.171 & 2.077 & 3.347 & 75.702 & 36.689 \\
\hline 24 & 0.134 & 0.073 & 0.026 & 0.014 & 0.03 & 0.033 & 5.532 & 3.214 & 1.976 & 2.932 & 75.832 & 40.381 \\
\hline 25 & 0.128 & 0.073 & 0.025 & 0.014 & 0.032 & 0.032 & 5.707 & 2.899 & 1.893 & 3.046 & 75.309 & 39.848 \\
\hline
\end{tabular}




\section{TABLE XVII}

RAW DATA FOR SESSION 12

\begin{tabular}{|c|c|c|c|c|c|c|c|c|c|c|c|c|}
\hline Minute & $\begin{array}{l}\text { Delta } \\
\text { Relative } \\
\text { Power }\end{array}$ & $\begin{array}{l}\text { Theta } \\
\text { Relative } \\
\text { Power }\end{array}$ & $\begin{array}{l}\text { Alpha } \\
\text { Relative } \\
\text { Power }\end{array}$ & $\begin{array}{l}\text { Low Beta } \\
\text { Relative } \\
\text { Power }\end{array}$ & $\begin{array}{l}\text { High Beta } \\
\text { Relative } \\
\text { Power }\end{array}$ & $\begin{array}{l}\text { Gamma } \\
\text { Relative } \\
\text { Power }\end{array}$ & $\begin{array}{l}\text { Theta/ Low } \\
\text { Beta Ratio }\end{array}$ & $\begin{array}{l}\text { Theta/ } \\
\text { High Beta } \\
\text { Ratio }\end{array}$ & $\begin{array}{c}\text { Theta/ Beta } \\
\text { Ratio }\end{array}$ & $\begin{array}{l}\text { Theta/ } \\
\text { Alpha } \\
\text { Ratio }\end{array}$ & "Focus" & "Alertness" \\
\hline 1 & 0.139 & 0.094 & 0.032 & 0.013 & 0.022 & 0.02 & 7.946 & 5.649 & 3.198 & 3.163 & 73.05 & 35.957 \\
\hline 2 & 0.141 & 0.078 & 0.026 & 0.012 & 0.025 & 0.025 & 7.371 & 5.349 & 3.033 & 3.225 & 73.601 & 37.421 \\
\hline 3 & 0.127 & 0.076 & 0.031 & 0.016 & 0.038 & 0.04 & 6.745 & 3.96 & 2.446 & 2.856 & 75.182 & 38.424 \\
\hline 4 & 0.135 & 0.08 & 0.029 & 0.015 & 0.042 & 0.043 & 7.623 & 4.305 & 2.675 & 3.265 & 74.866 & 38.131 \\
\hline 5 & 0.13 & 0.077 & 0.03 & 0.016 & 0.047 & 0.041 & 6.472 & 3.44 & 2.189 & 2.999 & 76.354 & 38.984 \\
\hline 6 & 0.125 & 0.073 & 0.028 & 0.016 & 0.046 & 0.044 & 6.693 & 3.928 & 2.41 & 3.186 & 76.394 & 37.611 \\
\hline 7 & 0.133 & 0.081 & 0.029 & 0.015 & 0.041 & 0.038 & 10.4 & 6.774 & 4.022 & 3.564 & 76.236 & 37.986 \\
\hline 8 & 0.139 & 0.082 & 0.025 & 0.013 & 0.035 & 0.03 & 7.743 & 4.099 & 2.616 & 3.549 & 76.331 & 37.577 \\
\hline 9 & 0.129 & 0.076 & 0.029 & 0.016 & 0.042 & 0.036 & 6.692 & 3.426 & 2.208 & 3.024 & 77.845 & 35.372 \\
\hline 10 & 0.132 & 0.073 & 0.029 & 0.015 & 0.041 & 0.034 & 6.727 & 4.166 & 2.467 & 3.129 & 77.134 & 36.59 \\
\hline 11 & 0.131 & 0.091 & 0.034 & 0.016 & 0.038 & 0.035 & 7.694 & 4.46 & 2.726 & 3.143 & 78.148 & 36.715 \\
\hline 12 & 0.128 & 0.087 & 0.043 & 0.031 & 0.08 & 0.093 & 6.309 & 3.488 & 2.167 & 3.086 & 77.634 & 37.735 \\
\hline 13 & 0.148 & 0.093 & 0.046 & 0.031 & 0.076 & 0.078 & 6.972 & 4.833 & 2.672 & 3.454 & 76.471 & 36.781 \\
\hline 14 & 0.155 & 0.105 & 0.069 & 0.04 & 0.096 & 0.093 & 7.679 & 5.611 & 3.076 & 3.333 & 77.645 & 35.519 \\
\hline 15 & 0.14 & 0.103 & 0.073 & 0.042 & 0.099 & 0.091 & 6.38 & 4.256 & 2.446 & 2.972 & 77.604 & 35.658 \\
\hline 16 & 0.14 & 0.101 & 0.078 & 0.045 & 0.106 & 0.093 & 6.632 & 4.04 & 2.416 & 3.045 & 77.622 & 35.468 \\
\hline 17 & 0.125 & 0.083 & 0.03 & 0.017 & 0.037 & 0.033 & 6.506 & 3.864 & 2.312 & 3.109 & 76.593 & 37.175 \\
\hline 18 & 0.133 & 0.08 & 0.029 & 0.018 & 0.04 & 0.041 & 5.923 & 3.231 & 2.009 & 3.021 & 75.893 & 38.992 \\
\hline 19 & 0.132 & 0.082 & 0.03 & 0.016 & 0.038 & 0.038 & 6.307 & 3.143 & 2.046 & 3.071 & 76.47 & 36.614 \\
\hline 20 & 0.129 & 0.084 & 0.028 & 0.015 & 0.031 & 0.028 & 6.941 & 4.228 & 2.525 & 3.201 & 76.996 & 35.567 \\
\hline 21 & 0.133 & 0.082 & 0.034 & 0.018 & 0.037 & 0.029 & 5.93 & 3.938 & 2.254 & 2.785 & 77.621 & 36.189 \\
\hline 22 & 0.118 & 0.09 & 0.037 & 0.019 & 0.045 & 0.042 & 6.499 & 4.003 & 2.332 & 2.921 & 76.569 & 35.314 \\
\hline 23 & 0.116 & 0.081 & 0.031 & 0.017 & 0.041 & 0.035 & 6.039 & 3.736 & 2.202 & 2.914 & 77.594 & 36.076 \\
\hline 24 & 0.127 & 0.095 & 0.035 & 0.019 & 0.041 & 0.036 & 7.005 & 4.408 & 2.591 & 3.418 & 76.396 & 37.127 \\
\hline 25 & 0.119 & 0.088 & 0.04 & 0.019 & 0.041 & 0.036 & 6.375 & 4.188 & 2.407 & 2.837 & 75.538 & 37.68 \\
\hline
\end{tabular}


B. T-test Results for ABC and IVA+Plus Measures

TABLE XVIII

SUMMARY OF ABC T-TEST

\begin{tabular}{|c|c|c|c|c|c|c|c|c|}
\hline & \multicolumn{9}{|c|}{$\begin{array}{c}\text { Paired } \\
\text { Measure }\end{array}$} & df & Mean & $\begin{array}{c}\text { Standard } \\
\text { Deviation }\end{array}$ & $\begin{array}{c}\text { Standard } \\
\text { Error } \\
\text { Mean }\end{array}$ & $\begin{array}{c}\text { 95\% Confidence } \\
\text { Interval of the } \\
\text { Difference }\end{array}$ & $\begin{array}{c}\text { t- } \\
\text { statistic }\end{array}$ & p-value \\
\cline { 6 - 9 } & & & & & Lower & Upper & \\
\hline Irritability & 17 & 3.330 & 3.926 & 0.925 & 1.381 & 5.286 & 3.602 & 0.002 \\
\hline Lethargy & 17 & 4.056 & 7.272 & 1.714 & 0.439 & 7.672 & 2.366 & 0.030 \\
\hline Stereotypy & 17 & 1.333 & 2.249 & 0.530 & 0.215 & 2.452 & 2.515 & 0.022 \\
\hline Hyperactivity & 17 & 4.444 & 5.913 & 1.394 & 1.504 & 7.385 & 3.189 & 0.005 \\
\hline $\begin{array}{c}\text { Inappropriate } \\
\text { Speech }\end{array}$ & 17 & 1.000 & 0.907 & 0.214 & 0.549 & 1.451 & 4.675 & 0.000 \\
\hline
\end{tabular}


TABLE XIX

SUMMARY OF IVA+PLUS T-TEST

\begin{tabular}{|c|c|c|c|c|c|c|c|c|}
\hline \multirow{3}{*}{$\begin{array}{c}\text { Paired } \\
\text { Measure }\end{array}$} & \multicolumn{8}{|c|}{ Paired Differences } \\
\hline & \multirow[t]{2}{*}{ df } & \multirow[t]{2}{*}{ Mean } & \multirow[t]{2}{*}{$\begin{array}{l}\text { Standard } \\
\text { Deviation }\end{array}$} & \multirow{2}{*}{$\begin{array}{c}\text { Standard } \\
\text { Error } \\
\text { Mean }\end{array}$} & \multicolumn{2}{|c|}{$\begin{array}{l}\text { 95\% Confidence } \\
\text { Interval of the } \\
\text { Difference }\end{array}$} & \multirow[t]{2}{*}{ t-statistic } & \multirow[t]{2}{*}{ p-value } \\
\hline & & & & & Lower & Upper & & \\
\hline $\begin{array}{c}\text { Response } \\
\text { Control } \\
\text { Quotient }\end{array}$ & 17 & -2.5 & 25.025 & 5.899 & -14.945 & 9.945 & -0.424 & 0.677 \\
\hline $\begin{array}{l}\text { Response } \\
\text { Control } \\
\text { Quotient } \\
\text { Auditory }\end{array}$ & 17 & -5.788 & 22.972 & 5.415 & -17.201 & 5.646 & -1.067 & 0.301 \\
\hline $\begin{array}{c}\text { Response } \\
\text { Control } \\
\text { Quotient } \\
\text { Visual }\end{array}$ & 17 & 1.444 & 24.181 & 5.7 & -10.581 & 13.469 & 0.253 & 0.803 \\
\hline $\begin{array}{c}\text { Attention } \\
\text { Quotient }\end{array}$ & 17 & -9.222 & 15.187 & 3.58 & -16.775 & -1.67 & -2.576 & $0.02^{*}$ \\
\hline $\begin{array}{l}\text { Attention } \\
\text { Quotient } \\
\text { Auditory }\end{array}$ & 17 & -8.667 & 18.279 & 4.308 & -17.757 & 0.423 & -2.012 & 0.06 \\
\hline $\begin{array}{c}\text { Attention } \\
\text { Quotient } \\
\text { Visual }\end{array}$ & 17 & -8 & 14.852 & 3.501 & -15.386 & -0.614 & -2.285 & $0.035^{*}$ \\
\hline $\begin{array}{l}\text { Sustained } \\
\text { Auditory } \\
\text { Attention } \\
\text { Quotient }\end{array}$ & 17 & -13.278 & 28.042 & 6.609 & -27.223 & 0.667 & -2.009 & 0.061 \\
\hline $\begin{array}{l}\text { Sustained } \\
\text { Visual } \\
\text { Attention } \\
\text { Quotient }\end{array}$ & 17 & -14.389 & 22.432 & 5.287 & -25.544 & -3.234 & -2.721 & $0.015^{*}$ \\
\hline $\begin{array}{c}\text { Auditory } \\
\text { Reaction } \\
\text { Time }\end{array}$ & 17 & 36.556 & 85.614 & 20.179 & -6.019 & 79.13 & 1.812 & $0.088 *$ \\
\hline $\begin{array}{c}\text { Visual } \\
\text { Reaction } \\
\text { Time }\end{array}$ & 17 & 21.833 & 38.938 & 9.178 & 2.47 & 41.197 & 2.379 & $0.029 *$ \\
\hline
\end{tabular}

*indicates $\mathrm{p}<0.05$ 


\section{MiniTab ANOVA Output and Pearson Correlation Test Output}




$\begin{array}{lrrrrrr}\text { Analysis of Variance for HighBeta, using Adjusted SS for Test } & \\ \text { Source } & \text { DF } & \text { Seq SS } & \text { Adj SS } & \text { Adj MS } & \text { F } & \text { P } \\ \text { Minute } & 24 & 0.0079419 & 0.0079419 & 0.0003309 & 1.58 & 0.045 \\ \text { Session } & 11 & 0.0130759 & 0.0130759 & 0.0011887 & 5.67 & 0.000 \\ \text { Error } & 264 & 0.0553263 & 0.0553263 & 0.0002096 & & \\ \text { Total } & 299 & 0.0763442 & & & & \\ & \\ \text { S }=0.0144765 & \text { R-Sq }=27.53 \% & \text { R-Sq }(\text { adj })=17.92 \% & \end{array}$

Analysis of Variance for Gamma, using Adjusted SS for Tests

$\begin{array}{lrrrrrr}\text { Source } & \text { DF } & \text { Seq SS } & \text { Adj SS } & \text { Adj MS } & \text { F } & \text { P } \\ \text { Minute } & 24 & 0.0083055 & 0.0083055 & 0.0003461 & 1.66 & 0.029 \\ \text { Session } & 11 & 0.0136444 & 0.0136444 & 0.0012404 & 5.97 & 0.000 \\ \text { Error } & 264 & 0.0548972 & 0.0548972 & 0.0002079 & & \\ \text { Total } & 299 & 0.0768471 & & & & \\ & \\ \text { S }=0.0144203 & \text { R-Sq }=28.56 \% & \text { R-Sq (adj) }=19.09 \% & \end{array}$

Analysis of Variance for T/LB, using Adjusted SS for Tests

$\begin{array}{lrrrrrr}\text { Source } & \text { DF } & \text { Seq SS } & \text { Adj SS } & \text { Adj MS } & \text { F } & \text { P } \\ \text { Minute } & 24 & 18.7700 & 18.7700 & 0.7821 & 2.12 & 0.002 \\ \text { Session } & 11 & 36.5648 & 36.5648 & 3.3241 & 9.02 & 0.000 \\ \text { Error } & 264 & 97.2409 & 97.2409 & 0.3683 & & \\ \text { Total } & 299 & 152.5757 & & & & \\ & \\ S=0.606908 & \text { R-Sq }=36.27 \% & R-S q(\text { adj })=27.82 \%\end{array}$

Analysis of Variance for $T / H B$, using Adjusted SS for Tests

$\begin{array}{lrrrrrr}\text { Source } & \text { DF } & \text { Seq SS } & \text { Adj SS } & \text { Adj MS } & F & P \\ \text { Minute } & 24 & 36.3625 & 36.3625 & 1.5151 & 6.11 & 0.000 \\ \text { Session } & 11 & 20.8368 & 20.8368 & 1.8943 & 7.64 & 0.000 \\ \text { Error } & 264 & 65.4268 & 65.4268 & 0.2478 & & \\ \text { Total } & 299 & 122.6260 & & & & \\ & \\ \text { S }=0.497824 & \text { R-Sq }=46.65 \% & R-S q(\operatorname{adj}) & =39.57 \%\end{array}$

Analysis of Variance for T/B, using Adjusted SS for Tests

$\begin{array}{lrrrrrr}\text { Source } & \text { DF } & \text { Seq SS } & \text { Adj SS } & \text { Adj MS } & \text { F } & \text { P } \\ \text { Minute } & 24 & 8.10683 & 8.10683 & 0.33778 & 4.82 & 0.000 \\ \text { Session } & 11 & 5.77449 & 5.77449 & 0.52495 & 7.49 & 0.000 \\ \text { Error } & 264 & 18.50584 & 18.50584 & 0.07010 & & \\ \text { Total } & 299 & 32.38715 & & & & \\ & \\ \text { S }=0.264760 & \text { R-Sq }=42.86 \% & R-S q(\operatorname{adj})=35.29 \%\end{array}$




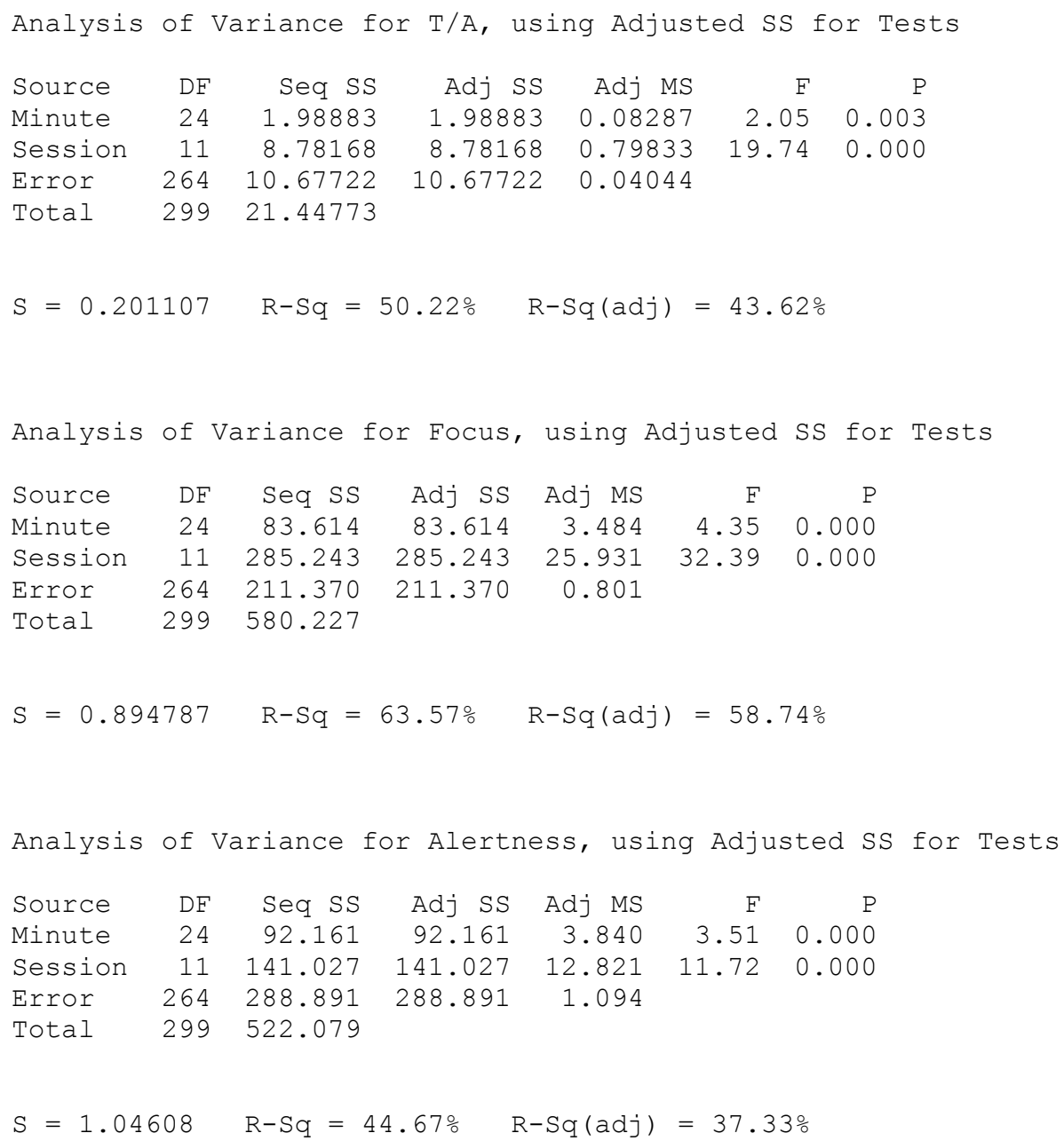




\section{Pearson Correlation Output}

\begin{tabular}{|c|c|c|c|c|c|c|c|c|}
\hline $\mathrm{T} / \mathrm{A}$ & $\begin{array}{r}\text { Focus } \\
-0.676 \\
0.000\end{array}$ & $\mathrm{~T} / \mathrm{A}$ & $\mathrm{T} / \mathrm{B}$ & $\mathrm{T} / \mathrm{LB}$ & $\mathrm{T} / \mathrm{HB}$ & A & LB & $\mathrm{HB}$ \\
\hline $\mathrm{T} / \mathrm{B}$ & $\begin{array}{r}-0.612 \\
0.000\end{array}$ & $\begin{array}{l}0.600 \\
0.000\end{array}$ & & & & & & \\
\hline $\mathrm{T} / \mathrm{LB}$ & $\begin{array}{r}-0.633 \\
0.000\end{array}$ & $\begin{array}{l}0.828 \\
0.000\end{array}$ & $\begin{array}{l}0.896 \\
0.000\end{array}$ & & & & & \\
\hline $\mathrm{T} / \mathrm{HB}$ & $\begin{array}{r}-0.577 \\
0.000\end{array}$ & $\begin{array}{l}0.523 \\
0.001\end{array}$ & $\begin{array}{l}0.993 \\
0.000\end{array}$ & $\begin{array}{l}0.843 \\
0.000\end{array}$ & & & & \\
\hline A & $\begin{array}{l}0.444 \\
0.006\end{array}$ & $\begin{array}{r}-0.733 \\
0.000\end{array}$ & $\begin{array}{r}-0.316 \\
0.057\end{array}$ & $\begin{array}{r}-0.526 \\
0.001\end{array}$ & $\begin{array}{r}-0.248 \\
0.138\end{array}$ & & & \\
\hline LB & $\begin{array}{l}0.423 \\
0.009\end{array}$ & $\begin{array}{r}-0.710 \\
0.000\end{array}$ & $\begin{array}{r}-0.513 \\
0.001\end{array}$ & $\begin{array}{r}-0.670 \\
0.000\end{array}$ & $\begin{array}{r}-0.463 \\
0.004\end{array}$ & $\begin{array}{l}0.846 \\
0.000\end{array}$ & & \\
\hline $\mathrm{HB}$ & $\begin{array}{l}0.373 \\
0.023\end{array}$ & $\begin{array}{r}-0.463 \\
0.004\end{array}$ & $\begin{array}{r}-0.579 \\
0.000\end{array}$ & $\begin{array}{r}-0.541 \\
0.001\end{array}$ & $\begin{array}{r}-0.573 \\
0.000\end{array}$ & $\begin{array}{l}0.465 \\
0.004\end{array}$ & $\begin{array}{l}0.795 \\
0.000\end{array}$ & \\
\hline Theta & $\begin{array}{r}-0.197 \\
0.242\end{array}$ & $\begin{array}{r}-0.045 \\
0.793\end{array}$ & $\begin{array}{l}0.328 \\
0.047\end{array}$ & $\begin{array}{l}0.138 \\
0.417\end{array}$ & $\begin{array}{l}0.369 \\
0.024\end{array}$ & $\begin{array}{l}0.584 \\
0.000\end{array}$ & $\begin{array}{l}0.356 \\
0.031\end{array}$ & $\begin{array}{l}0.010 \\
0.953\end{array}$ \\
\hline
\end{tabular}


VITA

I am originally from Elizabethtown, KY and received my high school education at Central Hardin High School. I am currently completing my fifth year at the University of Louisville in the bioengineering department. During my undergraduate education, I was inducted into the engineering honor society of Tau Beta Pi and was named to the Dean's List during multiple semesters in my undergraduate studies. I received my B.S. in bioengineering from the University of Louisville in May 2011. Currently, I am completing this thesis and the other course requirements necessary for graduation with a Master of Engineering degree in Bioengineering in May of 2012. In conjunction with completion of this thesis, I have been provided additional opportunities to present the findings of this research. I presented a poster titled "Analysis of EEG Rhythms During Neurofeedback for ADHD Subjects" at Research!Louisville in the Fall of 2011 outlining the initial findings of the research. This poster was also displayed at the annual meeting for the Association for Applied Psychophysiology and Biofeedback in Baltimore, Maryland. Also, the research culminated in a submission of a journal paper titled "Neurofeedback Training Aimed to Improve Focused Attention and Alertness in Children with ADHD: A Study of Relative Power of EEG Rhythms Using Custom-Made Software Application" which was submitted to Clinical EEG and Neuroscience. This journal submission is presently waiting to be assigned for review. After completion of my Master's degree in May of 2012, I plan to attend medical school starting in the fall of 2012. I have been accepted to both the University Of Kentucky College Of Medicine and the Indiana University School of Medicine. I will make a final decision on which school I will be attending in May of 2012. 